\title{
Final Project Report
}

Project Title:

Covering Period:

Date of Report:

Recipient:

Award Number:

Working Partners:

Cost-Sharing Partners: Contacts:

DOE Project Team:
Whitestone Poncelet RISEC Project

October 1, 2010 to September 30, 2011

September 23, 2011

Whitestone Power and Communications

DE-EE0004573

Hasz Consulting, LLC; CE2 Engineers; Energetic Drives, LLC; Applied Power and Control

Hasz Consulting, LLC

John R. Hasz, President, 907-895-4770

jrhasz@haszconsulting.com

DOE HQ Program Manager - Jacques Beaudry-Losique

DOE Field Contract Officer - Pam Brodie

DOE Field Contract Specialist - Jane Sanders

DOE Field Project Officer - Tim Ramsey

DOE/NAVARRO Project Monitor - Samantha Quinn 


\section{Table Of Contents}

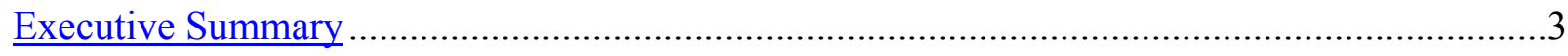

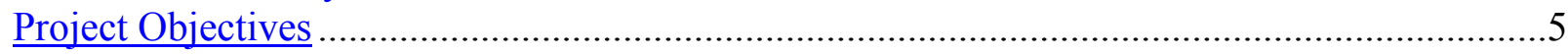

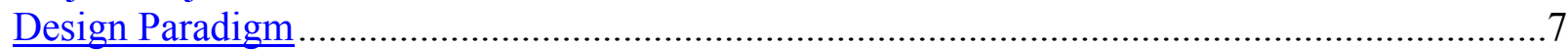

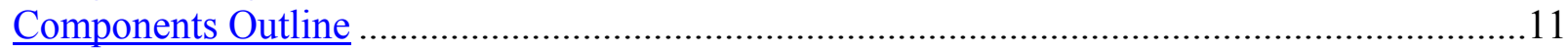

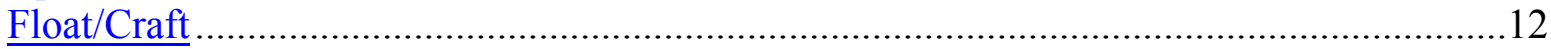

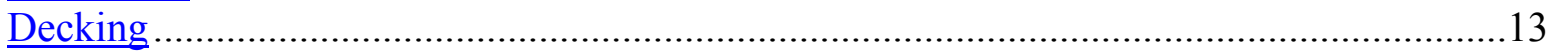

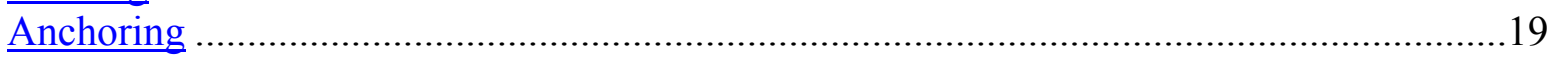

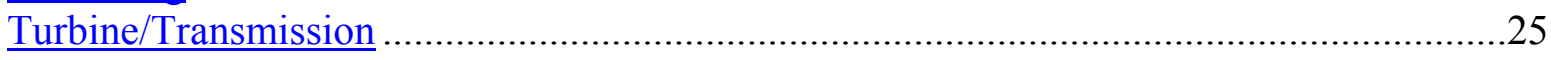

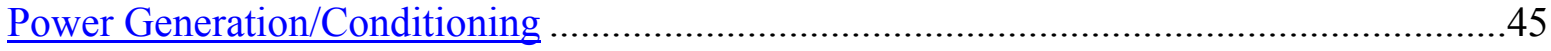

Electrics/Controls/Monitoring ..............................................................................47

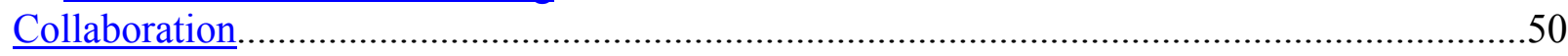

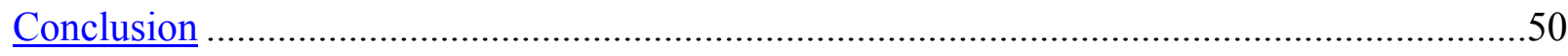




\section{Executive Summary}

The efforts of this project were primarily devoted toward developing a practical River In-Stream Energy Conversion (RISEC) device for Alaskan rivers. This resulted in several important benefits to RISEC research specifically, and for alternative energy research in general.

1. Surveying and site analysis - This project contributed significantly toward determining suitable sites for RISEC application in Alaska, as well as providing precisely surveyed maps of the area.

2. Theoretical Modeling - The project also contributed theoretical models for all structural components. These models were thoroughly analyzed using analytical closed-form equations as well as finite element analysis. Additionally, kinetic flux and power output calculations were applied and validated.

3. Prototyping and Experimentation - Several important components, notably turbine blade and mounting components were prototyped and tested. These tests validated analytical predictions; resulted in refined, broadly applicable engineered solutions; and contributed to a cohesive body of knowledge regarding RISEC design methodology.

4. Application Paradigms- This project required the formulation of specific strategies regarding logistics, debris management, craft assembly and deployment, RISEC/grid interfacing and craft anchoring. Many of these approaches simplified RISEC implementation across a broad scope of project scenarios.

\section{Effectiveness and Feasibility}

Four crucial factors justify the economic and technical applicability of the device as follows:

1. Efficiency Paradigm - This project analyzed attempted applications of RISEC technology in Alaska, and concluded that two primary factors determine system efficiency - turbine efficiency and operational up-time. Many turbines with high theoretical efficiency were investigated, but in the debris laden Alaskan waters, potential down-time and costly maintenance and repairs prevented meaningful application. This project formulated a design which combined efficient power extraction with high robustness. This ensured continuous and consistent output across a wide range of environmental conditions.

2. Remote Location Application - Economic effectiveness is largely contingent on the pay-off period of an installed device. This particular device is designed for Alaskan villages, which may have kilowatt-hour costs of up to $\$ 0.90$. A current economic model for a $100 \mathrm{KW}$ model operating 8 months a year includes a 1.8 million dollar project cost covering component cost, assembly and installation. An average load of $100 \mathrm{~kW}$ at $\$ 0.90 / \mathrm{kWh}$ equates to $\$ 259,200$ annually. A $\$ 1,800,000$ installation will then yield a simplified return on investment of 7 years. Each installation is anticipated to function for 30 years, which would mean an average power cost of approximately $\$ 0.21 / \mathrm{kWh}$. The project return on investment would be prohibitively long for locations with ready access to inexpensive power; however this installation is readily justifiable for application in 
remote Alaskan villages. It is worth noting that the entire project cost is comparable to the price of a new diesel power plant.

3. Component Methodology - An important factor in providing efficient and low cost power was the design choice to integrate Commercial Off-The-Shelf (COTS) technology into the design wherever possible. This project integrated stock items for mechanical craft components such as pontoons, transmission, generator, connection and anchoring hardware. Additionally, the project integrated a novel electrical control system designed by Energetic Drives, LLC. This system integrated stock electrical components to provide efficient and clean power output, optimal turbine performance, and operational versatility. The choice to employ commercially available technology was beneficial for three reasons. First, the time devoted to designing new components was reduced, allowing more time to meaningful application research. Additionally, proper application of state of the art technology improved overall product performance. Finally, installation and replacement time and cost was reduced.

4. Permitting - Many novel concepts in RISEC technology have been discussed; however, many designs require permanent structures or involve disturbance of the riverbed and/or significant alteration of wildlife habitats. While these devices may eventually be successfully permitted, such design choices imply extensive permitting efforts. In contrast, this project involved closely working with permitting agencies to specifically engineer a design with streamlined and realistic permitting goals. While requiring adherence to strict design constraints, the resulting environmentally friendly design will ultimately pay off by reducing permitting time at each deployment site. 


\section{Project Objectives}

a) A feasibility study that describes the basic properties and operational characteristics of the technology, and identifies the technical and economic merits of the concept (TRL 1-2)

i) Completed prior to the start of the project

b) A preliminary design and engineering (TRL 1-2)

i) Completed prior to the start of the project

c) A systems engineering analysis that may include a needs analysis, requirements flowdown to define $R \& D$ pathways, work breakdown structure, concept definition, management plan, and risk assessment (TRL 1-2)

i) Completed during the second quarter of the grant period

d) Consider and identify potential deployment sites and the associated potential resource i) Completed prior to the start of the project

e) Identification of the intended marine resource application, with potential extractable energy estimates

i) Completed during the second quarter of the grant period

f) Engineering and design focused on advancing the device/component for proof of concept modeling, developing solutions to technology hurdles, determining all components/subsystems, developing high fidelity estimates of such values as device/component size, weight, layout, interfacing and performance (TRL 3)

i) Completed during the second quarter of the grant period

g) Small scale prototyping and testing of components to reduce uncertainty provide input into numeric models and validate high level assumptions (TRL 3)

i) Planned Work for the Quarter: It was planned to complete this task during the fourth quarter.

ii) Actual Work Completed During the Quarter: This task was partially complete when the project began. The gearbox transmission, permanent magnet generator, electronic controls systems, floatation systems, anchoring systems and propulsion systems were individually tested to the satisfaction of the WPC technical team. However, the design of the prime mover wheel and the blades which engage with the water required more resources than originally planned. As a result, the process of prototyping this component and initiating the completion of a scale model of the entire system was delayed until the fourth quarter.

iii) Explanation of Variance: The design of the blades changed substantially from the conceptual design model delineated in the conceptual design report (CDR) submitted with the initial application to DOE. For this reason, prototyping was delayed till the fourth quarter. All component prototyping has now been completed.

h) Assess Commercial Off The Shelf (COTS) equipment that can be employed within the system

i) Completed prior to the start of the project

i) Develop specifications for a proof-of-concept model and fabrication plan/costing

i) Completed during the second quarter of the grant period

j) Test and integration plan

i) Completed during the third quarter of the grant period

k) Numerical model(s) and simulation(s)

i) Planned Work for the Quarter: It was planned to complete this task during the fourth quarter.

ii) Actual Work Completed During the Quarter: This task was completed in full during the quarter.

iii) Explanation of Variance: Due to a greater research burden than originally anticipated, the design of the blades for the prime mover was not ready for prototyping as quickly as planned. That process is now complete with the result of full validation of the theoretical design. 
Whitestone Poncelet RISEC Project Whitestone Power and Communications

FY2011

l) Assessment of risks and barriers - resource, environmental, ecological, stakeholder, etc. Define a proposed follow-on RD\&D effort that seeks to prove out the concept

i) Completed during the third quarter of the grant period

m) Conduct stage transition design reviews (go/no-go commitment criteria)

i) Completed during the second quarter of the grant period

n) Consider and discuss Permitting and NEPA requirements where needed to meet future testing and deployment plans.

i) Completed prior to the start of the project 


\section{Design Paradigm}

\section{Overall Design Criteria}

Alaskan river environments and permitting requirements have placed significant design constraints on hydrokinetic turbine development to date. Alaskan rivers tend to be swift, shallow and debris laden; and many potential areas for hydro power development are not readily accessible. Additionally, many rivers and streams are sensitive and environmentally significant habitats. This incurs significant challenges for RISEC development; consequently, the following stringent design criteria were developed:

\section{Environmental Criteria}

1. Turbine shall not disturb the river bed, incur risks of pollution, or harm either land or aquatic habitats.

2. The system shall not involve any permanent structures.

3. The turbine shall not require impoundments or races to constrict or substantially alter water flow.

\section{Assembly Criteria}

1. Turbine design shall be modular; turbines shall be easily specified and outfitted for a wide range of remote locations and power needs.

2. Turbine assembly and deployment shall be readily accomplished in remote locations without requiring on-site welding or machining.

3. All components shall be sized for easy shipping to any potential deployment location.

\section{Performance Criteria}

1. Turbine must be able to produce power over a wide range of river height and velocity levels, and withstand high debris load flows.

2. Turbine shall have simple mechanical operation and low maintenance effort and costs.

3. Turbine shall be able to function consistently to provide standalone power, provide power cooperatively in tandem with one or more power sources, and provide power on an infinite grid.

\section{Engineered Solutions}

Modern research in hydrokinetic technology has typically focused on axial flow turbines such as Darrieus turbines, and vertical cross flow turbines such as Grashov or Kaplan turbines. Considerable research effort has been devoted to improving the coefficient of performance (power output/power available) for these turbines. These turbines typically turn at comparatively high RPM (60-100 RPM). 
Most of the turbines above share the common drawback of requiring rapid rotation for efficient power production. Such lightly built turbine assemblies provide low torque, high speed operation, and are efficient when running. However, they remain vulnerable to debris collision. Additionally, full submersion demands a deployment depth no less than turbine height, and potentially threatens aquatic life.

The solution considered here was an undershot cross flow turbine. The Poncelet style turbine extracts optimum energy when blade tips travel at $40 \%$ water speed, implying a high torque, low speed turbine. This would require a transmission for practical electric generation. It allowed for deployment in shallow water and a robust design attenuated problems encountered with debris collision. This design was eventually chosen for the project.

Consequently the general design paradigm was as follows: The craft would consist of two pontoons supporting a deck. On this would be mounted the Poncelet style turbine, a transmission, an electrical generator, and any controls and electrical components. This assembly would be positioned in the current using an anchoring system entirely fastened to the river bank.

\section{Paradigm Shifts}

Within the context of the engineering solution above, several significant paths of design methodology were considered during development.

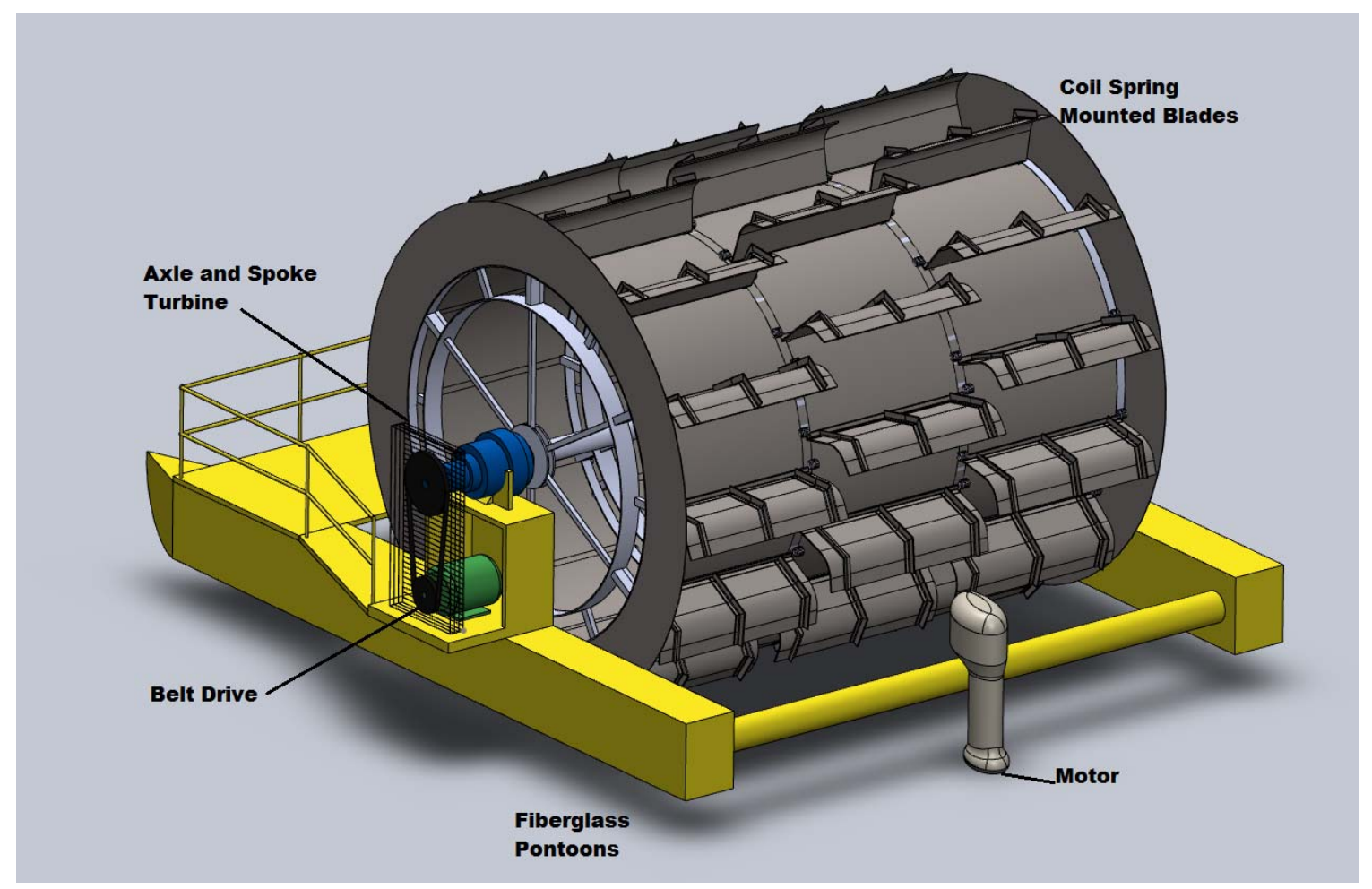

Figure 1: Early embodiment of RISEC device 


\section{Navigation and Deployment}

Initial design concepts included a pilot station, controls, and motor on the craft itself. A selfpropelled craft was certainly the most compact method of deployment, and eliminated the need for another vessel for moving the craft. However, this method required installing control, fuel storage, and a motor which would be used infrequently, and could not be otherwise utilized. Additionally, expensive and unmonitored components of this nature in a remote environment might increase the incidence of vandalism or theft.

For this reason, a paradigm shift was made toward utilizing another boat to deploy the craft. To this end, a workboat with "pushing knees" was specified. This boat would be capable of pulling or pushing the craft into position, and would additionally be useful for transporting workers, tools, and components to and from the craft. The boat would be secured to the craft using a cabling system. In many remote communities, such boats are likely to be available to be rented for the project allaying any need to purchase additional hardware.

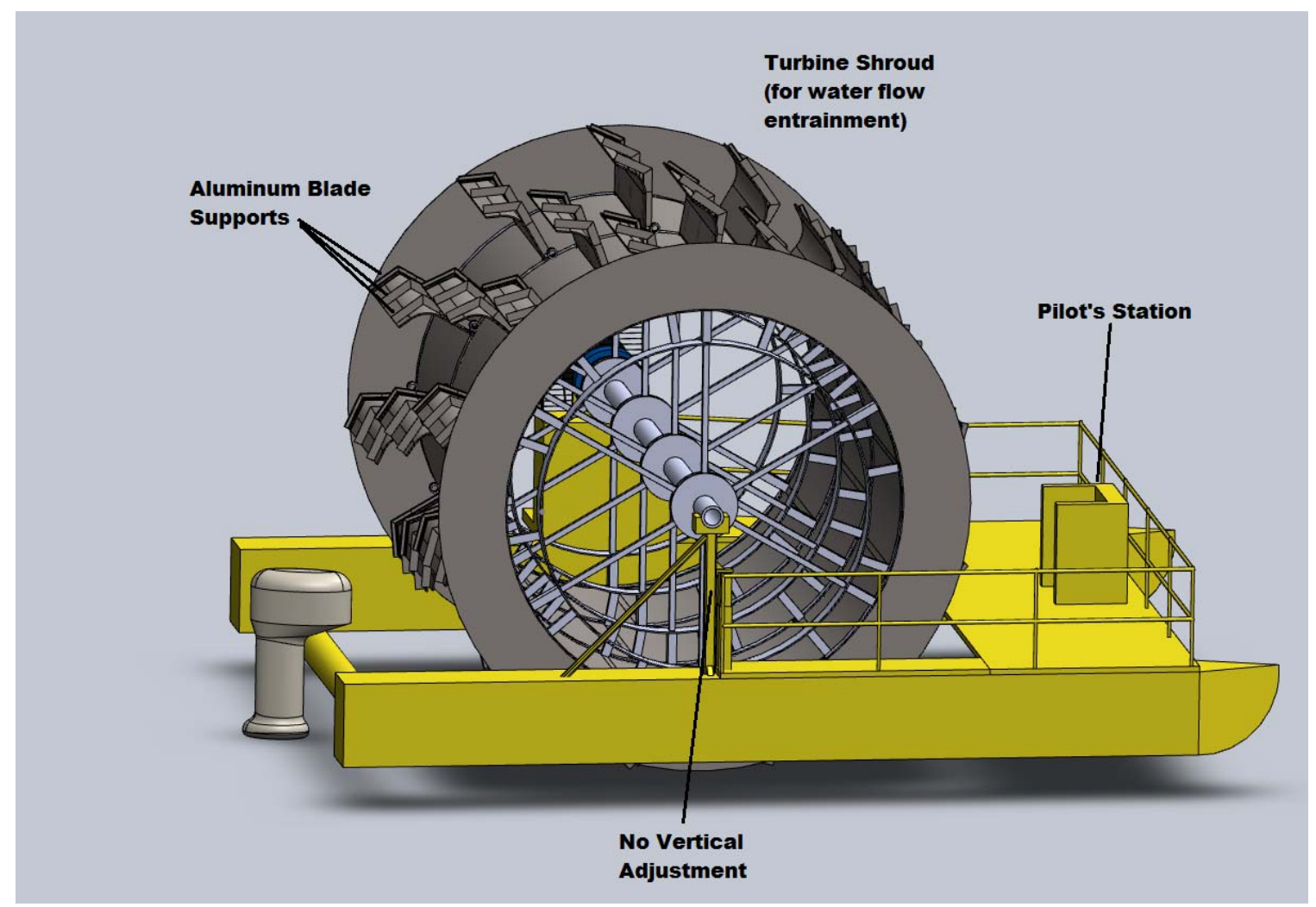

Figure 2: Early Embodiment of RISEC device

\section{Power Generation}

The initial design involved using a compact, inexpensive induction generator for power. This paradigm involved low costs for the generator, but implied certain design constraints. For instance, an inductive generator required excitation to produce power, and had specific synchronous speeds it must exceed before it would produce power. This meant that certain mechanical braking controls would be installed. Additionally, an induction generator could not 
be relied upon to provide standalone power. Essentially, the initial design would be more compact and inexpensive, but less versatile in application.

A number of factors contributed to a significant paradigm shift regarding power generation. It was desirable to design a craft able to provide standalone power, interface with other power generation sources, and provide power to an infinite grid. Additionally, a search was conducted for a more efficient solution for providing clean power; this led to the discovery of and collaboration with Energetic Drives, LLC. The benefits in terms of power generation and mechanical simplification caused a significant paradigm shift; the final model had a more expensive and heavier permanent magnet generator. It was anticipated that, on balance, the benefits from mechanical simplification, efficiency, and versatility, would outweigh the costs of a permanent magnet generator.

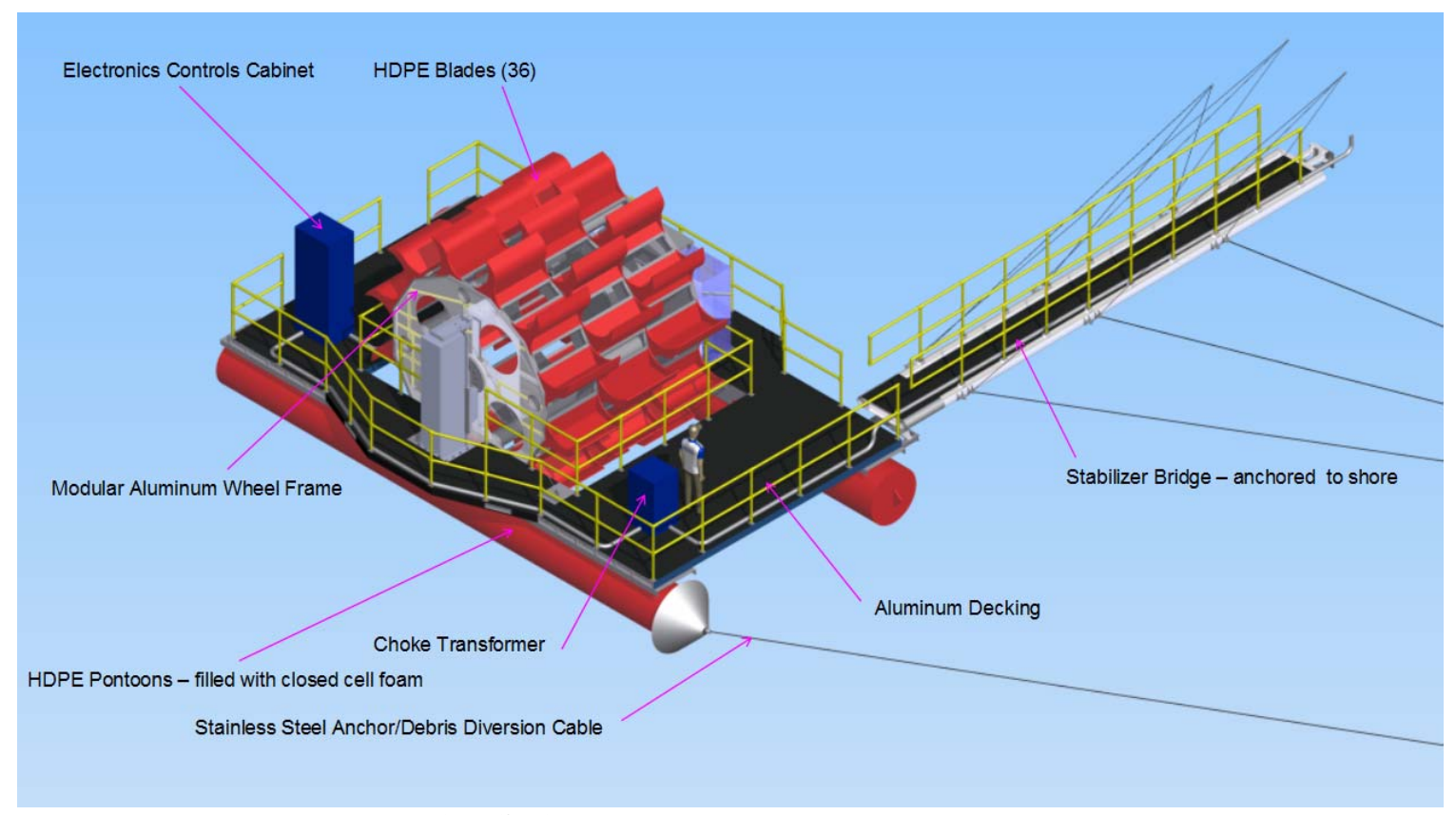

Figure 3: Final embodiment of RISEC device 


\section{Components}

\section{Float/ Craft}

\section{Pontoons}

1. General Design Requirements (loading, debris, fastening)

2. Previous Designs (material selection process, manufacturing availability etc.)

\section{Decking}

3. Advantages of current design

1. General Design Requirements (loading, twisting moment)

2. Design parameters (size, material, section geometry)

3. Advantages of current design

\section{Anchoring}

\section{Cables}

1. General Design Requirements

2. Vortex Shedding

3. Mounting Considerations (pulleys, height adjustments)

4. Debris (Shedding, deflection etc.)

\section{Rigid Strut}

4. General Design Requirements
a. Buckling Load
b. Vertical Load
c. Assembly
d. Water level variation

5. Previous Designs
a. Monopole
b. Sliding Unit Types
c. Fastening Types

6. Advantages of Current Design

\section{Turbine/ Transmission}

\section{Blade Design}

1. Previous Designs.

2. Geometry (dictated by Poncelet)

3. Materials (dictated by geometry $<$ machinability issues $>$, loading)

4. FEA, analytical, experimental results

\section{Turbine Section Design}

1. Design Requirements (modularity, simplicity, loading, etc.)

2. Previous Designs (axle/spoke, etc.)

3. Materials

\section{Bearings/adjustments}

1. Design Requirements

2. Methods (screw jack, ball screw actuators etc.)

\section{Transmission}

1. Design Requirements (required gear reduction ratios) 
2. Previous Designs (chain, belt drives etc.)

3. Benefits of Brevini two-stage epicyclic (coupling options, maintenance etc.)

\section{Power Generation/ Conditioning}

I. Generator

1. Design Requirements (rotation speed, power output, flexibility, cost, weight)

2. Previous Designs (induction generator)

3. Advantages of PM motor

II. Conditioning

1. Design Requirement ( universal grid, stand-alone, diesel pairing)

2. Previous Designs

3. Advantages of Energetic Drives System

\section{Electrics/ Controls/ Monitoring}

\section{SCADA controls}

1. Design Requirements

\section{Emergency Alert System}

1. Design Requirements

\section{Float/Craft}

The craft design was subject to specific operational requirements. In order to maximize stability and load handling, a pontoon mounted craft was specified.

\section{Pontoons}

The pontoon design had several requirements. Pontoons are required to be light, resistant to debris, tough, and equipped with appropriate fastening hardware.

Initially, an aluminum design was considered. A pontoon with required floatation and weight was specified; however some concern was voiced that debris collision or dragging along rocky terrain during launch might dent or permanently deform pontoon skin. Additionally, aluminum pontoons are comparatively heavy.

Fiberglass pontoons were also investigated. However, fiberglass was considered more likely to crack or splinter under collision or abrade if dragged over gravel or rocks during deployment.

Having rejected the idea of using fiberglass or aluminum pontoons, the concept of high-densitypolyethylene (HDPE) pontoons was investigated. HDPE has low flexural stiffness; however a stiffening channel section fastened on top attenuated this problem. It was recommended to fill the pontoon with closed cell foam to ensure continued floatation in case of hull failure. Additionally a steel plated pulling head option for cable attachment was offered with a load capacity of over 200,000 lbs. This exceeded operational requirements for anchoring. An 
aluminum cone would be installed over the pulling head to reduce the energy loss due to the occurrence of turbulent flow around the pontoons.

The advantages of this design were numerous. The resulting pontoons were comparatively light, structurally sound, tough, relatively inexpensive, and offered robust performance during deployment and operational phases.

\section{Decking}

Due to a combination of design choices, the craft was specified with a turbine mounted with a generator on one side and a free bearing on the other. During operation, this implied a twisting moment between the torque (generator mount) side and the non-torque (plain bearing) side of the craft.

The force distribution through the pontoons, decking, and frame components was complex. Understanding the forces and designing components to withstand them, was a crucial aspect of project development.

The torque is transmitted to the frame through the generator mount and exerts a rotational moment on the pontoon which "buries" the upstream side of the pontoon and lifts the downstream side. The torque is transmitted through the decking (which is rigidly attached to the mounting channels on each pontoon) to the plain bearing mount pontoon. Thus the pontoons share the torque loading of the blades by rotating to equilibrium. Any difference in co-planarity of the pontoons would be due to distortion in the decking. Additionally, anchor cable placement implied a compressive axial load in the decking.

First it was desirable to determine what angle of heel the craft would assume due to the torque, and then assess the internal stresses in the craft frame the moment would create. Assuming a static equilibrium, it was assumed that the torque moment must be resisted by an equal and opposite "righting moment".

This may be related to the angle of heel by the following equation:

$$
\text { R.M. }=\gamma \times \text { Volume }_{\text {displaced }} \times \text { Height }_{\text {metacentric }} \times \alpha
$$

where $\alpha$ is the angle of heel, in radians, $\gamma$ is the density of water, and metacentric height the distance between the metacenter and center of gravity of the craft.

To determine values for substitution, first the center of gravity was calculated. For a given number of objects with known heights and weights, this may be expressed:

$$
\frac{\text { Weight }_{1} \cdot \text { Height }_{1}+\text { Weight }_{2} \cdot \text { Height }_{2}+\ldots+\text { Weight }_{n} \cdot \text { Height }_{n}}{\text { Weight }_{1}+\text { Weight }_{2}+\ldots .+ \text { Weight }_{n}}
$$

A simplified center of gravity for craft + wheel was estimated as follows:

A 15,000 pound craft with CG at 4 feet, 5000 pound wheel with CG at 7 feet. 


$$
\frac{15,000 \cdot 4+5000 \cdot 7}{20,000}=4.75
$$

Thus a simplified estimate of CG is 4.75 feet.

The center of buoyancy could be readily calculated by determining the CG of displaced water. This was done by simplifying the model analytically by assuming the minor center of buoyancy change under loading makes a negligible difference in calculations- this was validated later.

A weight of 20,000 lbs in water with a density of 62.5 pounds per cubic foot required 320 cubic feet of displacement. To simplify calculations, the pontoons were considered to have a square rather than round cross section - the difference being assumed negligible (this too was validated later, as will be seen). For a 34 foot simplified pontoon of 3.5 foot width and height, the immersion height is 2.68 feet.

Metacentric Height is calculated as follows:

$$
\begin{aligned}
& \text { Height }_{\text {metacentric }}=\frac{I}{\text { Volume }_{\text {displaced }}}-\text { Center }_{\text {gravity }}+\text { Center }_{\text {buoyancy }} \\
& \frac{I}{\text { Volume }_{\text {displaced }}}=\frac{\text { Width }_{\text {craft }} \times \text { Length }_{\text {craft }}{ }^{3}}{12 \times \text { Volume }_{\text {displaced }}}=\frac{19 \times 34^{3}}{12 \times 320}=194.47 \mathrm{feet}
\end{aligned}
$$

It is clear that the primary factor in metacentric height is inertia controlled, so the simplifications of square pontoons and small heel angle are validated since they have negligible effect- the metacentric height was then

$194.47-4.75+2.68=192.4$ feet

Thus the overall craft angle of heel is calculated by substituting into equation above:

$$
\frac{R . M .}{\gamma \times \text { Volume }_{\text {displaced }} \times \text { Height }_{\text {metacentric }}}=\alpha=\frac{105,000 f t \cdot l b}{62.4 \frac{\mathrm{lb}}{\mathrm{ft}^{3}} \times 320 f t^{3} \times 192.4 f t}=0.027 \text { radians }=1.56 \mathrm{deg}
$$

Since the decking provides the sole structural interface between these elements, the decking must be sufficiently stiff to withstand this torque. To this end, a decking solution was sought which would fasten between the pontoons. Such a decking design would need to be lightweight and resistant to bending and twisting- that is, a high polar and area moment of inertia. 


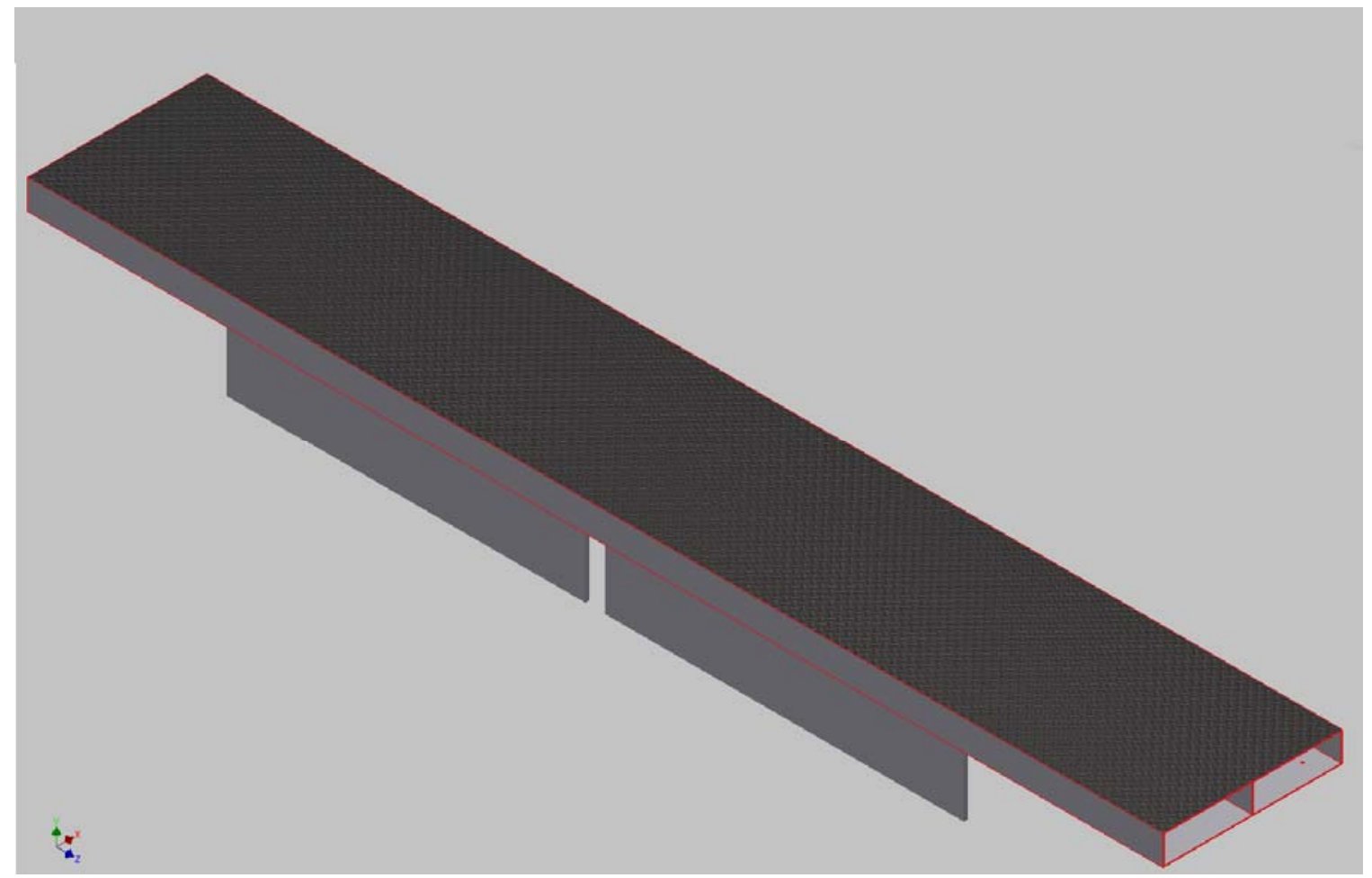

Figure 4: Hollow decking section showing cross section with support rib

Hollow, closed, geometric sections were chosen for decking cross-section, since they combine high area and polar inertial moment with low weight. The decking had an additional design constraint of being flat- this led to the choice of a hollow rectangular cross section. The area moment of inertia would be analytically expressed:

$\frac{\text { Width }_{\text {outer }} \cdot \text { Height }_{\text {outer }}^{3}}{12}-\frac{\text { Width }_{\text {inner }} \cdot \text { Height }_{\text {inner }}^{3}}{12}$

and bending stresses would be expressed:

$\sigma=\frac{\text { Moment } \times C}{I}$

where $C$ is the distance from neutral axis to outer edge of beam, and $I$ is area moment of inertia

For an axial torque, the maximum shear loading for a thin walled beam is determined by first calculating shear flow in the hollow section:

$q=\frac{\text { Torque }}{2 \times \text { Area }_{\text {midline }}}$

where $q$ is the shear flow, and midline area is the area defined by the midline of the beam cross section. 
Shear stresses are found by dividing the shear flow by wall thickness. Then shear stresses and bending stresses are combined to determine principal stresses.

$$
\sigma_{a, b}=\frac{\sigma_{x}+\sigma_{y}}{2} \pm \sqrt{\left(\frac{\sigma_{x}-\sigma_{y}}{2}\right)^{2}+\tau_{x, y}}
$$

Alternatively, the von Mises effective stress may be calculated in terms of applied stresses:

$$
\sigma^{\prime}=\sqrt{\sigma_{x}^{2}+\sigma_{y}^{2}-\sigma_{x} \sigma_{y}+3 \tau_{x y}^{2}}
$$

The problem with this method was that the specific geometry of the craft implied that the highest bending stresses occurred at the ends, with lower stresses in the middle - since for a given angle difference between the pontoons, the forces were not equally distributed. It was very difficult to develop an accurate closed form equation to describe the stresses due to a combination of bending and twisting.

The design methodology was as follows: the decking would be of uniform height, and would need to be able to transmit torque between the pontoons without incurring unacceptable stress levels. The pontoons themselves were considerably less stiff than the mounting channels on top of them. Thus the mounting channels were designed to maintain shape and integrity under axial twisting and transverse bending loads - the small displacements were not anticipated to produce high stresses in the pontoons (see FEA results in figures 5, 6, and 8).

Material selection was an important design decision. Steel was considered for its ease of welding and construction, and high strength. However, certain aluminum alloys offered superior strength to weight ratios and better corrosion resistance. Below is a table of relevant mechanical properties for several candidate materials.

Material Properties Table

\begin{tabular}{|l|l|l|l|l|}
\hline Material Type & $\begin{array}{l}\text { Density } \\
\text { (lb/in) }\end{array}$ & $\begin{array}{l}\text { Elastic } \\
\text { Modulus (psi) }\end{array}$ & $\begin{array}{l}\text { Yield Strength } \\
\text { (psi) }\end{array}$ & $\begin{array}{l}\text { Fatigue } \\
\text { Strength }{ }^{\mathbf{1}} \text { (psi) }\end{array}$ \\
\hline $\begin{array}{l}\text { 440 C annealed } \\
\text { Stainless Steel }\end{array}$ & 0.28 & $30,000,000$ & 65,000 & 33,000 \\
\hline $\begin{array}{l}\text { 304 annealed } \\
\text { Stainless Steel }\end{array}$ & 0.28 & $30,000,000$ & 35,000 & 17,000 \\
\hline $\begin{array}{l}\text { 5086-H32 } \\
\text { Aluminum }\end{array}$ & 0.10 & $10,300,000$ & 33,000 & 23,000 \\
\hline $\begin{array}{l}\text { 5086-T0 } \\
\text { Aluminum }\end{array}$ & 0.10 & $10,200,000$ & 17,000 & N/A \\
\hline $\begin{array}{l}\text { 7075-T6 } \\
\text { Aluminum }\end{array}$ & 0.10 & $10,400,000$ & 83,000 & 23,000 \\
\hline $\begin{array}{l}\text { 6061-T6 } \\
\text { Aluminum }\end{array}$ & 0.10 & $10,000,000$ & 40,000 & 14,000 \\
\hline $\begin{array}{l}\text { 6061-T0 } \\
\text { Aluminum }\end{array}$ & 0.10 & $10,000,000$ & 8,000 & 9000 \\
\hline
\end{tabular}

\footnotetext{
${ }^{1}$ At 500,000,000 cycles- measured in fully reversed bending using R.R. Moore apparatus and sample type
} 
Several noteworthy details with regard to design are shown in the table above. First, heat treatment and tempering make considerable differences in mechanical properties. Additionally, high yield strength is not necessarily an indication of fatigue performance. The performance of candidate materials under repeated load cycling was of definite significance in material choice.

Eventually 5086 (aluminum-magnesium alloy) was chosen for decking construction. The resulting deck pieces were constructed of hollow rectangular sections with widths varying from $18-24$ inches and a height of 8 inches.

Since the individual bending loads in the decking sections were difficult to calculate utilizing closed form analysis, an FEA model was developed to ensure that the decking and channel components were sufficient. In this model, a moment was developed at the generator mount pontoon, and a cable anchoring force at the pulling head of the other pontoon. Both pontoons were constrained at the ends using theoretical radially flexible spring bearings to simulate water buoyancy and floatation, and a roller constraint was applied at a decking section to simulate the rigid strut constraint (more detail about this design element will be presented in a later section). A limitation of the model is that the spring bearings are an imperfect model of water support in several ways. First, they constrain in every radial direction rather than merely providing buoyant forces. This causes artificial resistance to anchor cable force where water floatation opposes vertical but not horizontal motion. Furthermore, since all bearing was at the ends of the pontoons, the FEA bearing stresses would be higher than actual stresses. Additionally, the moment in the model was exerted, not at the generator mount, but at the pontoon (see Figure 5).

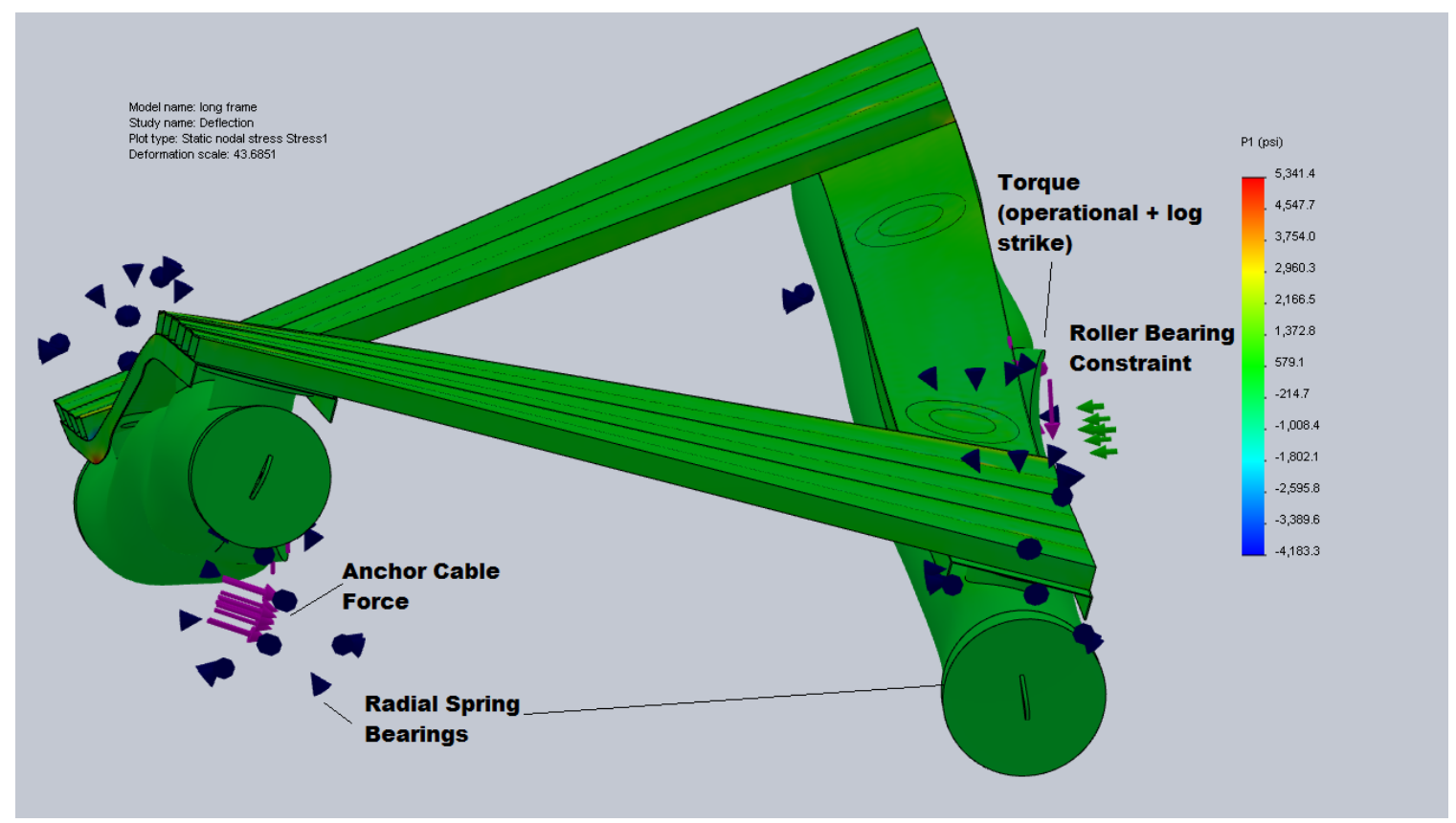

Figure 5: FEA stress and deflection plot showing loads and constraints

Nevertheless, the FEA testing resulted in displacements and stress which validated expectations. Note the deviation from planarity caused by warping in deck elements in figures above and 
below. The deflections are normalized to make small deflections visible; hence, the aspect ratios are skewed.

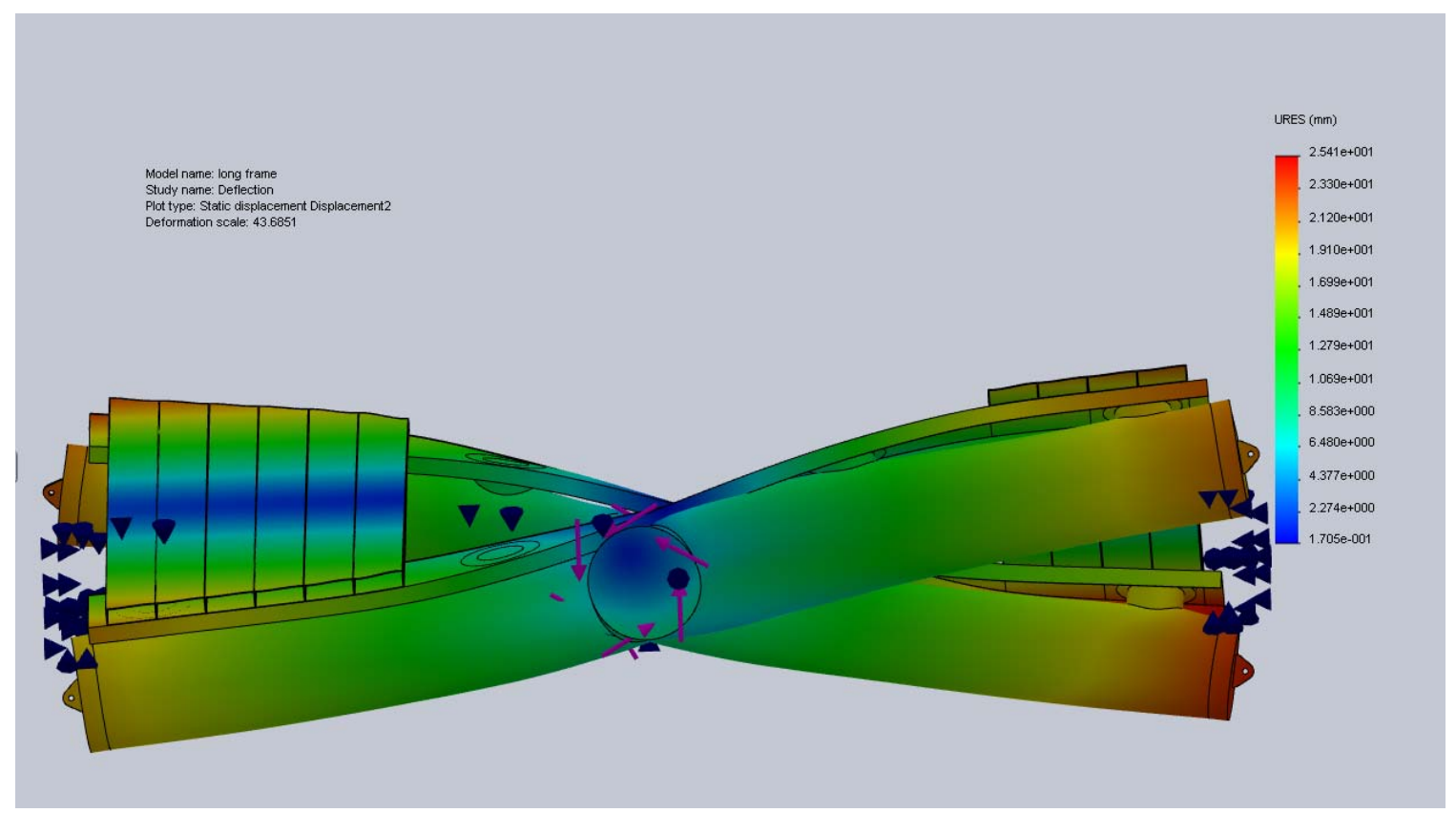

Figure 6: FEA results of decking and frame deflection under operational loading.

To obtain a more precise picture of stress distributions, Solidworks "Iso Clipping" was utilized to select minimum stress value to display. Note that the only locations above $2000 \mathrm{psi}$ are in the inner deck plates and mounting channels, with a maximum stress of 5,341.4 psi. For 5086 aluminum, this indicates an acceptable factor of safety of 4.31 .

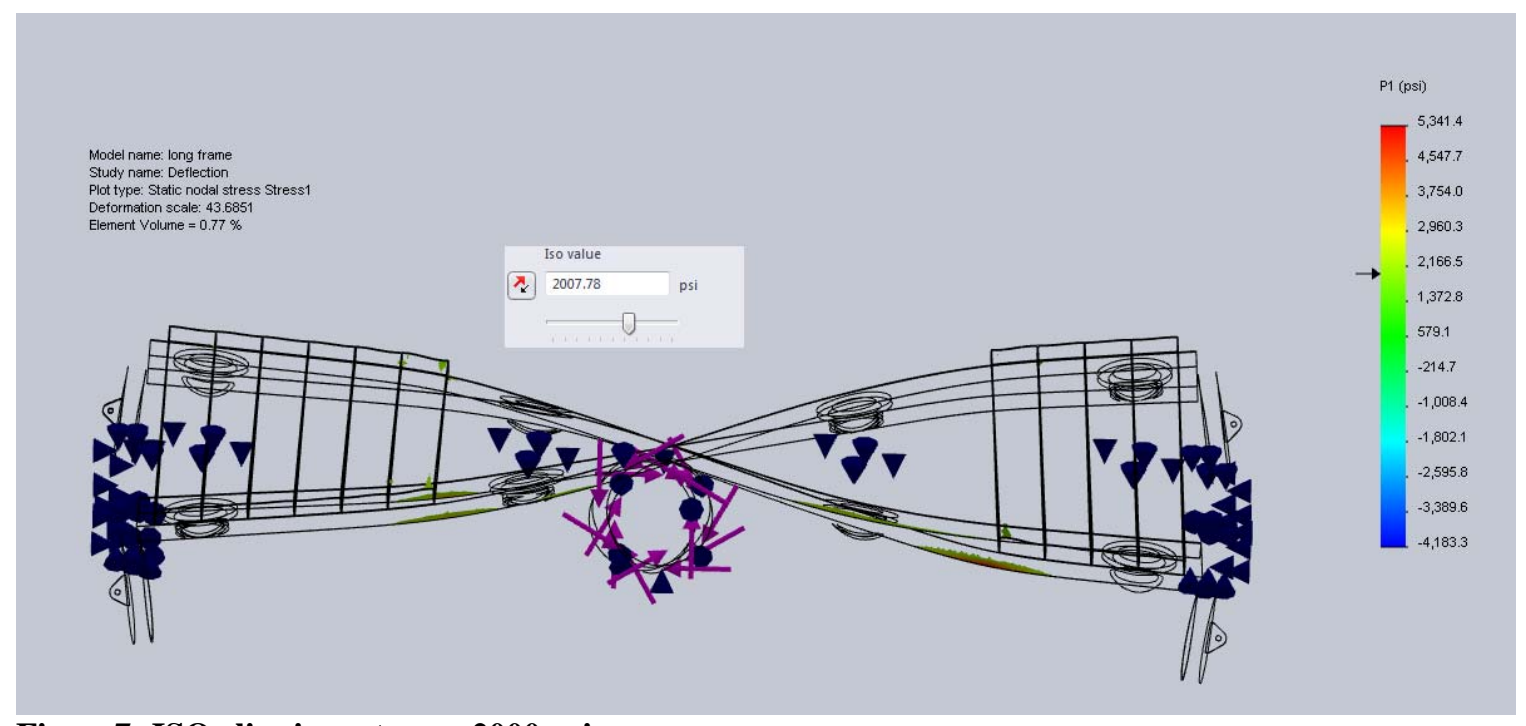

Figure7: ISO clipping- stress $<2000$ psi 
To isolate and examine the stresses in the pontoons, a minimum display value of 102 psi was determined. As anticipated, most stresses in the pontoons were lower than this value. For yield strength of $3000 \mathrm{psi}$, this indicates a factor safety of 29 .

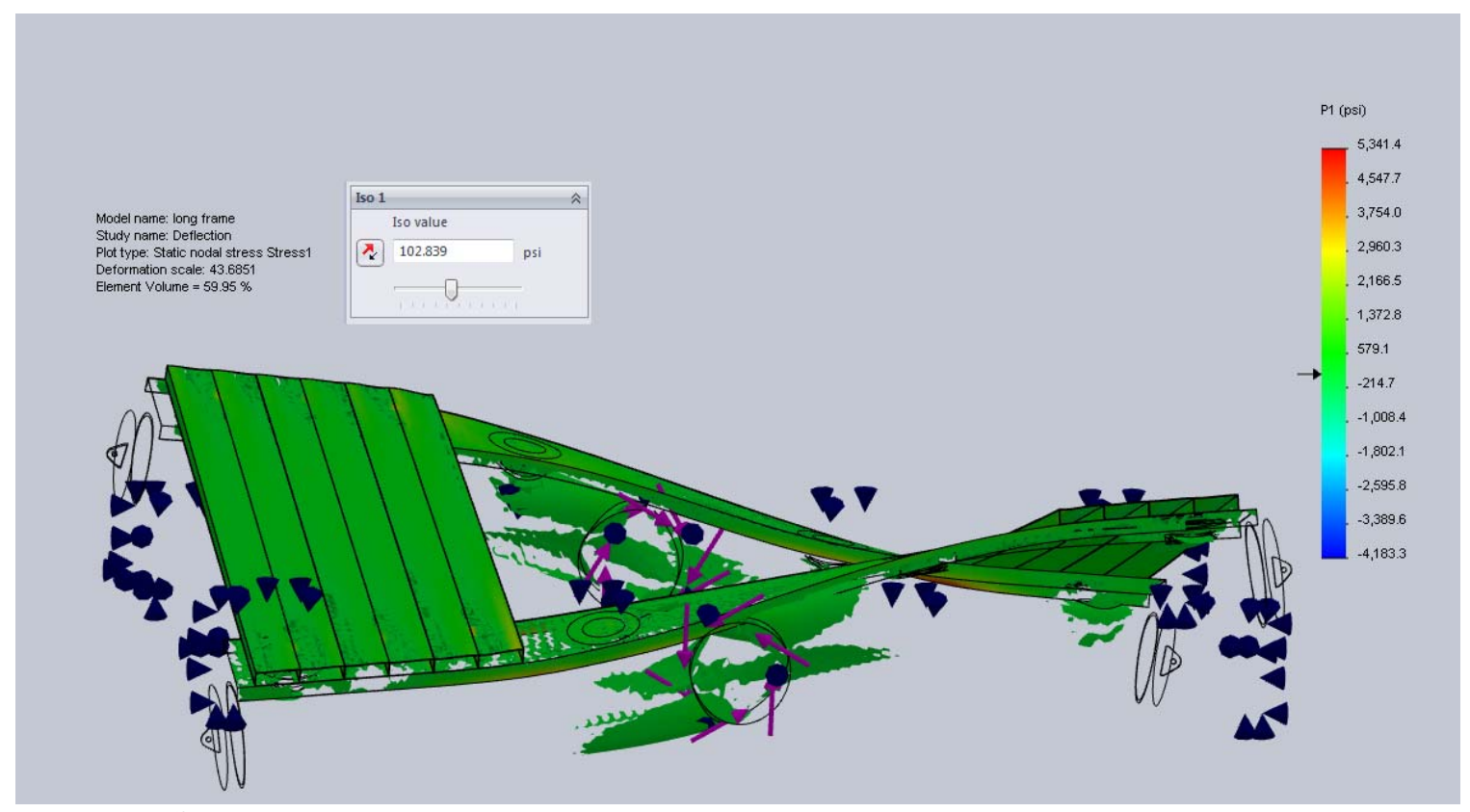

Figure 8: ISO clipping- stress $>102$ psi

\section{Anchoring}

\section{Cables}

An anchoring system was required to prevent craft motion during deployment. Several significant environmental factors incurred design requirements on the anchoring system.

1. Permitting constraints required any system to have a small footprint. Any design including disturbance of, or anchoring to, the river bottom, or involving any permanent structure would require prohibitive permitting efforts (not to mention that river bottom profile changes could involve undesirable anchor point motion). Consequently all system components must be portable, environmentally friendly, and non-invasive of the river bed. This implied a system anchored to the shore.

2. It was desirable to integrate debris diversion with anchoring systems since such systems would necessarily bridge between the craft and shore. Although all craft components were designed with debris collision survivability in mind, the intent of anchoring design was to eliminate this hazard as much as was practically feasible.

3. An anchoring system was desired which would not substantially hamper flow to the turbine, or harmfully accrue debris on any individual component. 
4. Water elevation changes substantially (up to ten feet over the course of a season). This required any anchoring system to be either adjustable or otherwise configured to provide support at a variety of water levels.

5. Any anchoring system would require some configuration to prevent the craft from moving toward the shore. Although apparently self evident, this requirement necessitated the inclusion of some rigid elements to hold the craft a fixed distance from the river bank.

To satisfy these general requirements, several designs were considered. The preliminary design was a monopole which was installed perpendicular to the bank. Cables would be installed to each pontoon. Height adjustment required that the pole have some articulation at its connection points on the craft and on the shore.

The other potential design plan was to mount a cable from the shore to the opposite front corner of the craft. This cable would provide an anchoring point and would be run just under the water surface to provide debris diversion. It was anticipated that large trees, especially those with root wads, would strike the taught cable and be diverted from craft. This method would imply a sideways force tending to push the craft toward the bank. Preventing this would require a rigid strut to maintain position.

Several variants of this design were considered. A preliminary proposal suggested providing vertical adjustment by mounting all components on dollies such as those used for overhead shop hoists. These dollies would then be actuated by a servo or crank controlled ball screw system. The dollies themselves would track on vertically oriented I-beams which would be fastened to the river bank. This would afford controllable height adjustment varying with river levels.

Another potential design to reduce cable size involved the use of pulleys running through sheaves attached to the anchor points and craft. A single capstan on the craft would then reel the cable in or out.

These designs were eventually abandoned in favor of a simpler design. A rigid strut member would consist of modular suspension bridge segments. These could be individually installed as suspension bridge segments above the water surface at low water. The connection between the craft and this suspension strut would be a king-pin/fifth wheel connection such as is employed for RV or trailer towing. The suspension strut would be fastened to the shore by a custom pintlestyle mount. This would allow it to bear axial loading, and also to tilt to accommodate varying river levels from a single shore position. The debris diversion cable would be strung from the shore to the opposite side of the craft. On the shore side, a series of rock anchor tie off points would be provided. As water levels vary, the cable could be installed at different points to ensure proper cable depth and functionality.

The actual installation height of the rigid strut relative to high/low water levels was a significant design consideration. An initial suggestion of splitting the difference between minimum and maximum water level height was made. However, at the desired installation site, water level varies approximately ten feet seasonally. At maximum water height (and maximum force in the strut) a five foot vertical difference over a thirty foot span makes a 9.5 degree angle between 
strut and water. The vertical force is equal to the axial force in the strut multiplied by the sin of the angle- for a 10,000-pound strut force, this meant a 1,643-pound vertical force. This force stresses fifth wheel mounting structure. Considering that the highest forces are at high water, the bridge anchoring position was changed to $3 / 4$ high water mark to make forces more equalized over deployment time.

Having determined the general method of securing and anchoring the device, individual component design was considered. Both the cables and suspension strut components were designed to be anchored into the shear rock face of the bluffs at the river bank. To this end, threaded rock anchors were specified for fastening components to the rock face. Manufactured by Williams Form Engineering, these rock anchors are one inch in diameter and five feet long. They are grouted into a pre-drilled holes and have a pullout strength of $60,000 \mathrm{lbs}$ in the quartzbiotite-gneiss rock which comprises the bulk of the bluffs.

The cables were specified with the following design criteria: The cables must be strong enough to bear the operational loading of the current flow plus any forces set up by debris impacts or accumulation. A flow of approximately 15 feet per second was calculated to exert a force of approximately $14,000 \mathrm{lb}$ in the direction of the current. An additional debris impact was calculated to exert approximately $3000 \mathrm{lb}$. Thus the total load in direction of the current is approximately $17,000 \mathrm{lb}$. If the angle $\theta$ between the cable and current direction is approximately 30 degrees, then the actual force in the cable is expressed

$$
\begin{aligned}
F & =1 / \cos (\theta) \\
& =19,600 \mathrm{lbs}
\end{aligned}
$$

Using simple force equilibrium principles, the resulting force in the rigid strut is expressed:

$$
\begin{aligned}
F & =(1 / \cos (\theta)) \sin (\theta) \\
& =9800 \mathrm{lbs}
\end{aligned}
$$

Several dynamic considerations were made in cable design. Some concern was discussed that at certain river speeds, vortex shedding frequency from the diversion cable might approach the cable's natural frequency, causing cable flutter. An equation was derived for the natural frequency and dynamic behavior of a flexible cylinder under tension with pinned ends.

The natural frequency of a tensioned cable in water may be very closely approximated as follows ${ }^{2}$ :

$$
\begin{aligned}
& f_{n}=\frac{1}{2 \times \text { Length }} \sqrt{\frac{\text { Tension }}{\text { Mass }_{\text {unit_length-water }}+\text { Mass }_{\text {unit_length-cable }}}} \\
& f_{n}=\frac{1}{2 \times 1440} \sqrt{\frac{20,000}{0.000731+0.0000937}}=1.71 \mathrm{~Hz}
\end{aligned}
$$

\footnotetext{
2 Dauchin, Benoit. Flow Induced Vibrations on a Cable Caused by Waves Plus Current. Diss. Ecole Centrale de Lyon France, 1996.
} 
The vortex shedding frequency is governed by the Strouhal number, a dimensionless parameter which is itself dependent on the Reynolds number:

$$
\mathrm{Re}=\frac{\text { Velocity } \text { Diameter }_{\text {cable }}}{\text { Vis } \cos \text { ity }_{\text {fluid }}}
$$

The Strouhal/Reynolds relation is graphically presented in the following figure:

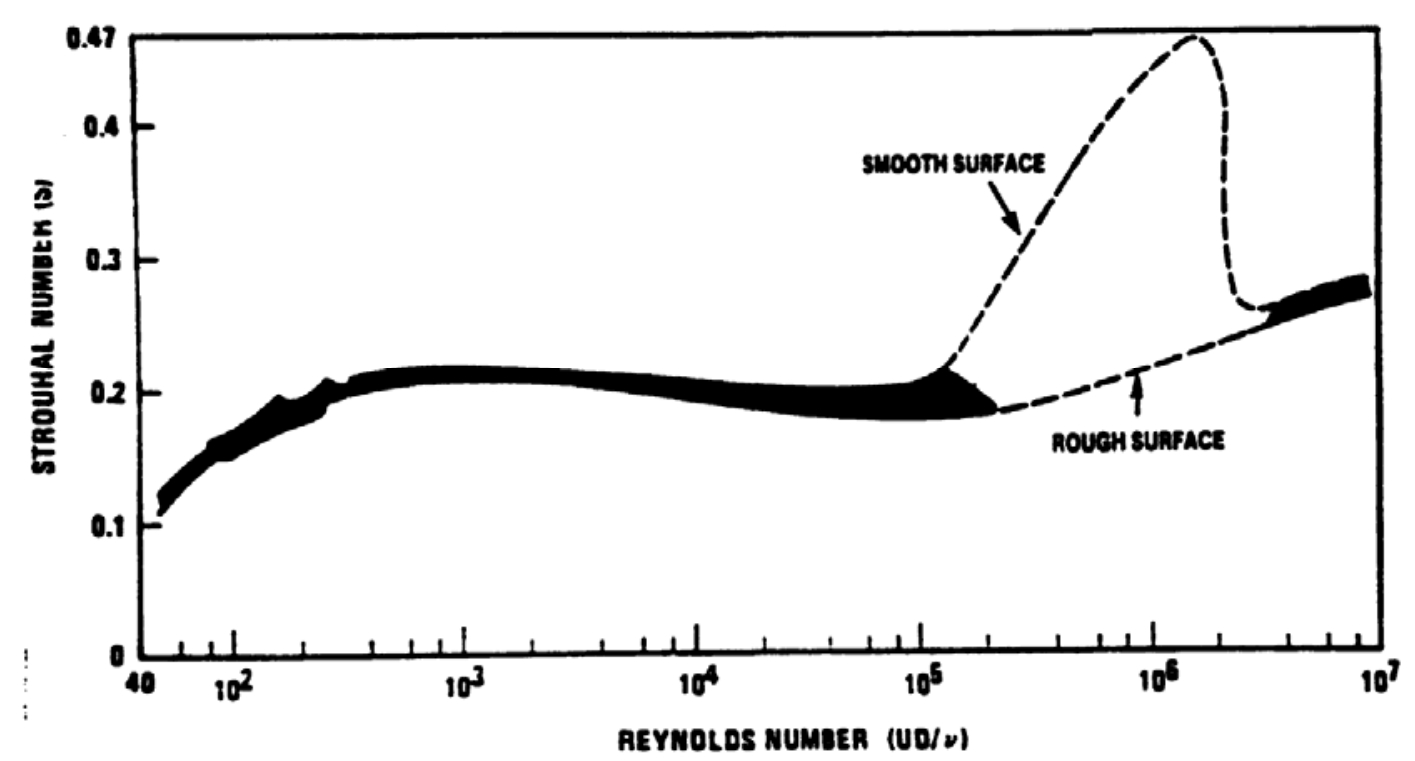

Figure 9: Chart relating dimensionless parameters for a cylinder in cross-flow

For a velocity of 15 feet per second, the resulting Reynolds number is approximately 65,400. The Strouhal number is approximately 0.21 ; this results in a shedding frequency of 42 hertz.

The vortex shedding frequency is described by the following equation:

$$
f_{\text {shed }}=\frac{\text { Strouhal } \times \text { Velocity }}{\text { Diameter }_{\text {cable }}}
$$

Since a $1.71 \mathrm{~Hz}$ shedding frequency only occurs at speeds of approximately 1.286 inches per second, there was no anticipated risk of flutter at operational flow rates.

\section{Rigid Strut}

A rigid strut component was required to maintain craft position in current flow. Such a component was subject to several design constraints. First, modularity was desirable for two reasons. 
First, assembly and disassembly was facilitated by employing small, individual subcomponents which could be installed and uninstalled sequentially rather than handling the entire cumbersome strut.

Secondly, since variable positioning in the current was potentially critically important, it was desirable to be able to add or subtract segments to optimize craft placement. The importance of modularity led to a design specification that the strut be comprised of ten foot sections which could be fastened together to create a strut of arbitrary length (as long as resulting strut is safe from buckling).

Obviously buckling failure was a significant design consideration, especially since the strut would be a long, slender design comprised of several sections. Several methods of analysis were considered to ensure that material and installation costs were minimized without compromising buckling resistance. An initial design specification was for six inch diameter 6061 T-6 Aluminum alloy structural tubes with quarter inch wall thickness to be used. Each section would be comprised of two such tubes placed 30 inches apart on center and cross braced with 1 " $\mathrm{x}$ 0.125 " square tubing.

Since the primary axial loading would be through the kingpin on the bottom of the strut, eccentric loading was anticipated. An analytical application of the secant method for calculating critical loading was used first. This formula is expressed as follows ${ }^{3}$ :

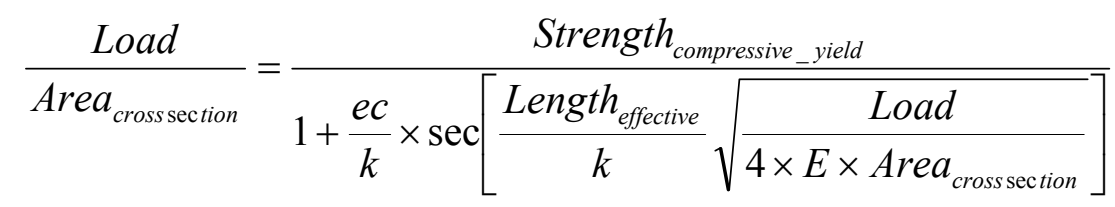

where

$k=\sqrt{\frac{2 x I}{\text { Area }_{\text {cross section }}}}$

$e c$ is the eccentricity (for this calculation it was assumed to be five inches)

$E$ is the elastic modulus.

Since the closest approximation to realistic end constraints was a pinned-pinned condition, the effective length was the same as real length, 30 feet.

This was iterated with varying loads until convergence to solution - the critical load was 12,550 lbs for a single 30 foot length. Since each strut section would include two such components, linear superposition was used to determine total assembled strut buckling load- 25,100 lbs. Since the anticipated maximum loading (operational forces + debris striking) is approximately 10,000 $\mathrm{lbs}$ at the bridge, this provides a factor safety of approximately 2.5 . The limitations of this calculation are that no transverse loading scenario is considered in the secant formula. Some concerns were discussed that gravitational loading over the 30 foot span, as well as any other

\footnotetext{
${ }^{3}$ Norton, Robert L. Machine Design, and Integrated Approach. Prentice Hall, Saddle River, New Jersey, 2006
} 
transverse loading, might significantly decrease buckling resistance. Additionally a higher moment of inertia was desired to increase buckling factor of safety, thus an 8 inch pipe was specified for analysis.

To this end, the Solidworks finite element analysis software was employed to create a buckling study. At this time, the design suggestion had been made to fasten each strut section together with pipes which would fit tightly on the inside of the eight inch pipes. These would have a length of 48 inches and would be plug welded on one side to the outer pipe. The other side would have a hole for a pin, which corresponds to a hole in the outer pipe. This way, each section may be pinned onto the last, with transverse bending support provided by the inner pipe, and axial bearing provided by the outer pipe. The FEA model included these inner pipes. Additionally, the FEA model included the gravitational load, and a transverse load of $500 \mathrm{lb}$, as well as an axial load of $5000 \mathrm{lb}$ (with an eccentricity of one foot).

FEA limitations were as follows: the Solidworks package was not able to calculate differences in buckling/bending resistance at the joints due to pipe clearances; therefore all touching surfaces were assumed in bonded contact. Additionally the actual design included a kingpin which gave a further pinned degree of freedom perpendicular to the bearing constraint. This was not included in the model.

The Solidworks package utilized an eigenvalue calculation to predict buckling shape and occurrence; this resulted in a loading safety factor of 8.4. This was determined to be acceptable; thus a final design decision was made to create individual bridge sections from ten foot sections of 8 " $\times 0.25$ " structural tubing, and pin each section together with 48 inch connecting tubes.

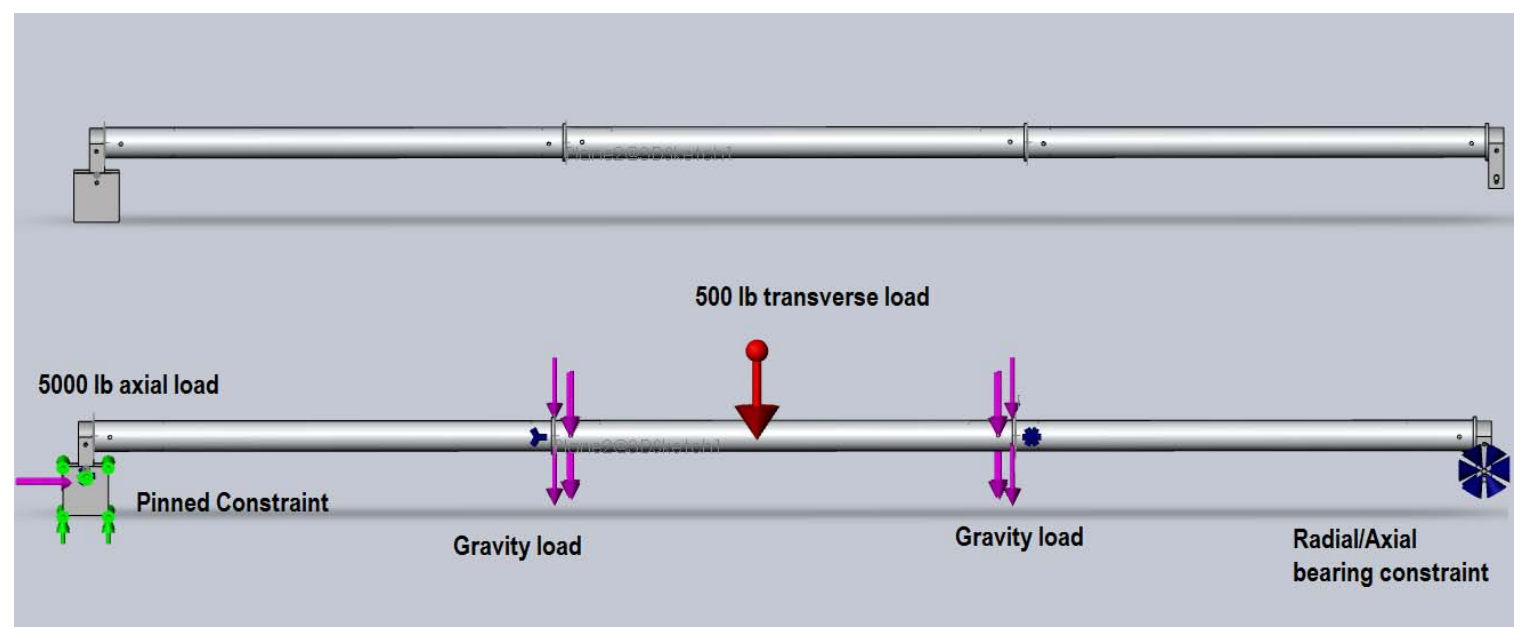

Figure 10: FEA model of rigid struts 


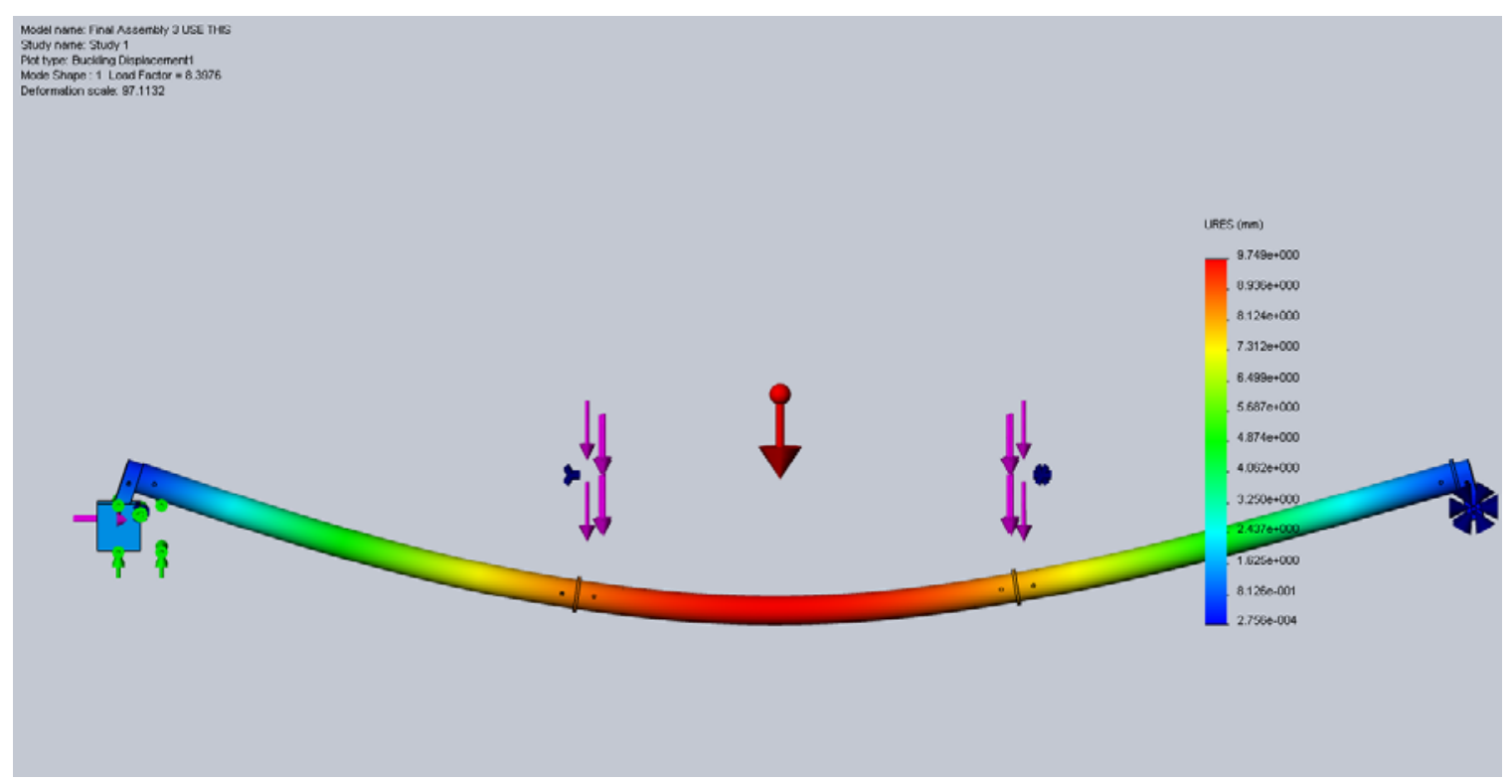

Figure11: Results of FEA model

\section{Turbine/ Transmission}

\section{Blade Design}

A number of requirements were imposed upon turbine blade design. In terms of size, the ratio of radial length to turbine diameter was fixed for optimum efficiency. Additionally, it was desirable to design a blade that would prove survivable and robust under operational conditions and debris strikes. It was also desirable to make any mechanisms highly robust to withstand submersion in silty water, and reduce moving parts as much as possible to decrease manufacturing and assembly costs, as well as maintenance.

Geometrically, a curved profile to trap water was desired to increase efficiency. Initial blade designs were also tapered to save material costs and weight while maintaining constant stress in the blade. This concept was eventually abandoned due to manufacturing constraints. A primary design concern was the collision of a log or piece of debris with the blade; a number of potential designs were considered.

\section{Blade Design Calculations}

The power developed by an undershot waterwheel in unconfined flow is expressed ${ }^{4}$ :

$$
F u=B \pi S \frac{v u(v-u)}{g}
$$

where $F$ is the force in pounds developed by the water on the blades of the wheel, $B$ is a constant determined experimentally to be $0.8, S$ is the total surface area of the blades in the water in square feet, $v$ is the velocity of the water in feet per second, $u$ is the tip velocity of the blades in

\footnotetext{
${ }^{4}$ Bresse, Jacques Antoine Charles, Water Wheels or Hydraulic Motors, University Press of the Pacific, 2003 (reprinted from 1876 edition)
} 
feet per second, $\pi$ is the weight of water equal to 64 pounds per cubic foot, and $g$ is the acceleration of gravity equal to $32.2 \mathrm{ft} / \mathrm{sec}^{2}$. For the case of wheels in unconfined flow, the maximum efficiency is obtained when

$$
\frac{u}{v}=0.4
$$

The force developed against the wheel could be determined by dividing the above equation by the tip speed of the blades $u$. In the case of this design, 9 blades were considered to be in the water at one time, with each blade having a total area of $8 \mathrm{ft}^{2}$ perpendicular to the direction of flow. The velocity of the wheel could be considered constant due to the high gear ratio between the wheel and generator. The electronic controls would use the generator to hold the optimal

speed ratio between the wheel and the water of $\frac{u}{v}=0.4$ at all times regardless of water velocity. Experimental results indicated that the depth of the blades should be less than or equal to $1 / 4$ of the wheel radius. In addition, experiment dictated that for a wheel $16 \mathrm{ft}$ in diameter, the number of blades should be 12 .

The curvature of the blades was determined by the water flow regime and was optimized to minimize shock as the blades entered and exited the fluid. In addition, the curvature allowed the blades to absorb more energy than they would otherwise do by lifting the water as the wheel turns. The theoretical efficiency of such a wheel in a confined flow is $100 \%$, however the maximum attainable efficiency given friction and fluid escape was somewhat less than $60 \%$. The curvature of the blades was determined by the approach of the blade into the water and the angle of the root of the blade to the circumference of the wheel. Experimental results showed that the approach angle of the blade to the water should be 30 degrees and that the root of the blade should be perpendicular to the circumference of the wheel.

The total force developed on the wheel by the water at $8 \mathrm{ft} / \mathrm{sec}$ is $4,500 \mathrm{lb}$ which computed to approximately $31,500 \mathrm{ft}-\mathrm{lb}$ of torque. At $15 \mathrm{ft} / \mathrm{sec}$ the total force developed on the wheel by the water is $15,500 \mathrm{lb}$ which corresponded to a torque of $108,500 \mathrm{ft}-\mathrm{lb}$. At these water speeds, the wheel produced $17 \mathrm{~kW}$ and $107 \mathrm{~kW}$ respectively. This power output took into account the inefficiencies of the drive train, generator, and inverter equipment.

\section{Blade Design Process}

The first embodiment of the above criteria was a curved plastic or aluminum plate with aluminum support ribs. This assembly would be pinned at the top with a coil spring. A heavy log strike would cause the assembly to rotate about the pin, with the spring absorbing energy from the moving log and allowing it to pass under the turbine. This concept was abandoned due to concerns that the aluminum ribs would permanently distort and that the coil spring would be constantly in angular displacement under operational load. Additionally, the coil springs would add prohibitive cost, weight, and installation difficulty. 


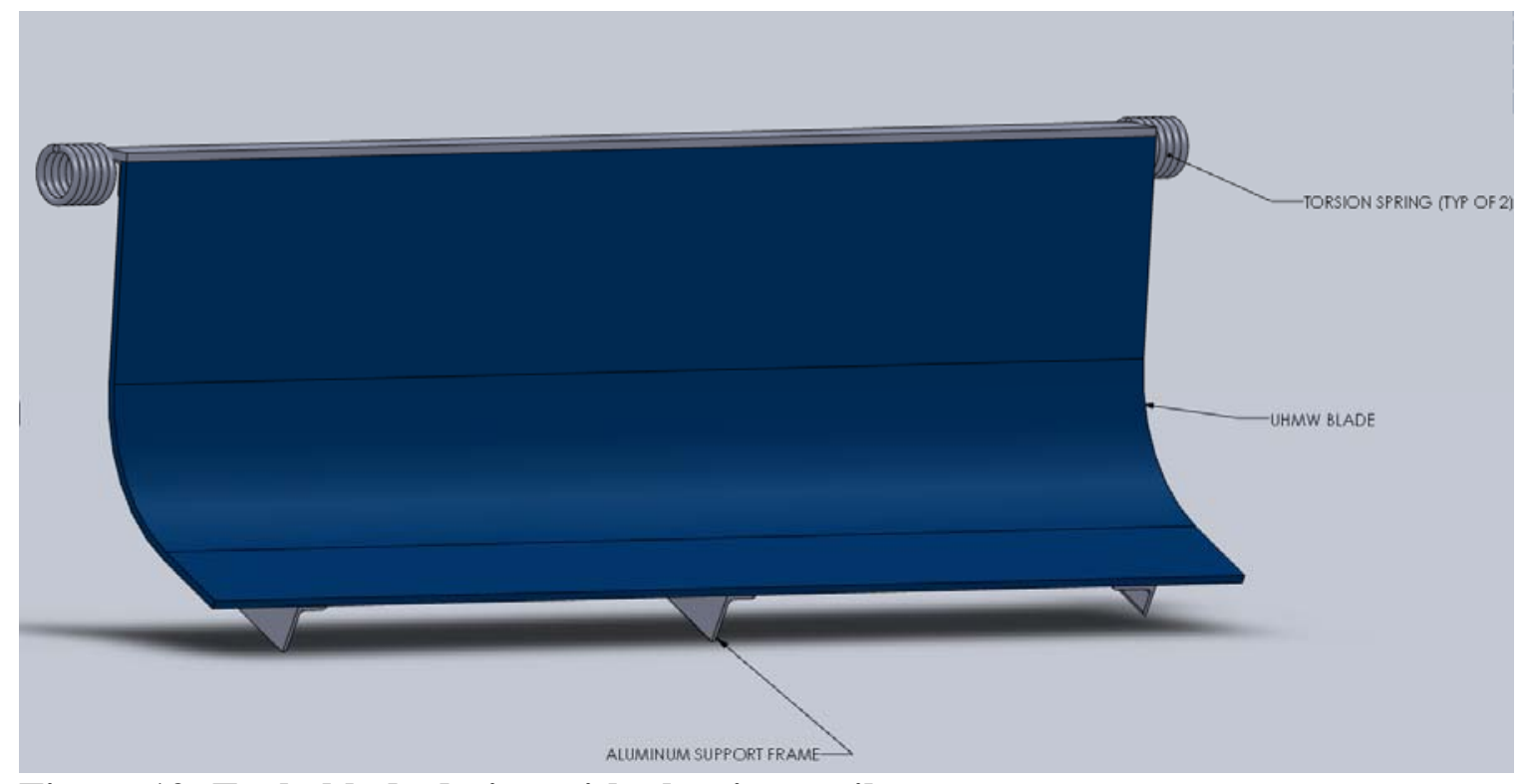

Figure 12: Early blade design with aluminum ribs

A second embodiment was to utilize a detente notch in the side of a metal disk and roller under spring pressure to hold the blade in place during normal operation. In the event of a log strike, the collision would cause the ball to pop out of the detente and the blade would rotate out of the way. When the blade was raised out of the water, gravity would cause it to rotate back to detente position. Potential designs were generated using Belleville washers, leaf springs, cantilever springs, and helical springs to provide the force to secure the roller in the detente notch.

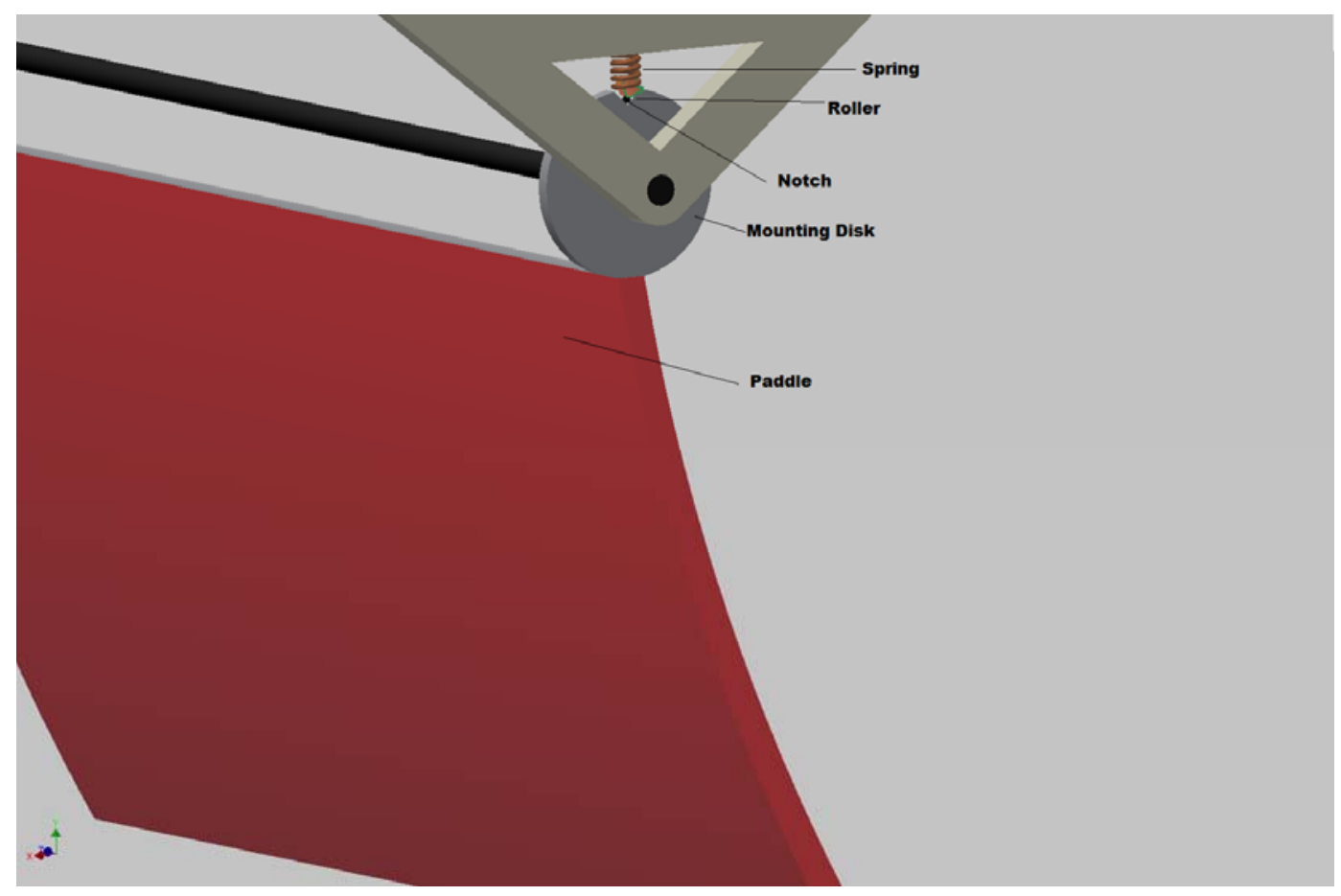

Figure 13: Detail of paddle with detente notch mount 


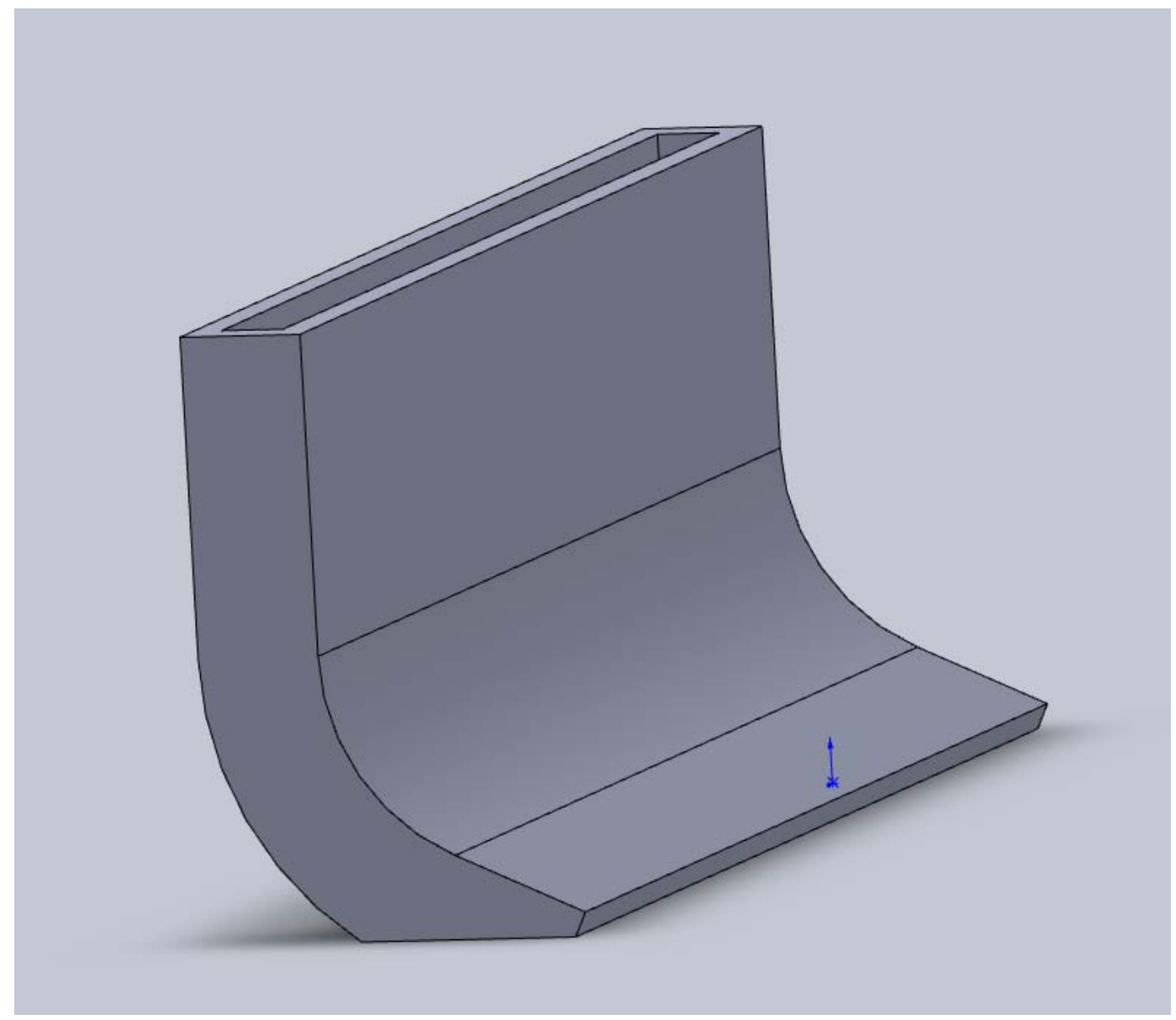

\section{Figure 14: Early all-plastic blade design}

For a detente disk with radius $r$, and notch angle $2 \times \theta$, the roller would only move in the notch if force in the spring $F$ was equal to upward force on roller. This may be expressed:

$$
\frac{\text { Torque } / r}{\sqrt{1-\cos ^{2}(\theta)}} \geq F_{\text {spring }}
$$

A third embodiment considered was the result of concerns that logs and other debris might not only damage the blades in the event of a direct collision, but also might become pinned under the turbine and exert a radial force against the outer tip of the blades. A turbine assembly that was robust to tangential impact forces as well as radial forces required to push a log under water was desired. To this end, a design employing a rod and coil spring which could move radially inside a sleeve guide on the wheel spoke was created. This would soften the impact of pushing a log under water. Ultimately this design was abandoned for three reasons. First, it involved numerous small moving parts, prompting concerns about silting and corrosion, as well as high maintenance and installation costs. Secondly, when the spring was compressed, the blade was still subjected to full buoyant force of the log. Finally, an unrelated design constraint caused the spoked wheel design to be eliminated, making the guide sleeve and spoke method unwieldy in the design context. 
Essentially, all three mechanical methods of reducing log impacts were abandoned because they required numerous moving components, implying high assembly and maintenance costs. This prompted a change in design paradigm away from mechanically actuated blade protection assemblies in favor of a simply fastened but robust blade design. This required a more careful selection of available materials.

Initial design ideas had relied heavily on mechanical breakaway safety mechanisms to reduce impact loading on the blades. Abandoning these mechanisms meant that the blade would need to be able to undergo full impact loading in both tangential and radial directions. Early designs included fully aluminum blades, and plastic blades with aluminum ribs. While these designs were typically able to handle operational loads, it was anticipated that debris collisions would permanently deform metal components.

Consequently, considerable research was conducted to determine a suitable material which would be both reasonably light and inexpensive, strong enough to hold shape under operational loading, and flexible enough to bend without permanent set in the event of a log strike.

Aluminum was considered for its machinability and corrosion resistance. However a design strong enough to withstand a log strike would require a prohibitively high material weight and cost.

A number of engineering plastics were available, ranging from acetals ${ }^{5}$ (yield strength: 10,200 psi, elastic modulus: 435,000 psi), polyethylene terephthalate, ultra high molecular weight polyethylene $^{6}$ (yield strength: 3100 psi, elastic modulus: 100,000 psi), polyimides, ABS plastics, and high density polyethylene. Since the simplified blade design would need to be flexible enough to recover after the potentially substantial distortion of a log strike, percent elongation was evaluated along with yield strength and elastic modulus for candidate materials. Besides mechanical properties, a suitable material would also need to be inexpensive in terms of material and machining costs. These requirements eliminated polyimides and acetals and PET because of the limited machining options and high manufacturing and material costs. Additionally these materials had limited flexibility (45\% elongation of acetal copolymer and $7 \%$ elongation of polyimide). ABS plastics were more easily machined, but had unsuitable mechanical properties.

Ultra High Molecular Weight Polyethylenes had similar properties to HDPE, with a slightly lower modulus of elasticity. This meant that it would provide a more flexible blade; this was initially attractive, but UHMW cannot be welded, which severely limited its application. High density polyethylene was eventually selected as the material for final blade design. The requirement of a 20 degree bend in the blade profile required forming that was unavailable for any other engineering plastic. Especially notable is its $500 \%$ elongation at rupture, and its high degree of shape recovery after distortion. $\mathrm{HDPE}^{7}$ has an elastic modulus of approximately 175,000 psi and an ultimate tensile strength of approximately 3500 psi.

\footnotetext{
${ }^{5}$ Dupont Delrin Acetal Resin- Product Property Guide- 2010

${ }^{6}$ Ultra High Molecular Weight Polyethylene (UHMWPE) Harvey L. Stein, PE. Reprinted from Engineered Materials Handbook Volume 2: Engineering Plastics, 1999

${ }^{7}$ HDPE Data Sheet, Chevron Phillips Chemical Company, 2009
} 
Below is a table with relevant mechanical properties of some of the candidate engineering plastics.

\begin{tabular}{|l|l|l|l|l|}
\hline Material & $\begin{array}{l}\text { Elastic Modulus } \\
\text { (psi) }\end{array}$ & $\begin{array}{l}\text { Yield Strength } \\
\text { (psi) }\end{array}$ & $\begin{array}{l}\text { \% Elongation at } \\
\text { Rupture }\end{array}$ & Machinability \\
\hline Acetals & 435,000 & 10,300 & 35 & $\begin{array}{l}\text { Stamped, extruded, } \\
\text { small parts only }\end{array}$ \\
\hline UHMW & 100,000 & 3100 & 350 & $\begin{array}{l}\text { Small sheet } \\
\text { extrusion, no } \\
\text { bending }\end{array}$ \\
\hline HDPE & 175,000 & 3000 & 500 & $\begin{array}{l}\text { Sheets may be } \\
\text { drape formed, } \\
\text { bent, and welded }\end{array}$ \\
\hline
\end{tabular}

\section{Analytical Predictions}

The following analytical method was employed to determine the stresses due to standard operation and potential debris strike:

A turbine blade-debris collision was modeled analytically as a case of horizontal striking impact using the kinetic energy method. The system was simplified by considering the log or debris as a moving mass with kinetic energy and the blade as an elastic member. In a collision, if we assume dissipation to be negligible*, all kinetic energy from moving mass $(\log )$ is converted to elastic energy stored in the struck member (turbine blade). This may be expressed:

$$
\frac{\text { Force }^{2}}{2 k_{\text {paddle }}}=\eta \frac{\text { mass }_{\log } \text { Velocity }_{\mathrm{log}}^{2}}{2}
$$

where $k$ is the stiffness of the paddle, and $\eta$ is the internal dissipation of kinetic energy in the blade (where a value of zero would imply total dissipation, and one no dissipation)* which may be further reduced:

$$
\text { Force }=\text { Velocity } \log \sqrt{\eta \times \text { mass }_{\log } k_{\text {paddle }}}
$$

The stiffness of the paddle (force/displacement) was determined by modeling the paddle as a cantilever beam with a cross-sectional profile similar to that of paddle. The displacement under load for a cantilever beam is expressed:

$$
\delta=\frac{F L^{3}}{3 E I}
$$

where $\delta$ is the displacement, $F$ the force, $L$ the beam length, $E$ modulus of elasticity of beam material, and $I$ the area moment of inertia. Rearranging for force/displacement, stiffness may be expressed: 
$k=\frac{3 E I}{L^{3}}$

The area moment of inertia of the paddle was estimated by considering a simplified cross section consisting of a composite of three rectangles as shown in Figure 11.

According to the parallel axis theorem, linear superposition of these individual beams may be used to express the moment of inertia as follows:

$I=\frac{b_{1} h_{1}^{3}}{12}+\frac{b_{2} h_{2}^{3}}{12}+\frac{b_{3} h_{3}^{3}}{12}$

Roark and Young provide a factor of correction value ${ }^{8} \eta=\frac{1}{1+\frac{\text { mass }_{\text {blade }}}{\text { mass }_{\log }}}$

A conservative (and fairly accurate for large logs) simplification is to assume $\eta=1$. Employing the equations above, the following assumptions were made:

- A log with weight of $1000 \mathrm{lbs}$, or a mass of $2.6 \frac{\mathrm{lbs} \cdot \mathrm{sec}^{2}}{\mathrm{in}}$ and an absolute speed of 10 feet per second (120 inches per second).

- A high density polyethylene ( elastic modulus $=100,000$ psi, yield strength in tension $=3000$ psi) paddle with cross sectional dimensions as shown in figure 10 velocity $40 \%$ that of flowing water, or 4 feet per second.

The area moment of inertia was calculated to be:

$$
I=\frac{1 x 6^{3}}{12}+\frac{1 x 6^{3}}{12}+\frac{48 x 1^{3}}{12}=18 i n^{4}+18 i n^{4}+4 i n^{4}=40 i n^{4}
$$

The stiffness was then expressed:

$$
k=\frac{3 E I}{L^{3}}=\frac{3 \times 100,000 \frac{\mathrm{lb}}{\mathrm{in}^{2}} \times 40 \mathrm{in}^{4}}{13824 \mathrm{in}^{3}}=781 \frac{\mathrm{lb}}{\mathrm{in}}
$$

These values may be substituted to determine the maximum force:

$$
\text { Force }=\text { Velocity }_{\log } \sqrt{\text { qmass }_{\log } k_{\text {paddle }}}=72 \frac{\text { in }}{\mathrm{sec}} \times \sqrt{1 \times 2.6 \times 781}=3240 \mathrm{lb}
$$

To determine maximum stress in paddle, the following equation is employed:

$$
\sigma=\frac{M c}{I}
$$

\footnotetext{
${ }^{8}$ R.J. Roark and W.C. Young, Formulas for Stress and Strain. $6^{\text {th }}$ ed. McGraw-Hill: New York, 1989
} 
where $\sigma$ is the bending stress, $M$ is the moment, $c$ is the distance from neutral axis to outer edge of beam, and $I$ is the moment of inertia. This implied that the maximum stress would be found in those parts of the beam which were furthest from the neutral axis. In this case, 3 inches was the furthest distance.

Substituting these values:

$$
\sigma_{\max }=\frac{3240 l b x 24 i n x 3 i n}{40 i^{4}}=5832 p s i
$$

This particular analytical method of ascertaining stress implied several limitations. First, as seen in Figure 15, the model geometry differed from actual profile in two important ways. First the analytical model was a straight beam, while the actual profile was a curved blade. Secondly, the actual beam tapered, whereas the analytical model was of constant cross-section.

The first error caused the model to be less stiff than a more accurate representation would suggest. The second error caused the model to be stiffer than a more accurate representation would suggest.

Since the analytical model exhibited considerably smaller deflections with higher stresses than either experimental or FEA results, it was concluded that the analytical model required refinement to represent a less stiff blade with lower stresses.

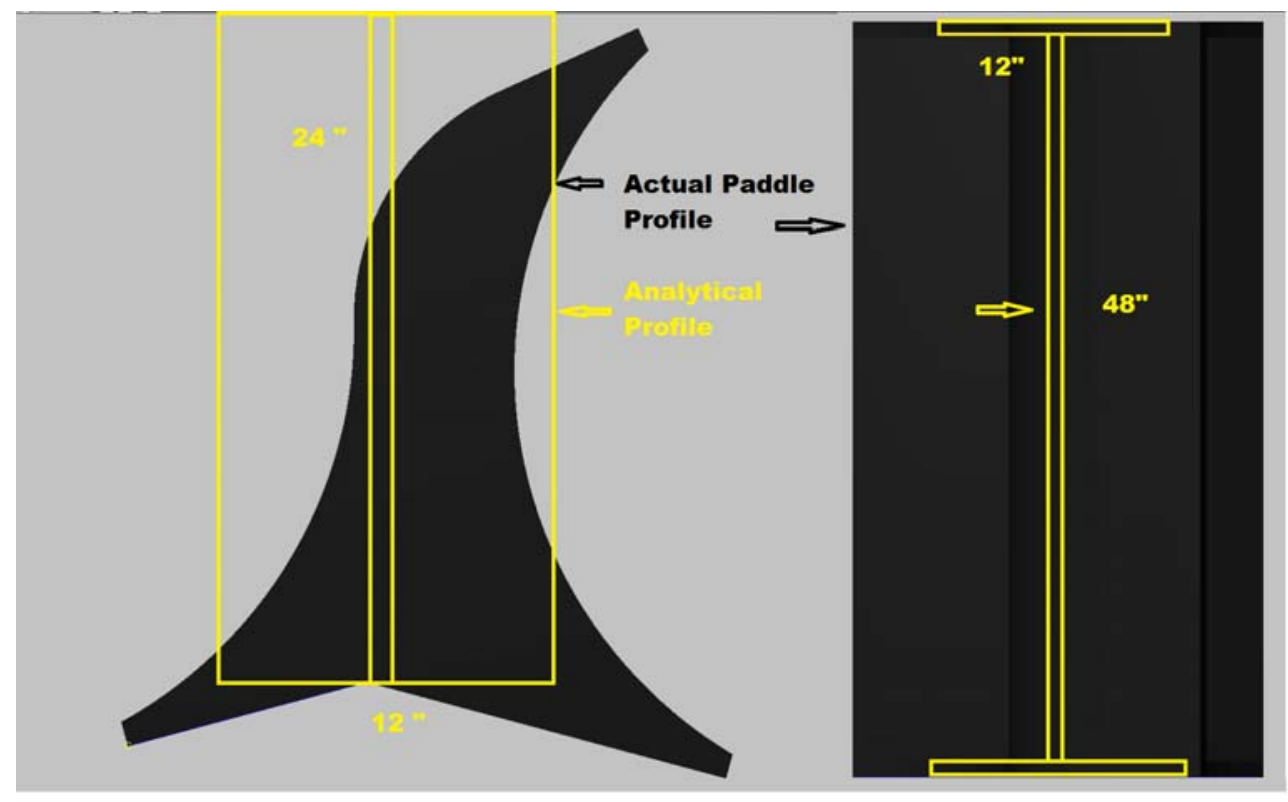

\section{Figure 15: Comparison closed form model to actual model}

\section{FEA Predictions}

A solid model and finite element mesh equivalent of the blade prototype was generated using the solid model/finite element software package Autodesk Inventor. The native finite element mesh generator employed elements with an average size of 0.1 inches, with automatic detection and 
recalculation of element groups with poor aspect ratios. This allowed very close geometric tolerances.

A static test was conducted with the following parameters:

1. Material- blade constructed of thermoplastic resin

2. Constraints- fixed constraints on mounting surfaces (see Figure 15)

3. Loads- Pressure load (operational water load) on turbine faces, $3000 \mathrm{lb}$ force at middle of blade tip (log strike impact force).

The maximum stresses were found in the support ribs at the sides of the blade, as predicted by the analytical formula. However, the maximum stress was considerably lower and the displacement higher than predicted by the analytical method. This was concluded to be the result of limitations in the analytical method; specifically that it did not account for lowered stiffness due to tapered profile.

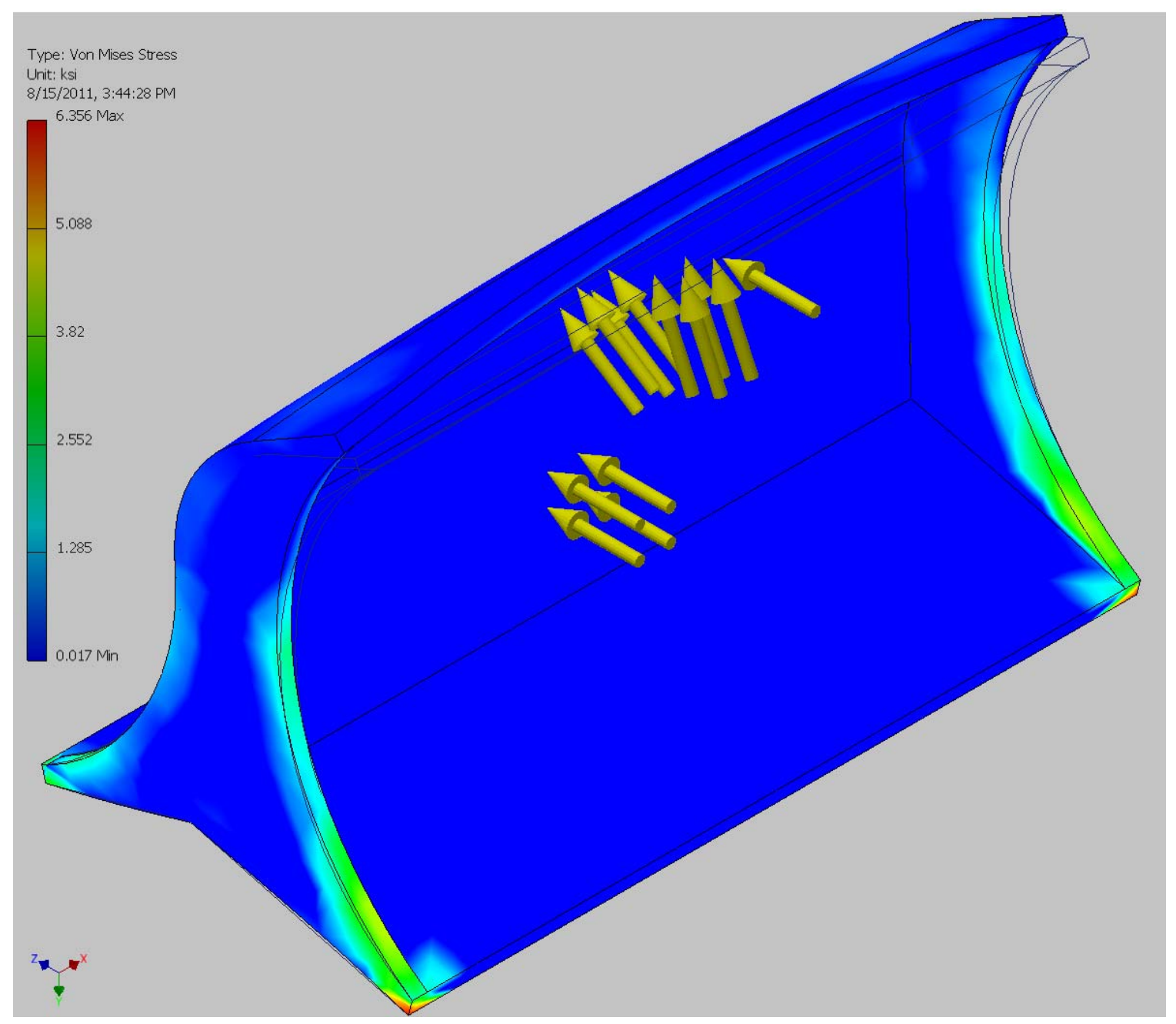

Figure 16: FEA results of paddle loading 


\section{Experimental Testing}

Two manufacturers built prototype turbine blades based upon the design requirements and drawings. A steel fixture was constructed with two primary design considerations. First its fastening system resembled the actual fastening brackets as closely as possible; and secondly its spring system made static force calculations feasible. The experimental testing regimen was two-fold. First it was desired to validate the FEA predictions of load response and survivability by observing behavior under known loads. Additionally, it was desired to validate analytical predictions of forces generated by placing the turbine blade in moving water.

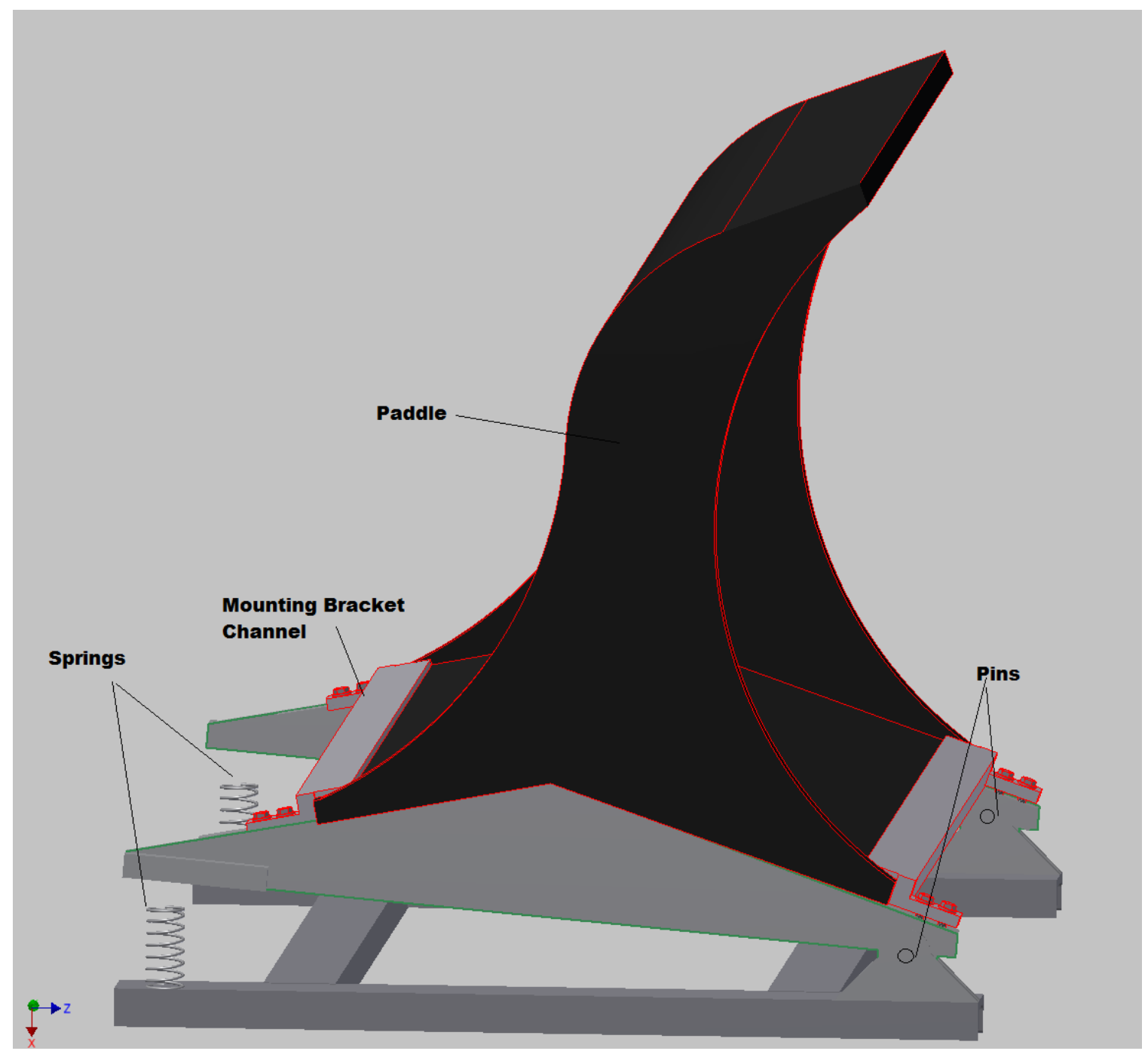

Figure 17: Testing jig with springs

The first test was conducted by securing the blade in the steel jig-shown above, which was itself securely constrained. Then a spring with known stiffness $(3000 \mathrm{lb} / \mathrm{in})$ with a steel end was pressed against the paddle at the tip, and the spring deflection measured. This test was applied to both paddles to simulate a log strike. 
DE-EE0004573

Whitestone Poncelet RISEC Project

Whitestone Power and Communications

FY2011

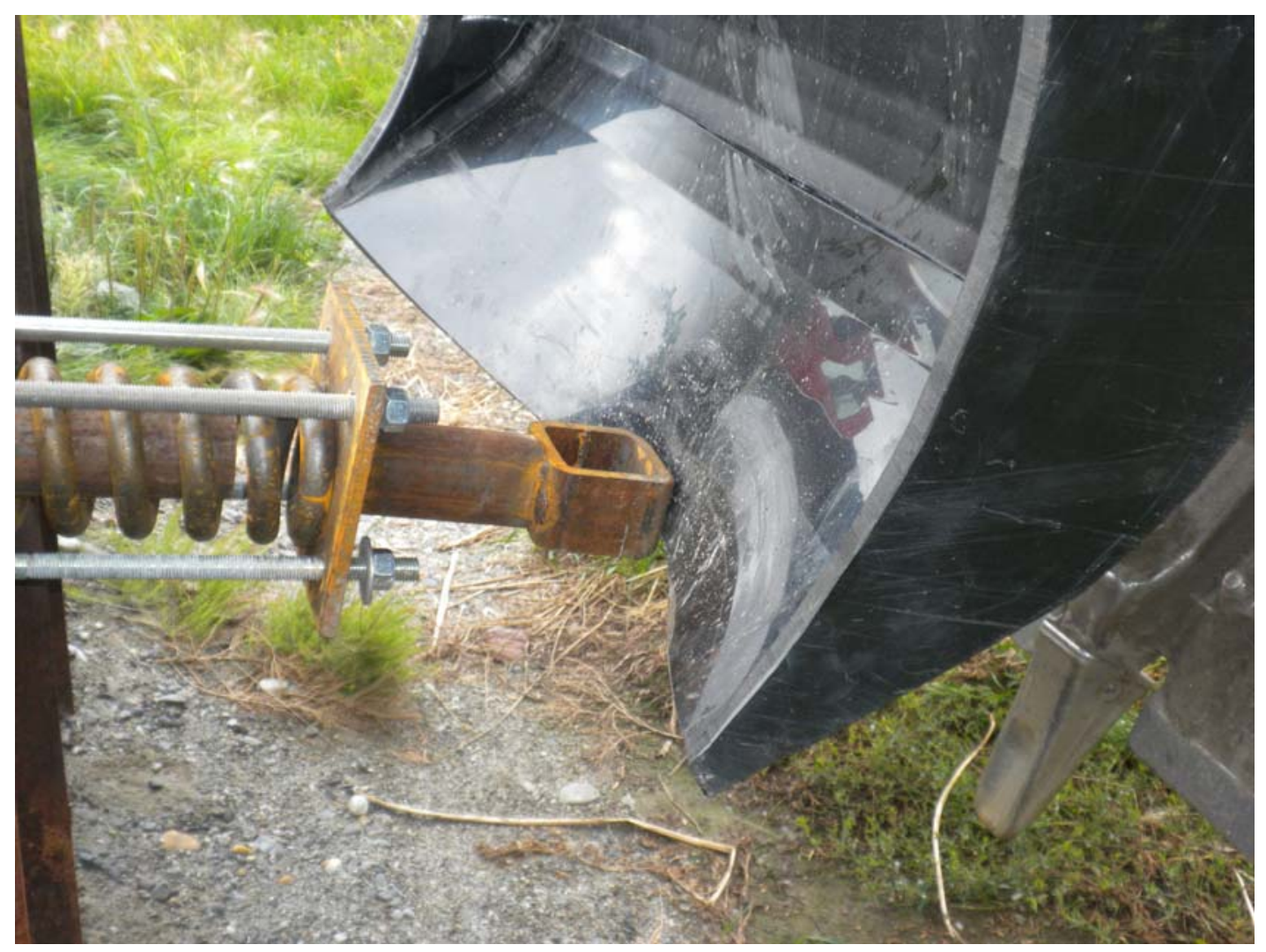

Figure 18: Log strike test- note cracking at weld seam.

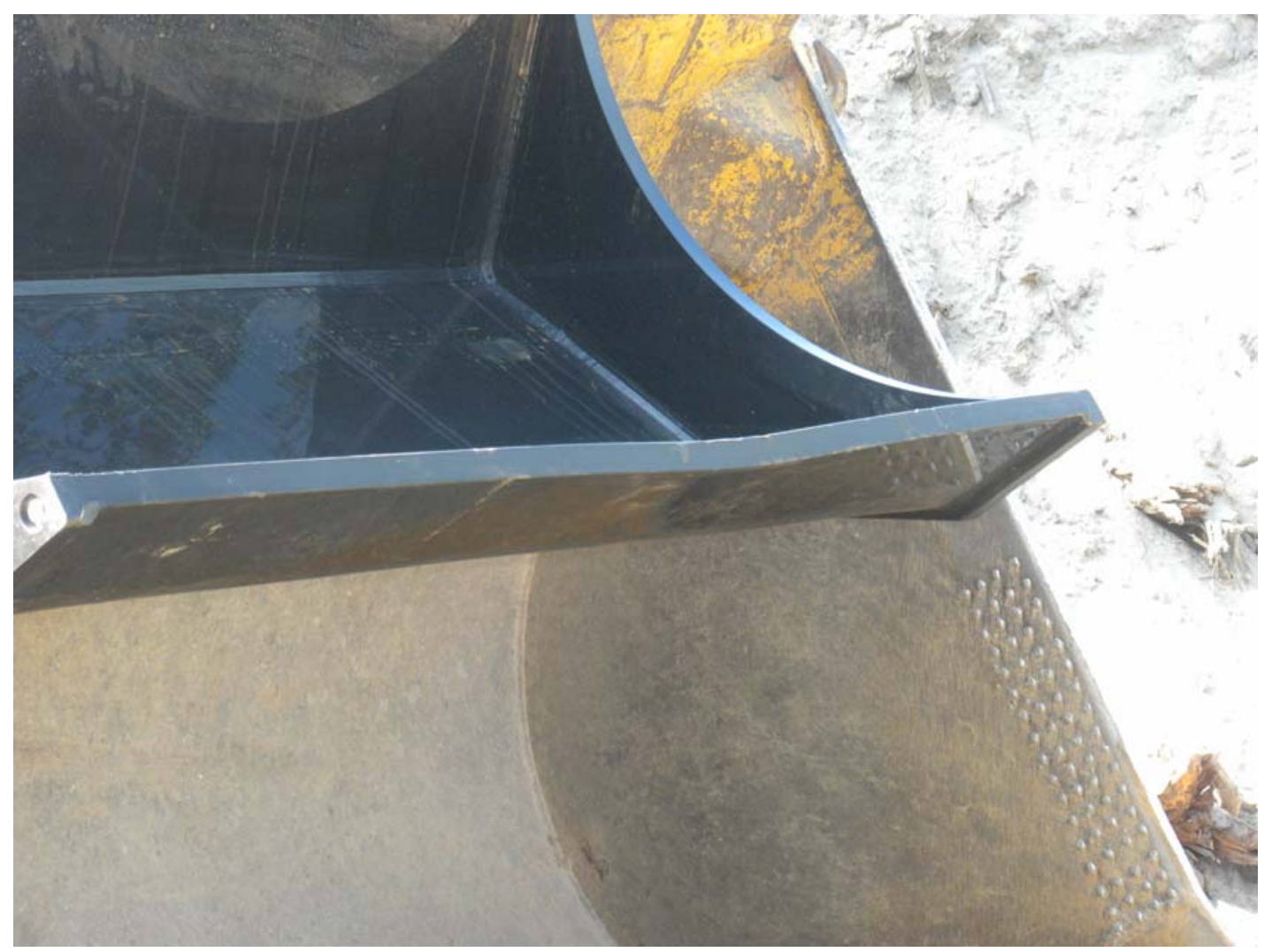

Figure 19: Blade deformation recovery after log strike test 
One paddle failed under the load, and one survived. Both blades exhibited excellent recovery from the distortion- see figure above.

The second test was performed on both blades; in this case the jig was fastened to a metal beam with U-bolts (see figure below) and the blade secured in the jig; the blade was placed into flowing water. The forces generated by the flowing water were calculated as follows:

$$
\frac{\text { Force } \times Y_{c p}}{l}=R_{\text {spring }}
$$

where $Y c p$ is the center of pressure $l$ is the distance from the pin to the spring, and $R$ is the reaction force at the spring.

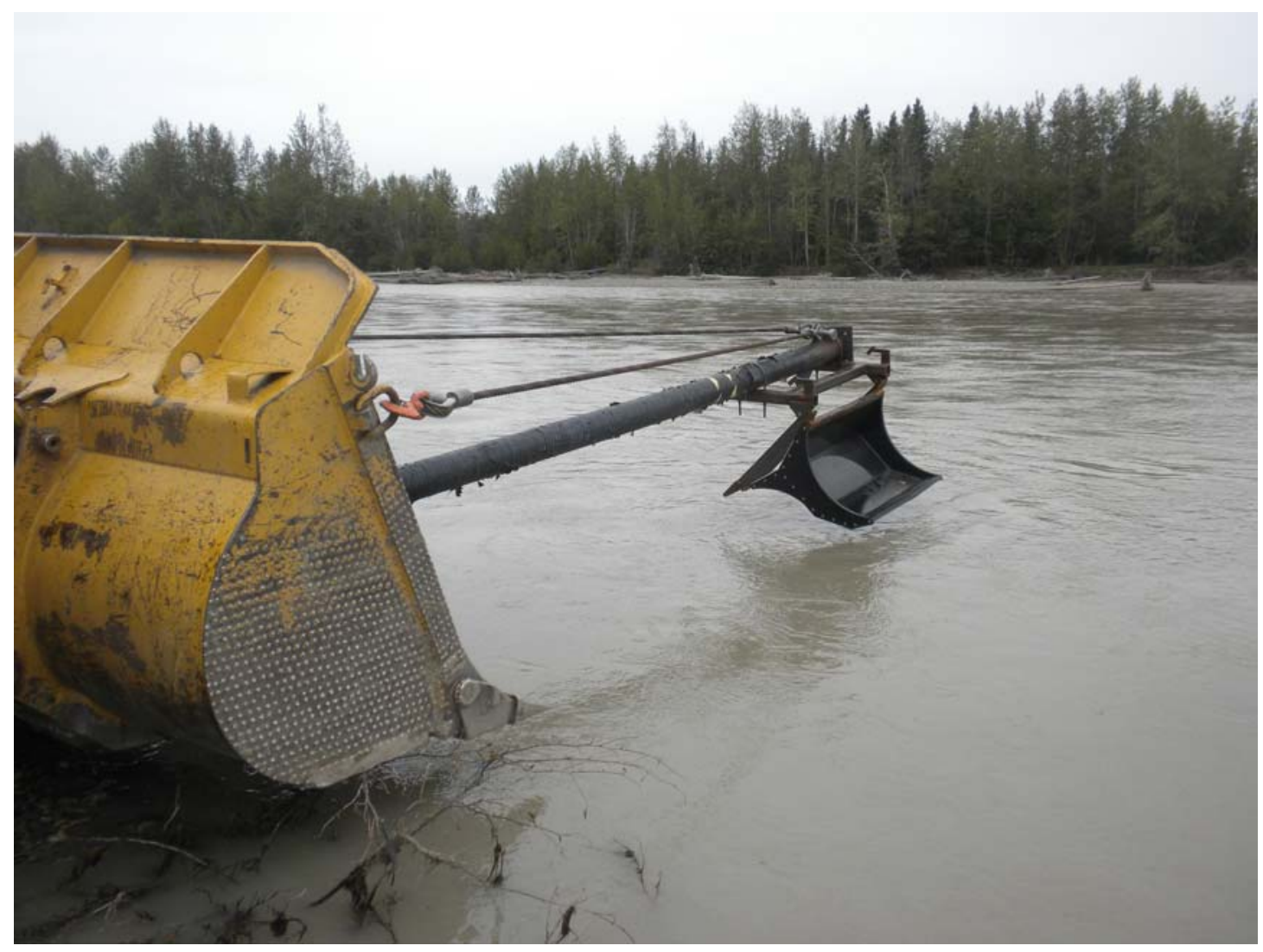

Figure 20: Water flow test setup 
DE-EE0004573

Whitestone Poncelet RISEC Project

Whitestone Power and Communications

FY2011

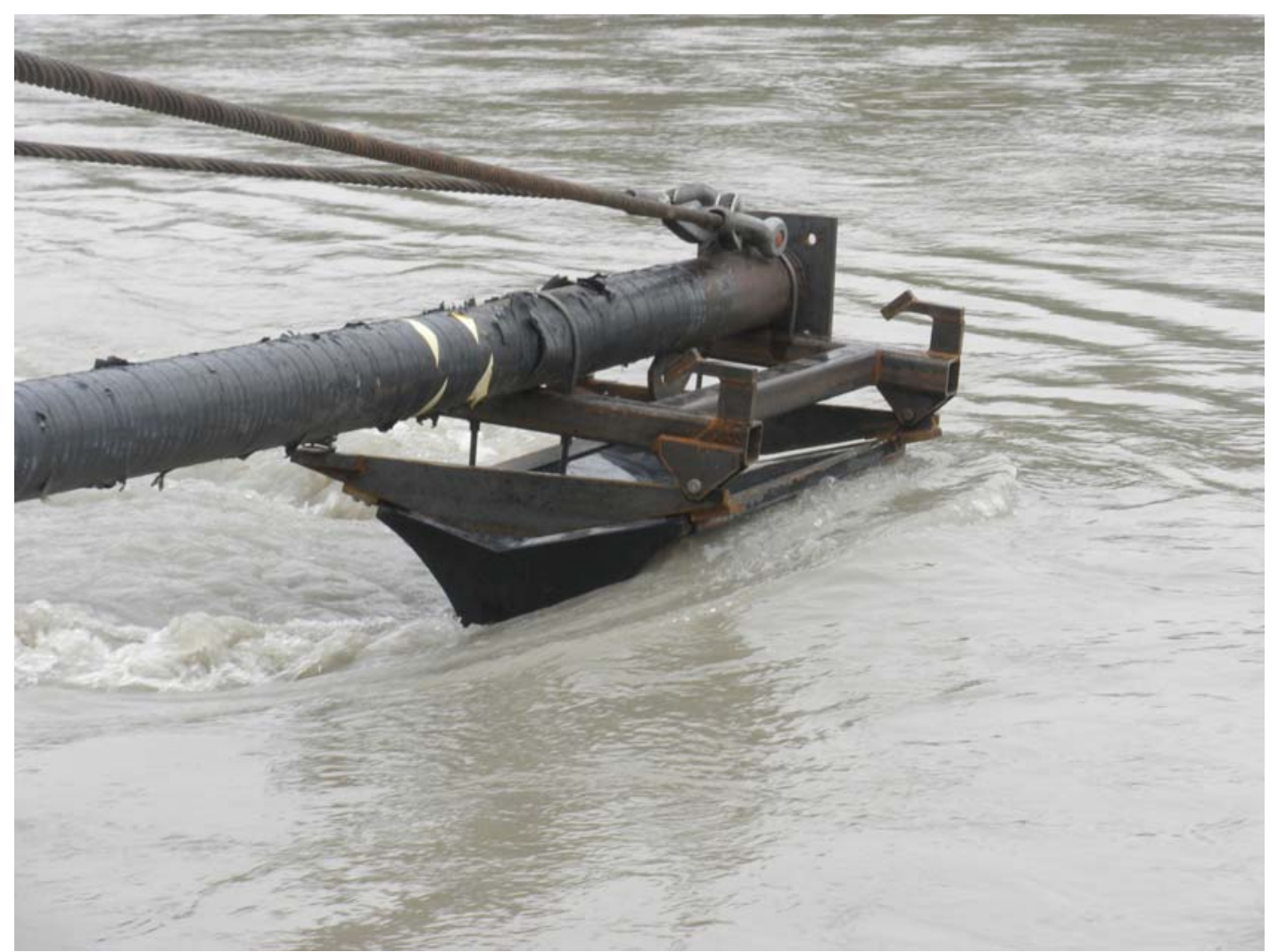

Figure 21: Blade under water flow test

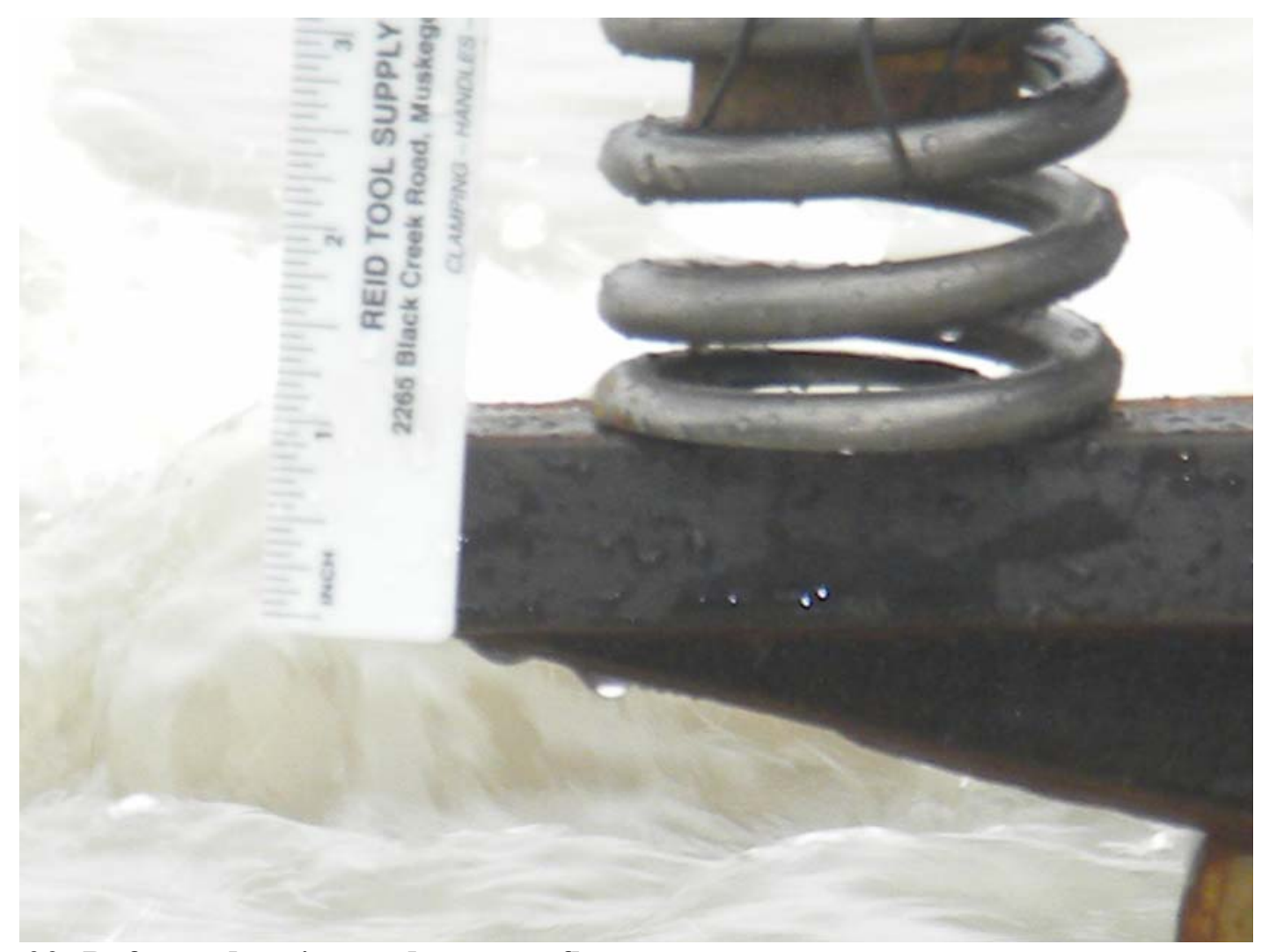

Figure22: Deformed spring under water flow test 


\section{Conclusions}

After experimental testing was concluded, the final design was a turbine blade constructed of one inch thick HDPE plate. This was bent and groove-welded to form a curve as specified, and one inch thick ribs were groove-welded onto the sides. In experimental testing, these blades were both able to sustain tip displacements of at least five inches, and tip loading of at least three thousand pounds, although a crack did appear at a welded seam of one of the blades when loaded.

\section{Turbine Section Design}

The turbine section itself underwent considerable design changes. Initially, a spoked wheel design with a central axle was considered. The initial design incorporated spokes which transferred torque from the blades to the central axle, which also supported the transverse load of the total turbine weight.

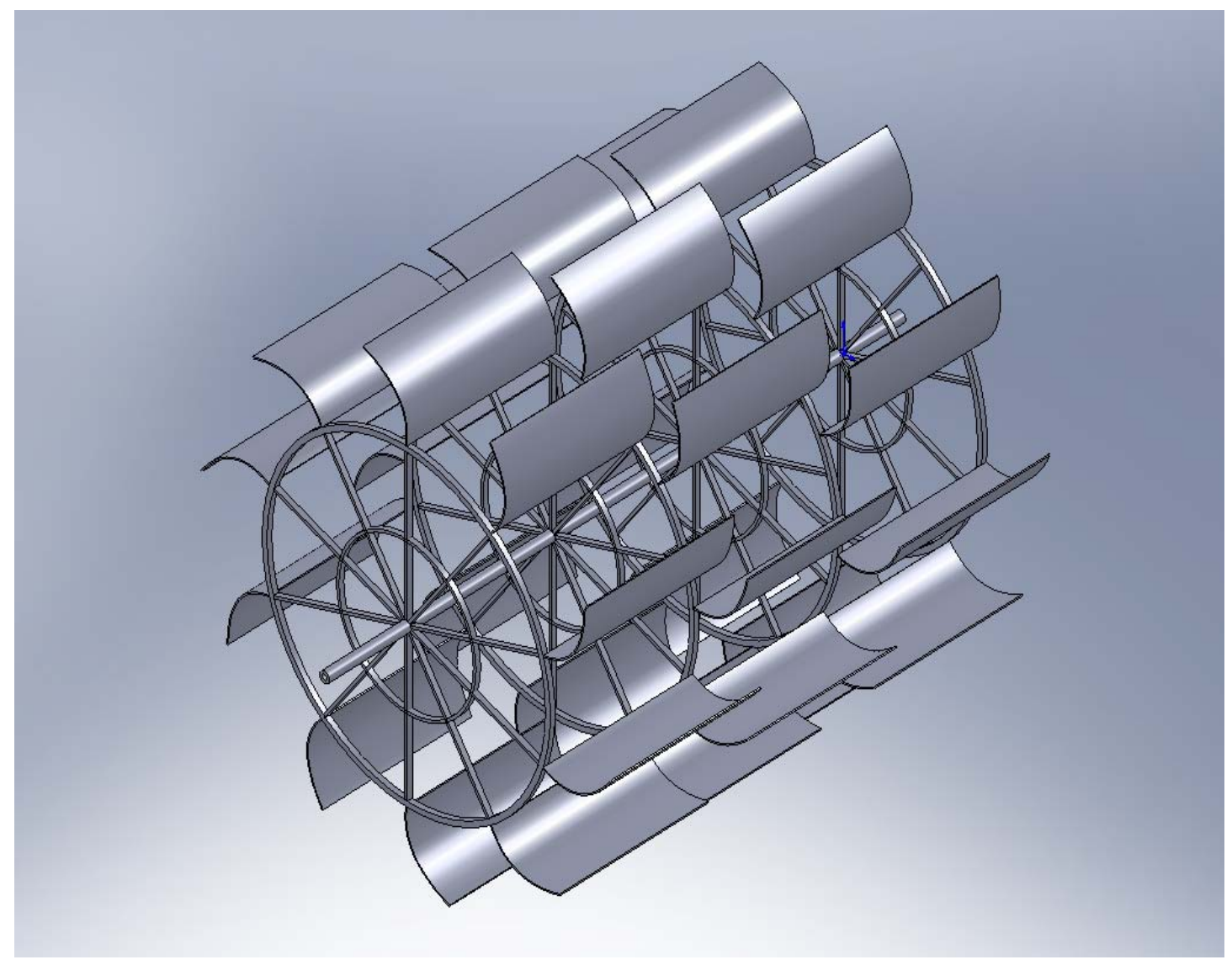

\section{Figure 23: Early turbine and blade assembly}

An initial design specification of an 8 inch diameter axle with 0.75 inch wall thickness and raised bosses for spoke attachment was suggested. An FEA calculation was made upon this model. The FEA model included no gravitational loading and simplified the mounting as a fixed restraint at the transmission end of the axle and a axial/radial bearing restraint at the other. A cumulative 96,000 foot pound torque was applied in 19,200 $\mathrm{lb}$ increments to each of the 
mounting bosses. This model had limited accuracy since the axial/radial bearing artificially forced alignment, and no gravitational force over the axle span was accounted for. Nonetheless, the model showed stress of 22,300 psi.

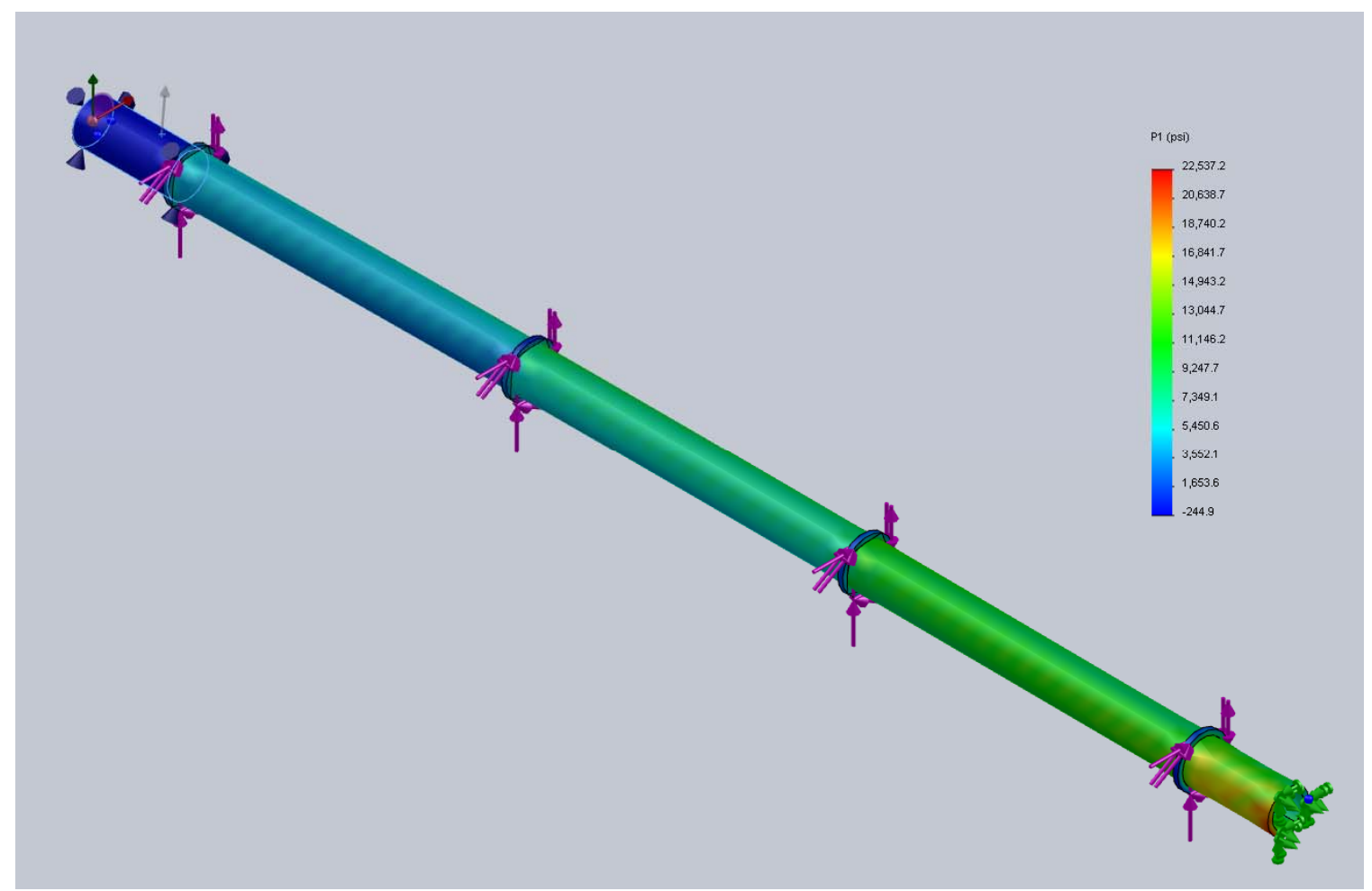

Figure 24: FEA results of axle torque test

The axle was designed to operate in fully reversed bending. Aluminum $6061 \mathrm{~T}-6$ alloys have fully reversed bending yield strength of 14,000 psi at 500 million cycles. This gives an unacceptable factor of safety $(0.627)$.

Eventually, the axle method of wheel support and torque transfer was abandoned because the 96000 foot pound torque required an exceptionally heavy axle, which incurred high material and logistic costs. Additionally, the need for a more flexible application implied the requirement of a modular design which could be applied in varying conditions.

The following requirements were determined for a satisfactory turbine section design:

1. High moment of inertia in torsion and transverse bending

2. Low weight

3. Ease of assembly

4. Modularity

A turbine comprised entirely of plastic was designed. However, although low stresses could be maintained, it was not able to hold geometric stability and could not be applied. 


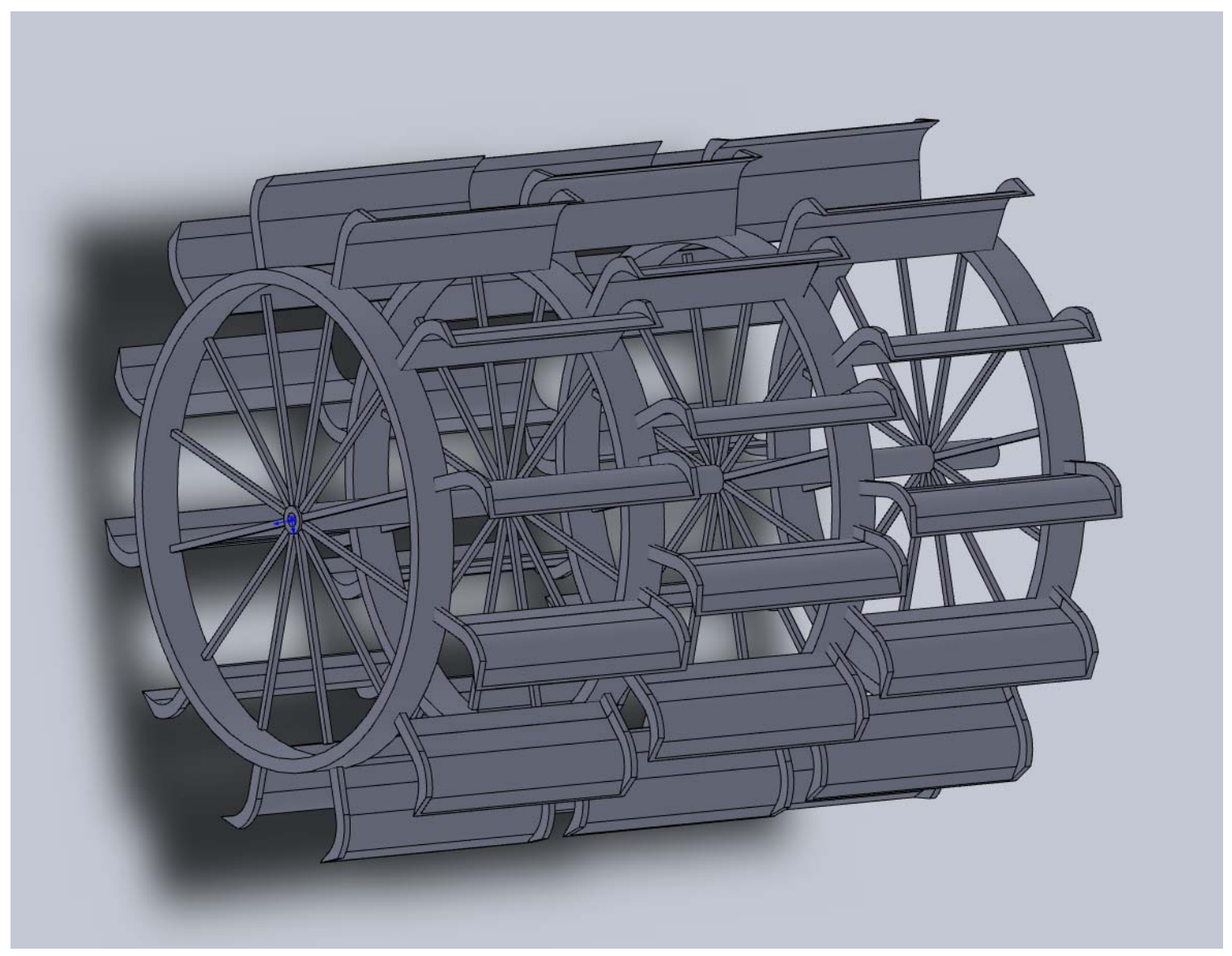

\section{Figure 25: All plastic turbine design}

Eventually a novel design using tubes mounted in an offset pattern from the center of end plates of a modular turbine section was presented. Using a plurality of tubes further from the central axis of rotation reduces the amount of material required for a desired polar or area moment of inertia. The basic dimensions were analytically derived to achieve acceptable multi-axial stress levels in bending and torque:

$\sigma_{\max }=\sigma_{x}+\sigma_{y} \pm \sqrt{\left(\frac{\sigma_{x}-\sigma_{y}}{2}\right)^{2}+\tau_{x y}^{2}}$

where $\sigma$ is the principal normal stress, and $\tau$ is the principal shear. 


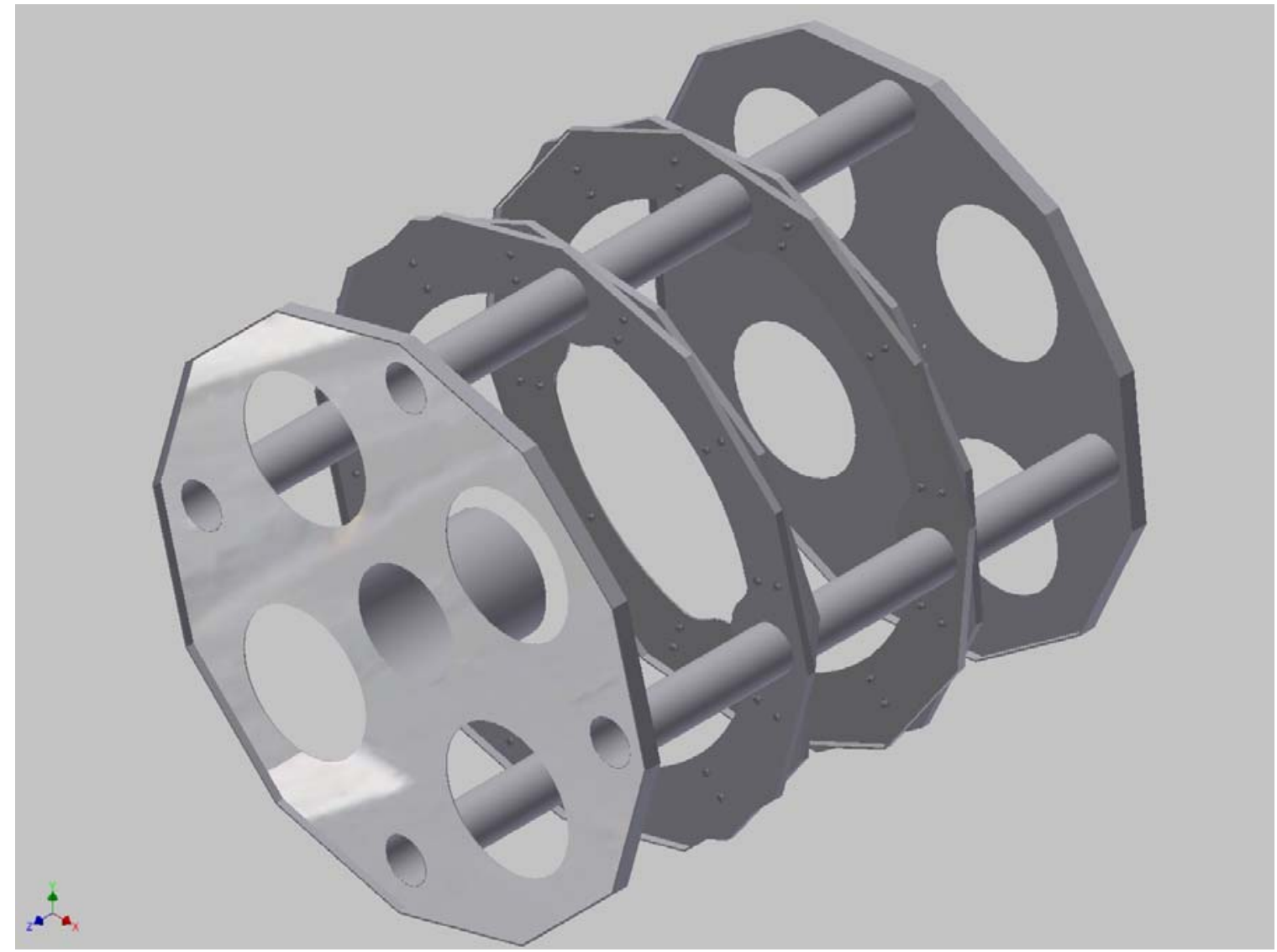

Figure 26: Final turbine design

The analytical results led to more specific parameters for an FEA analysis using 12 inch tubes at a five foot offset from center, and a thickness of 0.25 inches (see Figure 22). The FEA model was evaluated using the Autodesk Inventor static analysis package. The built-in mesh generator used 0.1 " tetrahedral elements to produce a very realistic geometric mesh. It was desired to refine the design and validate analytical predictions by modeling the combined stress of transverse loading due to turbine weight and moment loading from turbine torque (the anticipated max torque being operational torque plus log strike). To this end, a fixed constraint was applied to the transmission flange, and a bearing constraint applied to the mounting flange on the other side. The bearing constraint prevented radial motion but not axial or tangential (rotational) motion. A torque was applied to the mounting flange (a limiting case whereby torques are not evenly distributed along turbine sections, but concentrated at one end - not anticipated during operation). A second load, gravitational acceleration, was employed along the transverse axis to simulate turbine weight. 


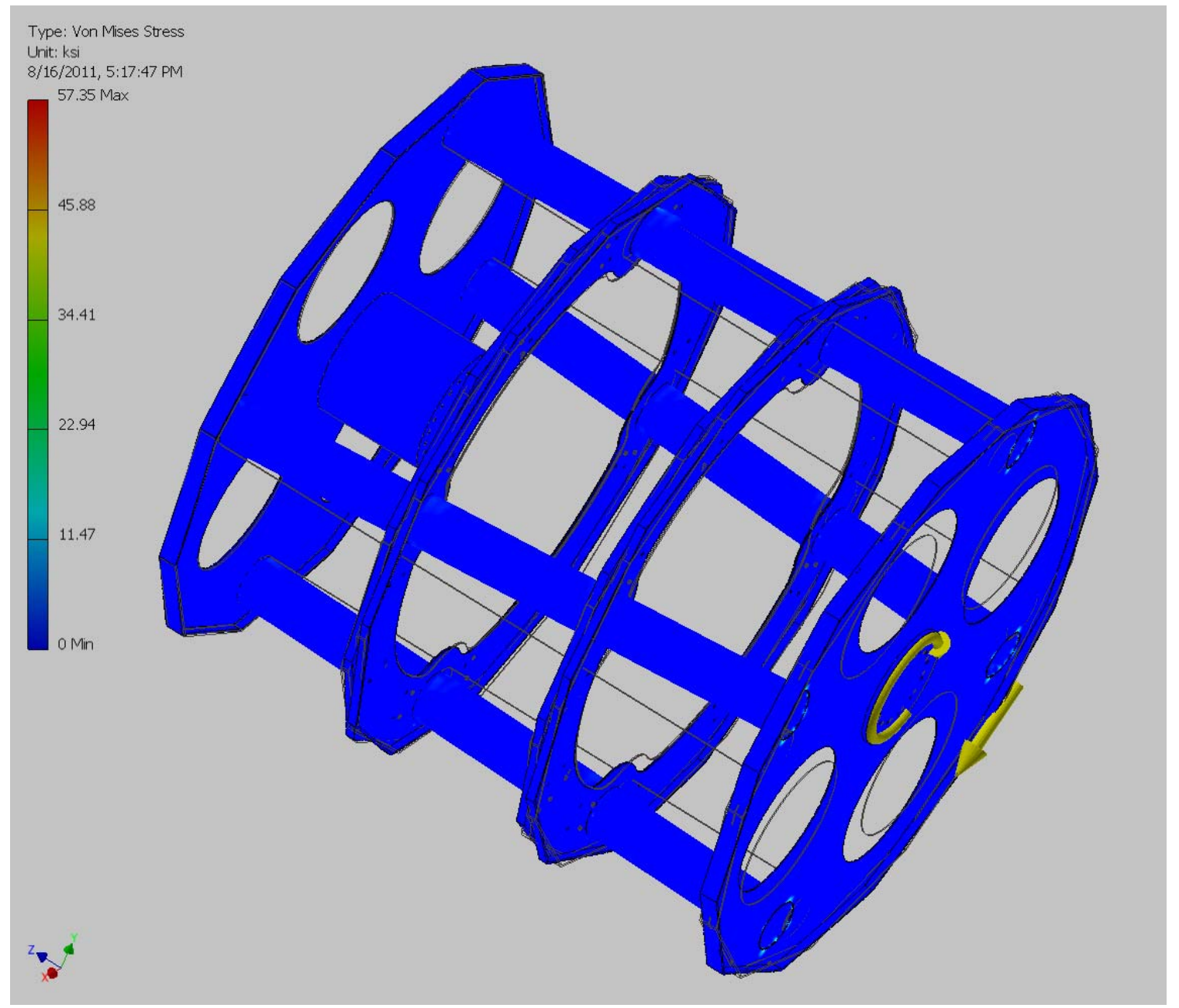

Figure 27: FEA results, turbine frame torque test

The limitations of this FEA analysis were primarily two fold; first the bearing constraints in Autodesk Inventor static analysis package could not specify a self-aligning bearing, giving the turbine a false degree of angular restraint. Additionally, the effects of fatigue loading in fully reversed bending could not be immediately evaluated using this software package.

However, it was concluded that the stress plots provided useful data insomuch that stresses were generally low in the structure (under $5000 \mathrm{psi}$, as predicted by analytical methods).

Materials selection for the turbine section structure centered around acquiring a material which possessed sufficient mechanical properties in terms of strength to weight ratio, fatigue and corrosion resistance, and which could be easily machined, welded, and manufactured to specification. Steel alloys were initially considered, due to their high fatigue resistance, reasonable weldability and machinability, and comparatively low cost. However, steel alloys typically require additional corrosion protection in marine environments, and are fairly heavy. Various aluminum alloys were considered. 7075-T-651 aluminum features unimpressive corrosion resistance, but has a 74,000 to 78,000 psi yield strength, and 23,000 psi fatigue 
strength in fully reversed bending at 500 million cycles ${ }^{9}$. Nevertheless it cannot be welded, and is a high cost alloy. 6061-T6 aluminum has a 14,000 psi fatigue strength at 500 million cycles in fully reversed bending ${ }^{10}$. 5086-H116 aluminum is a marine grade type aluminum with excellent yield (30,000 psi) and fatigue strength (21,800 psi at 500,000,000 cycles fully reversed bending stress) ${ }^{11}$ and light weight. Welding causes a local reduction in strength to $O$ temper (yield strength at 17,000 psi), but it can be welded, and a FEA analysis of stress locations predicted acceptably low stress at welds. The excellent fatigue and corrosion resistance of 5086 series aluminum alloys made it a preferred material for turbine and craft components.

\section{Bearings and Adjustments}

The turbine was specified with several inter-related design considerations in terms of mounting and adjustment. First it was desirable for the transmission input shaft to act as the mounting component for one side of the wheel. Second, the turbine should be vertically adjustable. That is, it could be lowered into water for operation (and raised out for maintenance) without moving craft. Finally, the structural potential for misalignment due to deck twisting moments and vertical adjustment necessitated a robust self-aligning bearing system.

The design considerations concerning the transmission in particular will be discussed in more detail in a later section; however it was specified with a low speed input flange rated for the shear load of the turbine as well as the twisting moment. On the other side, a pillow block with an integral self-aligning housing and precision plane bearing was specified. Both the pillow block support and transmission assembly were designed to be fastened to vertically sliding mounts actuated by linear actuation system. Initially, servo controlled linear actuators such as those employed for machine tool positioning were discussed. These were abandoned in favor of a more robust system, hand crank actuated screw jacks. Some concern about screw jacks potentially failing under buckling was discussed; however the rating of the screw jacks specified was considerably greater than the specified load required, and no risk of buckling was anticipated.

\footnotetext{
${ }^{9}$ Aerospace Specification metals Inc. Aluminum 7075 T-6, T651 http://asm.matweb.com/search/SpecificMaterial.asp?bassnum=MA7075T6 Accessed Online, August 18, 2011

${ }^{10}$ Aerospace Specification metals Inc. Aluminum 6061 T-6, T-651 http://asm.matweb.com/search/SpecificMaterial.asp?bassnum=MA6061t6 Accessed Online, August 18, 2011

${ }^{11}$ Aerospace Specification metals Inc. Aluminum http://asm.matweb.com/search/SpecificMaterial.asp?bassnum=MA5086H116 Accessed Online, August 18, 2011
} 


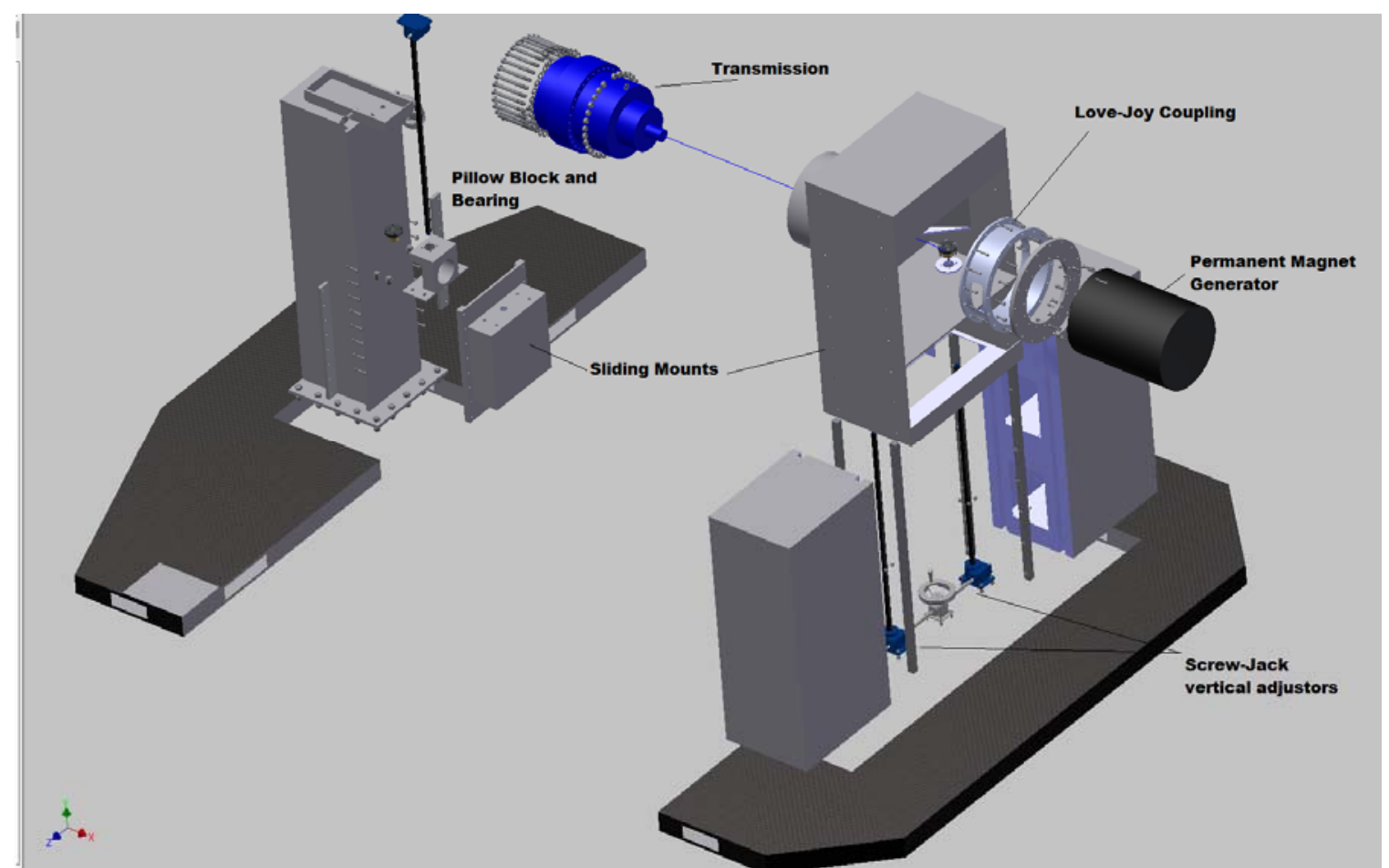

Figure 28: Assembly view- transmission and power generation components

\section{Transmission}

The general paradigm of the Poncelet turbine system is to provide low speed, high torque power output. Optimum efficiency is obtained by running the wheel such that blade tip speed is $40 \%$ of current speed, so a 15 foot diameter turbine constrained to run at optimum speed* in a 15 foot per second current will rotate at approximately 8 revolutions per minute. Efficient electrical power generation typically requires generator input with higher speeds and lower torques; to this end, a transmission system was specified.

Several design requirements were formulated to narrow the field of potential transmissions. The generator chosen was a low speed 36 pole AC permanent magnet generator with optimum efficiency in the 150-200 RPM range (More discussion on this design paradigm will be conducted in a later section). Thus the transmission must have a speed ratio of 30:1 with a 5-8 RPM input. The transmission must be weight and cost effective, and be readily mounted and coupled to turbine and generator. It must be sufficiently compact to fit on the slider mechanism and be sealed and protected from wind, silt and water. If lubricated, the lubricant must be sufficiently sealed so as to present no environmental hazard.

Several transmission variants were considered for potential application. A caged belt drive was initially considered. However, belt drives are most efficient at high speeds, and a 30:1 reduction would require multiple sets of prohibitively large sheave/belt combinations. A chain drive would be more efficient at low speeds, but would be large and require lubrication; additionally concerns about noise pollution were discussed. 
It was concluded that most custom transmission solutions were excessively large and expensive; therefore a commercial off the shelf option was explored. A Brevini epicyclic two-stage transmission was selected. This transmission used planetary gear sets in series to provide compact, light, zero maintenance transmission solution. This planetary gearset package offered custom couplings and mounts on both high and low speed ends.

It was concluded that the transmission itself would be specified with tapped holes by which it would be fastened to the sliding mount, which would bear the torque load of the generator resistance. A love-joy gear coupling would provide misalignment tolerance on the turbine side, and the generator would be rigidly mounted to the output side of the transmission.

\section{Braking and Turbine Control}

It was desired to maintain control over turbine speeds for three reasons: First in the event of emergency, it would be desirable to stop the turbine. Secondly, concerns were discussed about the risk of turbine "runaway" if inductive motor power output was exceeded. Finally, concerns regarding inductive motor cut-in speeds, and the need to potentially slow and control wheel rotation were discussed. More discussion regarding generators and generator controls is available in a later section.

Initially, the general design paradigm regarding turbine design was as follows: the turbine would provide motive power to the inductive generator, and any modification of rotational speed would be executed mechanically. A hydraulic brake was specified to slow or stop the wheel if necessary. This brake would require servo-actuation interfacing with the electrical generator controls, or an operator to set cut-in speed and slow turbine if need be.

Due to design paradigm changes (discussed in more detail in a later section) regarding the generator and control setup, a partnership with Energetic Drives led to the specification of a new control system. This novel power generation/conditioning and controls system utilized a permanent magnet generator, and automatically controlled generator resistance to provide optimum torque and could cut in and out either automatically (by preset setpoints), manually (by on-craft actuation) or remotely (by SCADA control).

The system designed by Energetic Drives allowed for considerable simplification of the mechanical system, and elimination of numerous components, including the mechanical braking system. In the current embodiment, the generator could be signaled by the control system to provide back emf, or regenerative braking, and could cut in or out at any velocity that was anticipated. This eliminated the hydraulic reservoir, lines, brakes, and actuation components.

\section{Power Generation/ Conditioning}

Specific application and design specifications were developed for pairing a generator with the turbine prime mover. It was desired to employ a generator compatible with three modes of application. The generator must function as a stand-alone power source (such as a backup power source in the event of grid power failure); it must be capable of pairing with diesels to provide 
power, and it must function as a source connected to infinite grid power. Functionally, a generator must be compact, inexpensive, robust, and tolerant of variance in rotor speed. To this end, both permanent magnet and induction generator solutions were considered.

Induction generators function by forcing the prime mover to drive the rotor above a synchronous speed, which is defined by following relation:

Hertz $=R P S \times$ Number $_{\text {pairs }}$

That is, the frequency of power generated depends on the rotational speed and number of pairs of poles on the stator. Induction generators are typically larger, but lighter, for a given rated power output than permanent magnet generators because they require no brushes or commutator. This also makes them more rugged. Induction generators also tend to be less expensive than their permanent magnet counterparts. The drawback of the induction generator is that they require a source of excitation current for magnetizing flux; thus an induction generator is not a suitable solution for stand-alone power. Additional concerns were that an error in controls could allow an induction generator connected to an infinite grid to run at lower speeds (ie: the rotor turning slower than rotating flux) whereby the machine would function like an induction motor and use grid power to bring wheel up to speed.

A permanent magnet solution was selected, because although such generators are more expensive, and contain more moving parts, they are more readily suitable for stand-alone power production. An off the shelf solution was provided, which had 36 poles (enabling low speed operation), and a wide operating band. Paired with an effective power signal conditioning system (A more detailed discussion of the particulars of this system will be discussed later), this solution offers a very acceptable range of operational productivity and flexibility.

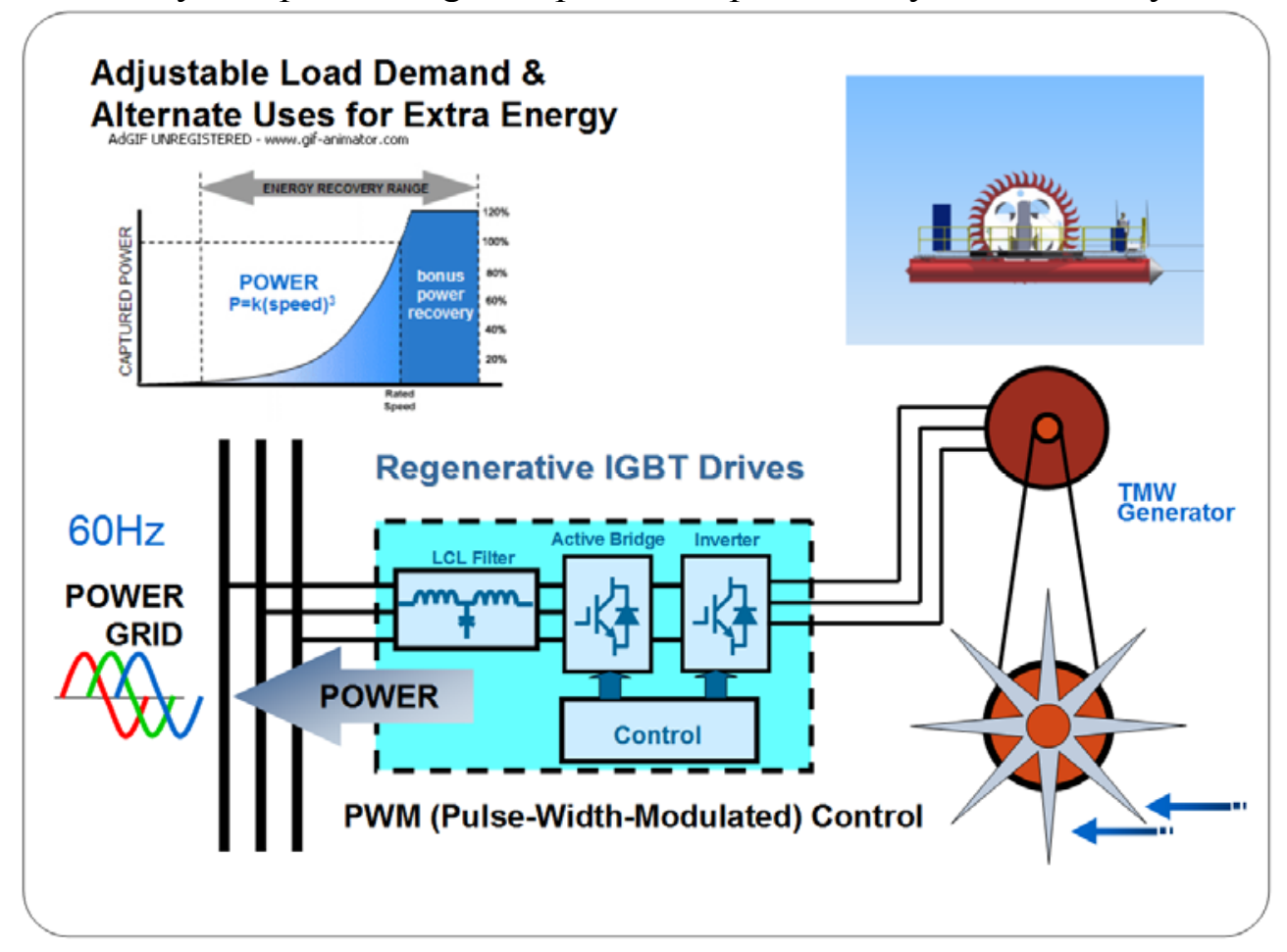

Figure 29: Circuit diagram of Energetic Drives Active Front End system 


\section{Electrics/ Controls/ Monitoring Generator Control Algorithm and SCADA Controls}

The operational imperatives driving craft design require a robust and complex feedback control and monitoring system with integral remote access and supervision capacity. To this end, a SCADA (supervisory control and data acquisition) system was specified. This system was subject to several design requirements. First, it must modulate generator resistance to maintain optimum ratio of blade tip speed to water speed, maintain cooperative master/slave power sharing in the event of diesel pairing power production, and provide real-time data for water velocity, wheel speed, voltage and reactive power production. Additionally, the SCADA system must be capable of producing alarm outputs to an integral personnel alarm system in the event of specific operating conditions.

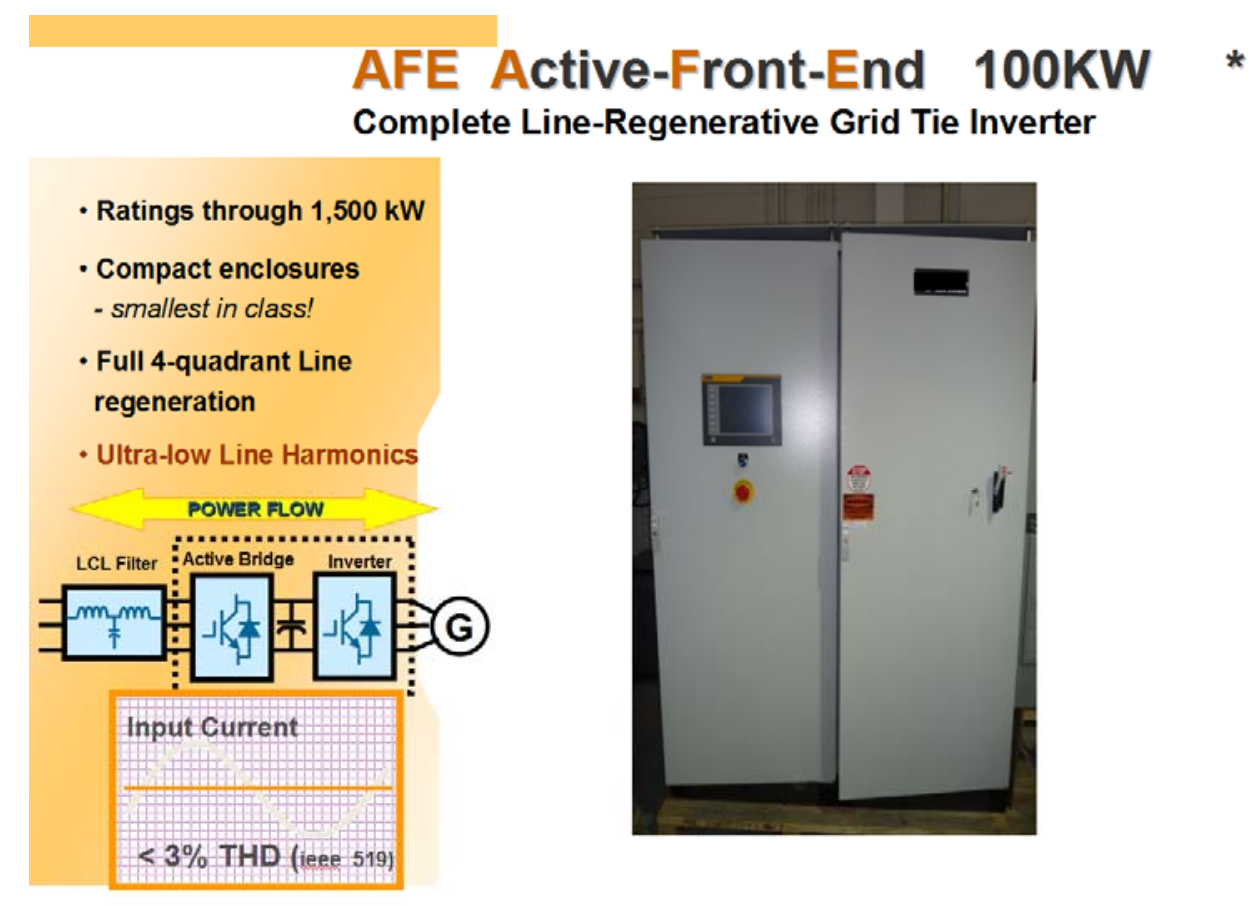

\section{Figure 30: Energetic Drives control cabinet}

\section{Generator Efficiency Optimization}

The theoretical Poncelet efficiency was optimized by adhering to specific geometric and relative velocity constraints. It was considered important for the control system to be designed such that it would increase or decrease generator torque to maintain proper velocity for maximum power output. 


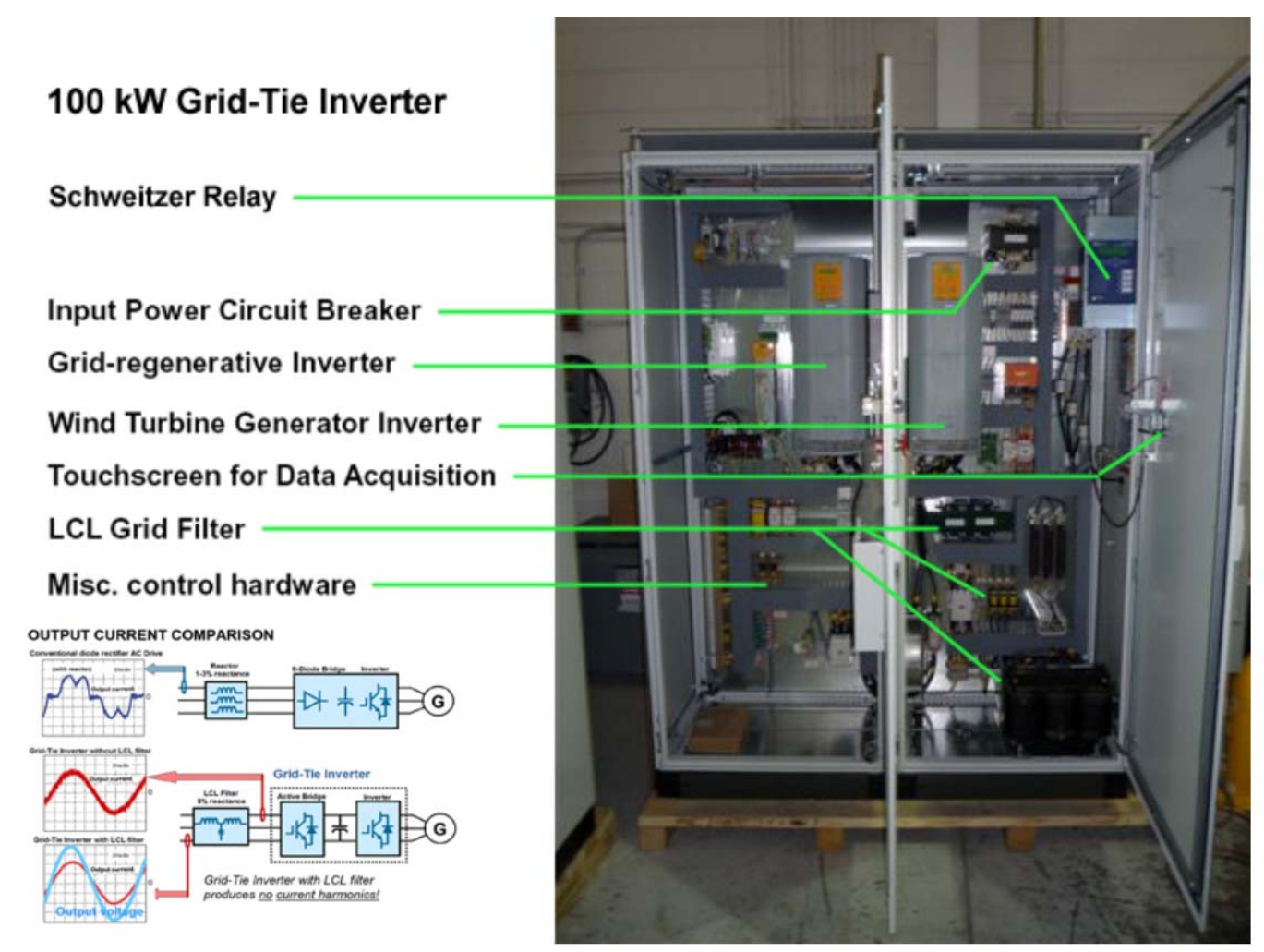

Figure 31: Control cabinet components

\section{Diesel Generator Pairing}

As mentioned previously, it was desired to design the hydrokinetic turbine for three modes of application. It had to be able to provide stand-alone power to a small grid; it had to be able to pair with other small power sources (such as existing diesel generators) to power a grid, or it had to be able to feed the infinite grid.

The standalone and infinite grid modes are fairly simple for a permanent magnet generator and controls. However diesel pairing introduces a potentially problematic feedback loop since the craft and most generators would have individual load sensing governor controls. Some concern was discussed that this might result in an unstable response, which would not only affect power output, but would cause oscillations which would cause diesel prime movers to run at inefficient speeds.

To attenuate this concern, a PLC driven control system with Schweitzer relay sensors was designed. If the relay sensed the activation/deactivation of another power source on a finite grid, it signaled a master/slave set point control which set an optimal speed for the diesel prime mover, and assigned the remaining load to the hydro-kinetic turbine.

\section{Real-Time Monitoring and Control}

Since the hydrokinetic turbine is designed for remote locations, it was considered desirable to enable remote monitoring. Thus voltage output, river current speed, and wheel rotational speed 
would be available at a power plant computer remotely. Additionally, manual control and programming changes to PLC set points could be executed remotely from a computer using the SCADA interface.

\section{Alarm Systems}

Since the hydrokinetic turbine was designed for potential swift water deployment in remote locations, some concerns were discussed concerning potential mooring component failure. A positional monitoring system employing a Dynamic Global Positioning System coupled with an excursion monitoring/reporting software package was specified for integration into the SCADA control system. If the system sensed the craft moving outside of the defined excursion envelope, an alarm would sound to indicate mooring cable failure; this system queries onboard GPS sensors for craft position every five seconds, updates a five-year data-logged history of craft positions and headings at a one-minute sampling rate, and additionally records alarms and events in a data $\log$.

The proposed positional monitoring system is tolerant of power outages and currently supports the following industry standard communication protocols:

1. MODBUS RTU Over TCP

2. MODBUS ASCII/RTU/TCP

3. NMEA 0183

\section{Means of Alerting Technicians}

The proposed SCADA system interfaces with a Protalk CV3 alarm dialing system with cellular amplification, integrated cellular module with voice and SMS text capabilities. This alarm system is tolerant of power outages, and may be programmed for four different shifts, is highly modular, and has low footprint. It will continue to dial numbers in its database until technicians give confirmation of alarm notification.

The proposed system also has built-in radio port and public address systems which may be programmed with redundant alert capability in after-hours situations.

An additional consideration for the SCADA monitoring/alarm system was alarm cascade. Since the Protalk interface was capable of supporting a wide array of specific alarm messages from digital and analog inputs, it was important that the acquisition and broadcast of craft data be configured to give technicians optimum awareness of the mode of failure and extent in the event of emergency involving several alarms from multiple component failures. The integrated PLC interface would then organize the alarm cascade such that technicians would be able to differentiate a transmission rotation stoppage caused by a debris jam from one caused by mooring cable failure or transmission component failure. This allows emergency personnel and technicians to best prepare themselves to address emergency situations. 


\section{Partnerships and Collaboration}

\section{Energy Stability Solutions and Energetic Drives, LLC}

During a survey of available power generation and control solutions, Hasz Consulting collaborated with Energetic Drives, a company which provides power generation solutions specifically for small $(10 \mathrm{~kW}$ to $1.5 \mathrm{MW})$ projects. The "active front end" power generation platform designed by Energetic Drives provides an exceptionally efficient production of clean power, and significantly simplifies mechanical requirements in terms of turbine control.

Most engineered solutions for a variable speed prime mover involve a diode bridge rectifier to convert "dirty" AC power to DC, and can only provide between 1-3\% reactive power (volt-ampreactive) to compensate for reactive loads. The design utilized by Energetic Drives employs an active bridge and LCL filter to eliminate harmonics while also providing the necessary reactive power to maintain a stable power factor regardless of the phase of the load.

\section{Potential Power Generation for Alaska and the Nation}

A large portion of the project was completed by CE2 Engineers, Inc. of Anchorage, AK. As a company with a successful history of completing highly technical projects in remote communities, it was decided they would be an excellent partner to help determine the viability of the chosen design. To this end, Hasz Consulting contacted them and they agreed to complete the portions of the project which would analyze extractable energy estimates as well as the obstacles to successful integration of the engineered system into the open market place.

Their full report is attached to this document. Their study was focused primarily on Alaskan communities. These communities specifically, being remote, operating in harsh environmental conditions and experiencing the highest cost of energy in the nation, are not only in the greatest need, they are also the best test beds of this technology. The full study includes an estimate of the extractable energy nationwide as well as the significant obstacles to full integration in the market.

\section{Conclusion}

The project was considered successful in three ways. First, site specific engineering solutions were developed for applying RISEC technology effectively in Alaskan river environment. Secondly, the wide integration of stock components reduced design, construction and component replacement costs. Finally, the modular construction design and flexible control system designed by Energetic Drives, contributed toward methodology with broad potential application to remote village power needs.

The effective deployment of RISEC technology in Alaskan rivers is tremendously significant in light of the extremely high costs of energy in remote communities. Providing an energy source which is both sustainable and economically feasible is crucial in preventing the extinction of 
remote Alaskan villages, many of which cannot remain financially solvent in the face of increasing fossil fuel costs.

A significant aspect of this project was a study conducted by CE2 Engineers which compiled a list of sites for potential commercial application of the project device. The study, which took into account topography, river speed, and local community power needs, concluded that this device would potentially be applicable at 46 village sites in Alaska alone, and 150 sites in the continental United States.

RISEC implementation offers the benefit of flexible, comparatively inexpensive power solutions for remote communities as well as providing a substantial step forward in the technical and commercial viability of alternative technology. 


\section{Riverine Resource Assessment}

\section{Poncelet Kinetics RHK100 Hydrokinetic Device}

Prepared by:

CE2 Engineers, Inc.

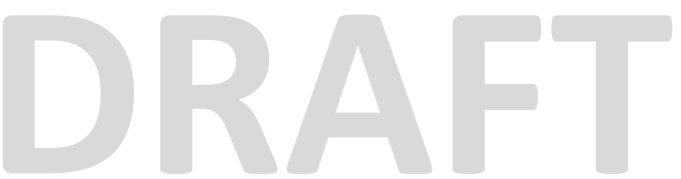

Report Date:

February 2011

Communities located on rivers in Alaska may potentially benefit by integrating an RHK100 hydrokinetic device into their existing power system. Potential benefit will depend on the community's proximity to water, the estimated stream velocity, the distance between the river and the community, the amount of summer power supplanted, and the future changes in community population and fuel costs. Benefits result from displacing some or all of a community's summer power load. Benefits to larger communities like Mountain Village, Tok, and Galena, will differ from those to smaller communities like Red Devil, Sleetmute, and McGrath. 


\section{Contents}

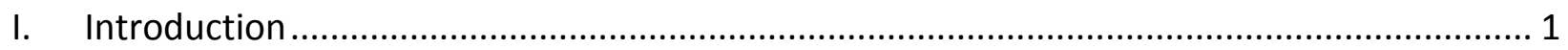

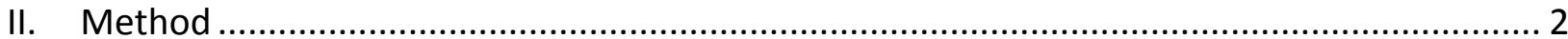

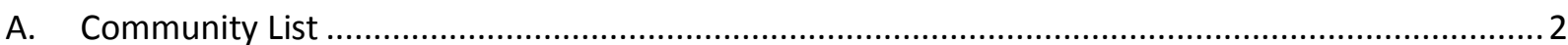

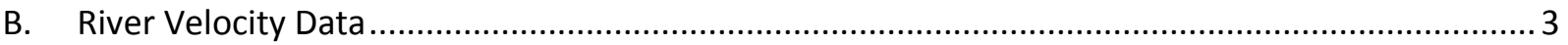

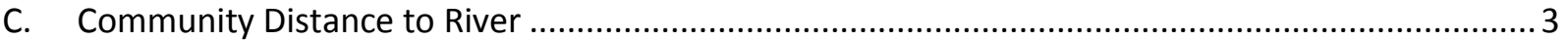

D. Suitable River Hydrokinetic Power Capacity...........................................................................

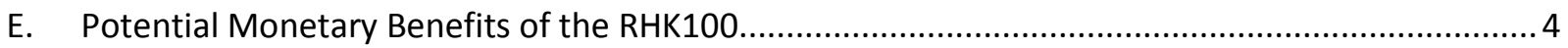

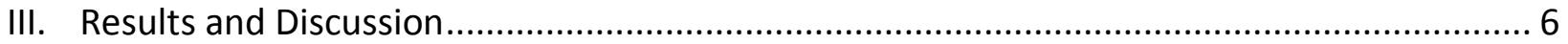

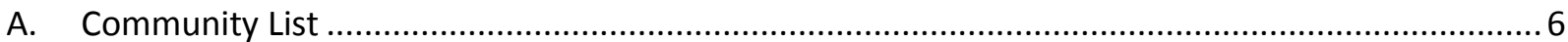

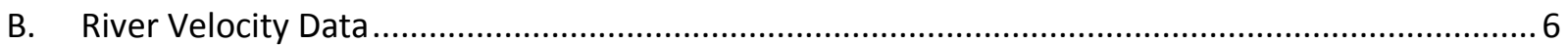

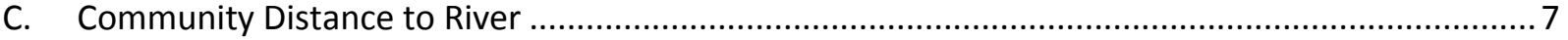

D. Suitable River Hydrokinetic Power Capacity ........................................................................... 7

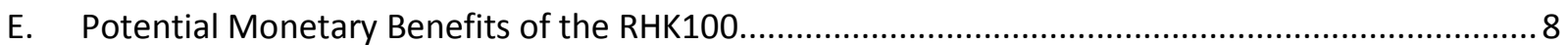

\section{List of Appendices}

Appendix A-Alaska Community List

Appendix B-Analysis of Alaska Community Power Consumption and Potential Energy Offset 


\section{Introduction}

Whitestone Power and Communications (WPC) is in the process of developing and trademarking an electrical generation device called "the Poncelet Kinetics RHK100". This River In-Stream Energy Conversion (RISEC) device, can be used in communities located in proximity to a sufficient water resource to generate electrical power from the hydrokinetic water flow. The RHK100 is a pontoonmounted Poncelet undershot water wheel (estimated at 12-foot-wide with a 16-foot diameter) with a nominal electrical power output capacity of $100 \mathrm{~kW}$. The float footprint is estimated at 34 feet by 19 feet, with a weight of approximately 15,000 pounds. The installation will be moored to the shore and protected with Coast Guard-approved safety equipment.

WPC contracted CE2 Engineers, Inc. (CE2) to perform a preliminary assessment of Alaska communities located near flowing rivers that might benefit from integrating a hydrokinetic device into its present power generation system. The assessment includes:

1. a list of communities situated near Alaska rivers where the RHK100 would be suitable,

2. an inventory and summary of existing river velocity data for rivers near these communities,

3. a description of the approximate distance between the river and the community's power plant,

4. an estimation of the potential amount of hydrokinetic-derived power needed for each community, and

5. an estimation of the potential monetary benefit to each community from the maximum suitably-sized RHK100 hydrokinetic device.

This assessment assumes that the production capacity of the RHK100 can be adjusted to work in rivers with velocity/flow rates as low as 1 foot/second, and depths of three feet or greater. 


\section{Method}

The five pieces of the assessment were done mainly independent of one another. The methods employed in each piece of the assessment are described here.

\section{A. Community List}

A community list was developed by consulting the data published on the website of the Alaska Community Database maintained by the State of Alaska, Department of Commerce, Community, and Economic Development (DCCED). From a list of all currently identified Alaska communities (presented in Appendix A), the following communities were initially eliminated:

- Communities listed with zero or very small population,

- Communities with no electrical power distribution system,

- North Slope communities (due to the extremely short ice-free season for the Arctic rivers)

Communities whose geography includes the absence of viable rivers, including no rivers, extremely slow-moving rivers, steep rivers, and rivers subject to the influence of tides were not evaluated, nor were those communities in the Railbelt. The list was further reduced to those located on major river systems, away from the lower, slower reaches of the rivers (such as Yukon River communities like Alakanuk and Kotlik, or Kuskokwim River communities like Tuluksak).

The result was a list of 45 communities primarily situated on major Alaska Rivers. From north to south, generally, those rivers include: Noatak, Kobuk, Koyukuk, Yukon, Tanana, Kuskokwim, Kvichak, Nabesna, and Copper. The following matrix is a summary list of the communities initially selected for the RHK100 device assessment.

\begin{tabular}{|l|l|}
\hline River & Community \\
\hline Copper & Chitina, Slana \\
\hline Kobuk & Ambler, Kiana, Shungnak \\
\hline Koyukuk & Allakaket/Alatna, Bettles, Hughes, Huslia \\
\hline Kuskokwim & $\begin{array}{l}\text { Aniak, Chuathbaluk, Crooked Creek, Kalskag (Upper and Lower), McGrath, } \\
\text { Nikolai, Red Devil, Sleetmute, Stony River }\end{array}$ \\
\hline Kvichak & Igiugig \\
\hline Noatak & Noatak \\
\hline Nabesna & Northway \\
\hline Tanana & Tok/Dot Lake/Tanacross, Tanana, Manley Hot Springs \\
\hline
\end{tabular}




\begin{tabular}{|l|l|}
\hline River & Community \\
\hline Yukon & $\begin{array}{l}\text { Anvik, Circle, Fort Yukon, Galena, Grayling, Holy Cross, Kaltag, Koyukuk, } \\
\text { Marshall, Mountain Village, Nulato, Pilot Station, Ruby, Russian Mission, St. } \\
\text { Mary's, Pitka's Point, Steven's Village }\end{array}$ \\
\hline
\end{tabular}

\section{B. River Velocity Data}

Data that describes flow rates for Alaska rivers and streams exists in several places on the web: the United States Geological Survey (USGS) National Water Information System at http://wdr.water.usgs.gov/nwisgmap/; the State of Alaska Department of Natural Resources (DNR), Alaska Hydrologic Survey Streams Database at http://dnr.alaska.gov/mlw/water/hydro/streams.cfm; and a presentation entitled "Assessment of Hydrokinetic Energy Resources in Alaska Rivers" written by faculty and staff at the University of Alaska Anchorage, Department of Engineering, and published on the Alaska Energy Authority website at http://www.akenergyauthority.org/OceanRiver/TomRavens REC4-2010.pdf.

Research staff at CE2 were surprised by the apparent scarcity of stream velocity data. However, several knowledgeable hydrologists with the USGS, National Park Service, and the Bureau of Land Management confirmed that stream velocity data are very rare in Alaska, mainly due to cost of recording and collecting those data.

\section{Community Distance to River}

Google Earth mapping tools were used to approximate the distance between the river channel and the vicinity of the power plant. Distances were rounded up to the nearest 100 feet.

\section{Suitable River Hydrokinetic Power Capacity}

The amount of river hydrokinetic power suitable for use in a community's existing power system will depend on the average load (measured in kilowatts) carried by that community during the months the RHK100 device would be working. The State of Alaska, Alaska Energy Authority's Power Cost Equalization (PCE) program published data on the power production, fuel and nonfuel costs, and population for many communities in rural Alaska.

For those communities initially deemed viable (see II.A), PCE data were collected, when available. Not all viable communities were included on the PCE roster, and some were on the roster but contained limited power production data. Some communities share power via an intertie, such as Tok, Tanacross, and Dot Lake, and similar groupings were treated as one entity. 
Because the RHK100 device will only operate during summer months (estimated here to be the four-month period from May 15 to September 15), an estimate of the average summer load was necessary to estimate how many kilowatts would be available to offset. Although a few communities have facilities such as fish processing plants that create a higher load on their community power system during the summer, most of these examples are balanced out by the power demands of the school building during the non-summer months.

Brent Petrie, Manager of Community Development at the Alaska Village Electric Cooperative (AVEC), which owns and operates power production and distribution systems in some 50 rural communities, estimated that the average community will require ten percent less power during the summer months than they will during the non-summer months. That is the measure used to determine the average monthly summer load for each community with published PCE data.

The Analysis of Alaska Community Power Consumption and Potential Energy Offset, presented in Appendix B, contains most of the data discussed in this assessment. As shown in this table, some communities have a summer load as low as 13 kilowatts (Stony River) or 15 (Red Devil), while others have loads of 300 kilowatts (St. Mary's/Pitka's Point, and Fort Yukon) and 400 kilowatts per month (Galena). The Tok/Tanacross/Dot Lake intertie pulls a load of approximately 1,200 kilowatts during an average summer month.

It is important to note that the published PCE data covers community power information for the years 2002-2009. A statistical method of projecting future numbers based on a known trend, "least square", was used to project power production, cost, and population data through the year 2020. An "average year", here and elsewhere in this report, represents the average PROJECTED figure for the twelve years from 2009-2020.

\section{E. Potential Monetary Benefits of the RHK100}

The monetary benefit of using an RHK100 hydrokinetic device will vary between communities insofar as each community has a unique set of energy production and cost characteristics. While the amount of diesel-generated electricity may be similar between communities (and, correspondingly, the amount of diesel displaced) the cost of generating that electricity will vary between any two communities. For the community where diesel-produced energy costs more, supplemental power from the RHK100 will realize greater cost savings than for a community where energy is more affordable. The customer base and distribution of costs will also affect the potential benefit of supplementing a community's electrical production, where small communities pay more per capita than their more populous neighbors. 
"Least square" trend lines were produced for power production, fuel costs, and population for each community. These projections varied greatly from one community to the next, being based on the fluctuations over the years 2002-2009, the years for which PCE data exist.

These data were used to make a general determination of: 1) the cost of producing power using diesel for each community; and 2) the amount of cost savings resulting from the RISEC-derived supplementary power initially identified as suitable for each community. Monetary benefit was calculated to reflect both the average annual per-capita cost savings, as well as the average annual overall cost savings to the community.

The amounts presented in this study for cost savings do not account for any of the costs for RHK100 construction (capital costs) or maintenance. And while the community's average nonfuel related expenses are shown in Appendix B, they do not affect any of the cost savings figures; cost savings only reflect displacement of diesel. 


\section{Results and Discussion}

\section{A. Community List}

The matrix introduced on page 2 of this report contains the list of Alaska communities initially judged viable for introduction of the RHK100 hydrokinetic device. These communities are, using the best available information: situated close to a river, where the flow rate is sufficiently rapid, where the river and the channel is not too steep or too shallow, and where the influence of coastal tides, waves, and shifts in flow direction will not interfere with the RHK100's operation.

Other communities are listed as non-viable due to one of the following reasons: insufficient population base, coastal influence, insufficient water flow, intertie-connected. Several locations were rejected because they are government facilities, such as Eielson AFB, and two were rejected as corporate or private utilities. Certain communities are marked non-viable for "environmental" considerations; where the presence of a popular sport fishery or an urban setting was seen as a significant impediment to the RHK100 hydrokinetic device implementation.

Twenty seven additional communities are considered potential sites for implementation of a hydrokinetic device, but additional data must be gathered for a full assessment. These communities are marked in Appendix A with the selection code " $\mathrm{P}$ ".

\section{B. River Velocity Data}

Appendix B presents the summary data discussed in this report, including river velocity measurements from the three sources mentioned above.

River velocity data McGrath, Aniak, and Sleetmute were extracted from the DNR Hydrologic Survey database, found at http://dnr.alaska.gov/mlw/water/hydro/streams.cfm.

Stream data for Kalskag, Aniak, Chuathbaluk, Mountain Village, Saint Mary's, Pilot Station, Marshall, Holy Cross, Anvik, Grayling, Nulato, Koyukuk, and Galena were drawn from UAA Professor Tom Ravens' presentation prepared for AEA and titled "Assessment of Hydrokinetic Energy Resources in Alaska Rivers, which is found at http://www.akenergyauthority.org/OceanRiver/TomRavens REC4-2010.pdf.

Stream data for Chitina, Kiana, Noatak, Tanana, Steven's Village, and Stony River were extracted from the USGS database, found at http://wdr.water.usgs.gov/nwisgmap/. 
For most an average flow rate, in feet per second, as well as a maximum flow rate are shown in the Analysis of Community Power Consumption and Potential Energy Offset presented in Appendix B. The measurements of river velocity vary widely, even for the same community. For example, flow rates recorded for the Noatak River near the village of Noatak average 0.9 feet/second, but a maximum rate was reported on the same day as $4.49 \mathrm{feet} / \mathrm{second}$. Because the RHK100 will produce power at an even, fixed level of output, the average velocity figure should be considered the baseline for devising the mechanical transfer of water flow to electricity production.

Both the USGS and the DNR websites have large amounts of stream data, but most of that is for streams that are near villages but are nonetheless very small, and slow-moving. These were not included in this analysis.

\section{Community Distance to River}

Appendix B identifies the approximate distances between each community and the river where the RHK100 would be placed. Many communities are located very close to their rivers, and 500 feet was the standard estimated distance incremental value. Some communities are farther away, between 1,000 feet and 4,000 feet. For Manley Hot Springs, a distance of approximately two (2) miles separates the community from the Tanana River channel.

A shorter distance would certainly result in a less-expensive, more efficient connection of the RHK100 to the community power grid, and a greater distance would be correspondingly more expensive and less efficient. The resulting expense and efficiency, however, are not included in this analysis.

\section{Suitable River Hydrokinetic Power Capacity}

The Analysis of Alaska Community Power Consumption and Potential Energy Offset (Appendix B) includes a column ("Water Turbine $\mathrm{kW}^{\prime}$ ) that assigns a number of kilowatts to each community. This number represents a river hydrokinetic energy output level, in kilowatts, suggested for each community as a supplement to its summer energy load. In some cases, this amount will supplant a good portion of the community's summer energy load. In others, it will provide for the entire load amount.

Because Red Devil and Stony River have such a low summer load level, an RHK100 hydrokinetic device that produces 25 kilowatts will result in maximum savings for those communities. For the St. Mary's/Pitka's Point as well as for the Tok/Tanacross/Dot Lake intertie, an RHK100 producing 400 kilowatts appears optimal. Because WPC's initial RHK100 hydrokinetic device proposal 
indicated a per-device output of 25 kilowatts, the figures identified in this column are in increments of $25 \mathrm{~kW}$.

The relationship between summer load levels, stream velocity, and the RHK100 capacity was only cursorily addressed in discussions between CE2 and WPC. WPC indicated that the RHK100 could be adjusted down for a low load situation, as well as ramped up at will to supplant larger loads. Therefore, nearly all communities show the RHK100 supplanting $100 \%$ of the power production requirements for the four-month-long summer period. Mathematically, that would eliminate the need to produce diesel power for one-third of the year (resulting in a $30 \%$ annual reduction, which accounts for the slightly higher power usage during the non-summer months).

\section{E. Potential Monetary Benefits of the RHK100}

Appendix B shows the "Yearly Production Cost Savings" for the RHK100 device configuration recommended for each community. Based on the projections tracking the cost of fuel (an increase, in nearly all cases) and the amount of power required (increase in some cases, decrease in others), supplementing summer power requirements with RHK100 devices will produce annual overall community cost savings in the $\$ 20,000$ range for communities like Koyukuk; the $\$ 30,000$ range for communities like Ruby, Chitina, and Hughes); upwards to annual savings of $\$ 300,000$ and $\$ 400,000$ in places like McGrath, Galena, St. Mary's/Pitka's Point, and Fort Yukon.

The annual per-capita cost savings measure shows how the members of a smaller community may benefit, since fewer people will pay a greater percentage of the community's total power costs and will benefit more from an overall reduction in community power production costs. Red Devil, for example, may only save $\$ 27,177$ yearly with a 25kW RHK100 device, but based on the high per-capita cost of energy in that community, each individual may save an estimated $\$ 1,182$ annually.

Figure 1, on the next page, illustrates both the annual per capita savings and the annual overall community savings for all of the communities evaluated.

Because the analysis presented here does not account for any of the costs for RHK100 device construction or maintenance, these cost savings figures must only be viewed as a baseline from which to develop a more extensive, precise economic assessment. 
Figure 1

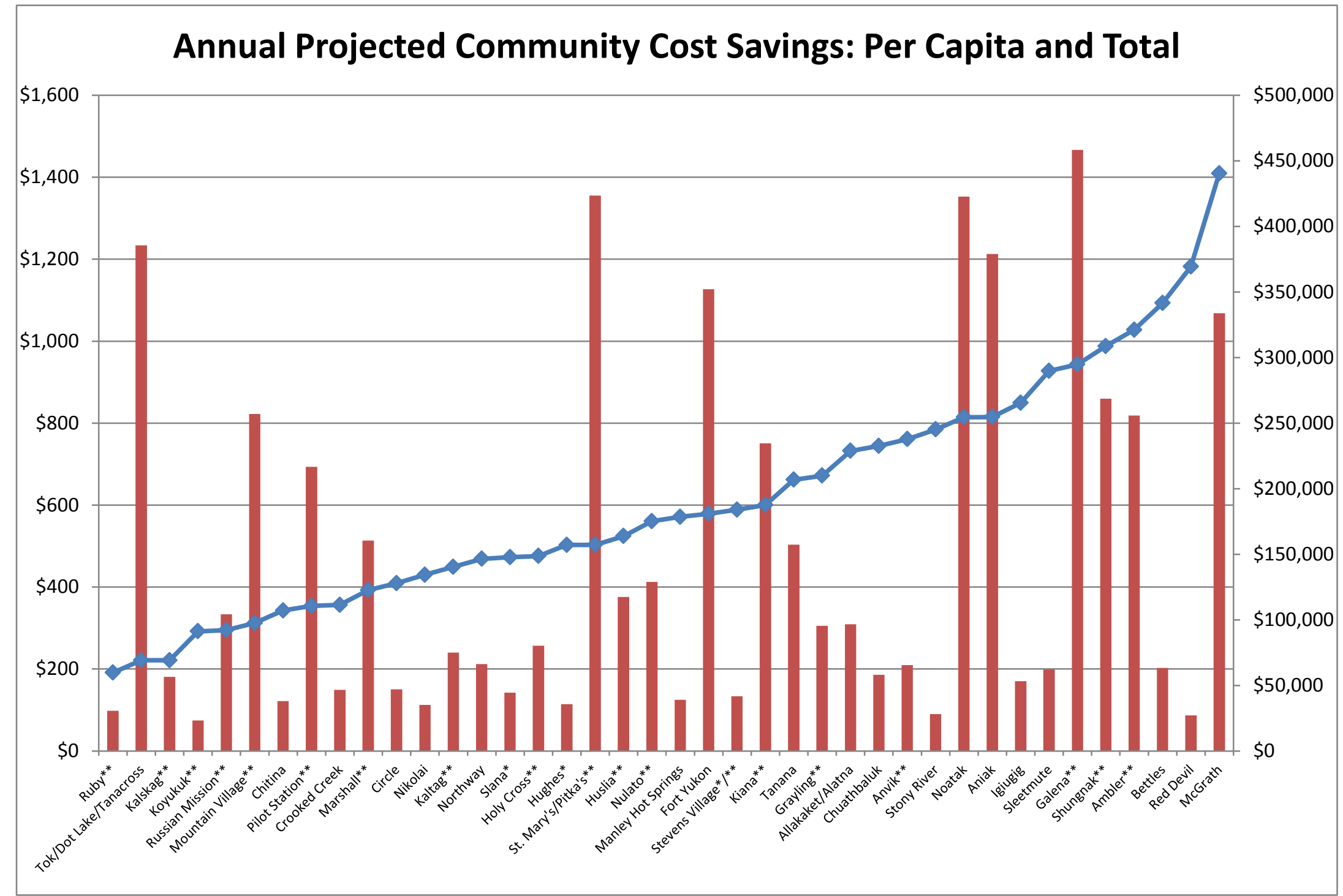


Alaska Community List

from State of Alaska Department of Commerce, Community, and Economic Development Community Database

\begin{tabular}{|c|c|c|c|}
\hline COMMUNITY & $\begin{array}{c}\text { DCCED } \\
\text { POPULATION }\end{array}$ & $\begin{array}{l}\text { Evaluation } \\
\text { Code }\end{array}$ & Notes \\
\hline Adak & 165 & NE & Tidal Influence \\
\hline Afognak & 0 & $\mathrm{R}$ & Insufficient Population \\
\hline Akhiok & 80 & NE & Water flows require further evaluation \\
\hline Akiachak & 645 & NE & Water flows need further evaluation \\
\hline Akiak & 346 & NE & Water flows need further evaluation \\
\hline Akutan & 846 & $\mathrm{NE}$ & Water flows need further evaluation \\
\hline Alakanuk & 686 & NE & Water flows need further evaluation \\
\hline Alatna & 22 & $\mathrm{E}$ & \\
\hline Alcan Border & 26 & NE & Water flows need further evaluation \\
\hline Aleknagik & 229 & $\mathrm{P}$ & \\
\hline Aleneva & 67 & $\mathrm{R}$ & No Power Distrib System \\
\hline Allakaket & 100 & $\mathrm{E}$ & \\
\hline Alpine & 0 & $\mathrm{R}$ & Insufficient Population \\
\hline Ambler & 261 & $\mathrm{E}$ & \\
\hline Anaktuvuk Pass & 287 & NE & Water flows need further evaluation \\
\hline Anchor Point & 1772 & NE & Railbelt \\
\hline Anchorage & 290588 & NE & URBAN \\
\hline Anderson & 275 & NE & Railbelt \\
\hline Andreafsky & 140 & $\mathrm{P}$ & \\
\hline Angoon & 442 & NE & Water flows need further evaluation \\
\hline Aniak & 485 & $E$ & \\
\hline Anvik & 75 & $\mathrm{E}$ & \\
\hline Arctic Village & 139 & $\mathrm{NE}$ & Water flows need further evaluation \\
\hline Atka & 71 & NE & Hydro in use \\
\hline Atmautluak & 296 & NE & Water flows need further evaluation \\
\hline Atqasuk & 201 & $\mathrm{R}$ & Short Season \\
\hline Attu Station & 15 & $\mathrm{R}$ & Govt Facility \\
\hline Barrow & 4119 & $\mathrm{R}$ & Short Season \\
\hline Bear Creek & 2009 & $\mathrm{NE}$ & Water flows need further evaluation \\
\hline Beaver & 58 & $\mathrm{P}$ & \\
\hline Belkofski & 0 & $\mathrm{R}$ & Insufficient Population \\
\hline Beluga & 24 & NE & Railbelt \\
\hline Bethel & 5803 & NE & Water flows need further evaluation \\
\hline Bettles & 19 & $\mathrm{E}$ & \\
\hline Big Delta & 840 & NE & Railbelt \\
\hline Big Lake & 3331 & NE & Railbelt \\
\hline Bill Moore's Slough & 0 & $\mathrm{R}$ & Insufficient Population \\
\hline Birch Creek & 31 & $P$ & \\
\hline Brevig Mission & 358 & $\mathrm{NE}$ & Water flows need further evaluation \\
\hline
\end{tabular}

Evaluation code:

$\mathrm{E}=$ Evaluated

NE or $\mathrm{P}=$ Potential sites, require additional data for evaluation

$\mathrm{R}=$ Rejected 
Alaska Community List

from State of Alaska Department of Commerce, Community, and Economic Development Community Database

\begin{tabular}{|c|c|c|c|}
\hline COMMUNITY & $\begin{array}{c}\text { DCCED } \\
\text { POPULATION }\end{array}$ & $\begin{array}{l}\text { Evaluation } \\
\text { Code }\end{array}$ & Notes \\
\hline Buckland & 432 & $\mathrm{NE}$ & Water flows need further evaluation \\
\hline Buffalo Soapstone & 738 & NE & Railbelt \\
\hline Butte & 3255 & NE & Railbelt \\
\hline Cantwell & 200 & $\mathrm{NE}$ & Railbelt \\
\hline Central & 96 & NE & Water flows need further evaluation \\
\hline Central & 96 & NE & Water flows need further evaluation \\
\hline Chalkyitsik & 60 & NE & Water flows need further evaluation \\
\hline Chase & 35 & $\mathrm{R}$ & No Power Distrib System \\
\hline Chefornak & 475 & NE & Water flows need further evaluation \\
\hline Chenega Bay & 71 & NE & Water flows need further evaluation \\
\hline Chevak & 945 & NE & Water flows need further evaluation \\
\hline Chickaloon & 277 & NE & Railbelt \\
\hline Chicken & 23 & $\mathrm{R}$ & No Power Distrib System \\
\hline Chignik Lagoon & 73 & NE & Water flows need further evaluation \\
\hline Chignik Lake & 105 & $\mathrm{NE}$ & Water flows need further evaluation \\
\hline Chignik & 62 & NE & Water flows need further evaluation \\
\hline Chiniak & 48 & NE & Water flows need further evaluation \\
\hline Chisana & 9 & $\mathrm{R}$ & No Power Distrib System \\
\hline Chistochina & 95 & $\mathrm{P}$ & \\
\hline Chitina & 117 & $\mathrm{E}$ & \\
\hline Chuathbaluk & 111 & $E$ & \\
\hline Chuloonawick & 0 & $\mathrm{R}$ & Insufficient Population \\
\hline Circle & 99 & $E$ & \\
\hline Clam Gulch & 166 & NE & Water flows need further evaluation \\
\hline Clark's Point & 61 & $\mathrm{NE}$ & Water flows need further evaluation \\
\hline Coffman Cove & 192 & NE & Water flows need further evaluation \\
\hline Cohoe & 1332 & $\mathrm{NE}$ & Water flows need further evaluation \\
\hline Cold Bay & 84 & $\mathrm{P}$ & \\
\hline Coldfoot & 13 & $\mathrm{R}$ & No Power Distrib System \\
\hline College & 12552 & NE & Railbelt \\
\hline Cooper Landing & 344 & $\mathrm{NE}$ & Railbelt \\
\hline Copper Center & 297 & $\mathrm{P}$ & \\
\hline Copperville & 131 & $\mathrm{P}$ & \\
\hline Cordova & 2126 & $\mathrm{NE}$ & Water flows need further evaluation \\
\hline Council & 8 & $\mathrm{R}$ & No Power Distrib System \\
\hline Covenant Life & 89 & $P$ & \\
\hline Craig & 1101 & $\mathrm{NE}$ & Water flows need further evaluation \\
\hline Crooked Creek & 131 & $\mathrm{E}$ & \\
\hline Crown Point & 77 & $\mathrm{NE}$ & Water flows need further evaluation \\
\hline
\end{tabular}

Evaluation code:

$\mathrm{E}=$ Evaluated

NE or $\mathrm{P}=$ Potential sites, require additional data for evaluation

$\mathrm{R}=$ Rejected 
Alaska Community List

from State of Alaska Department of Commerce, Community, and Economic Development Community Database

\begin{tabular}{|c|c|c|c|}
\hline COMMUNITY & $\begin{array}{c}\text { DCCED } \\
\text { POPULATION }\end{array}$ & $\begin{array}{l}\text { Evaluation } \\
\text { Code }\end{array}$ & Notes \\
\hline Cube Cove & 0 & $\mathrm{R}$ & Insufficient Population \\
\hline Deering & 118 & $P$ & \\
\hline Delta Junction & 1128 & NE & Railbelt \\
\hline Deltana & 2355 & NE & Railbelt \\
\hline Diamond Ridge & 860 & $\mathrm{P}$ & \\
\hline Dillingham & 2264 & NE & Water flows need further evaluation \\
\hline Diomede & 117 & $\mathrm{NE}$ & Water flows need further evaluation \\
\hline Dot Lake Village & 37 & $\mathrm{E}$ & (see Tok/Dot Lake/Tanacross) \\
\hline Dot Lake & 16 & $E$ & (see Tok/Dot Lake/Tanacross) \\
\hline Douglas & 4890 & NE & Water flows need further evaluation \\
\hline Dry Creek & 87 & $\mathrm{R}$ & No Power Distrib System \\
\hline Eagle River-Chugiak & $\begin{array}{c}30,000 \\
\text { (2000 pop.) }\end{array}$ & NE & Railbelt \\
\hline Eagle Village & 54 & $P$ & \\
\hline Eagle & 146 & $\mathrm{P}$ & \\
\hline Edna Bay & 49 & $\mathrm{R}$ & No Power Distrib System \\
\hline Eek & 282 & NE & Water flows need further evaluation \\
\hline Egegik & 73 & $\mathrm{NE}$ & Water flows need further evaluation \\
\hline Eielson AFB & 2896 & $\mathrm{R}$ & Govt Facility \\
\hline Eklutna & 384 & NE & Railbelt \\
\hline Ekuk & 0 & $\mathrm{R}$ & No Power Distrib System \\
\hline Ekwok & 109 & NE & Water flows need further evaluation \\
\hline Elfin Cove & 25 & $\mathrm{NE}$ & Water flows need further evaluation \\
\hline Elim & 337 & $\mathrm{NE}$ & Water flows need further evaluation \\
\hline Emmonak & 774 & $\mathrm{NE}$ & Water flows need further evaluation \\
\hline Ester & 2034 & $\mathrm{NE}$ & Railbelt \\
\hline Evansville & 13 & $\mathrm{P}$ & \\
\hline Excursion Inlet & 11 & $\mathrm{R}$ & No Power Distrib System \\
\hline Eyak & 107 & $\mathrm{NE}$ & Water flows need further evaluation \\
\hline Fairbanks & 32506 & $\mathrm{NE}$ & Railbelt \\
\hline False Pass & 41 & NE & Water flows need further evaluation \\
\hline Farm Loop & 1313 & $\mathrm{NE}$ & Railbelt \\
\hline Ferry & 36 & $\mathrm{R}$ & No Power Distrib System \\
\hline Fishhook & 3337 & $\mathrm{NE}$ & Railbelt \\
\hline Flat & 0 & $\mathrm{R}$ & No Power Distrib System \\
\hline Fort Greely & 413 & $\mathrm{R}$ & Govt Facility \\
\hline Fort Yukon & 585 & $\mathrm{E}$ & \\
\hline Four Mile Road & 39 & $\mathrm{NE}$ & Railbelt \\
\hline Fox River & 604 & $\mathrm{NE}$ & Water flows need further evaluation \\
\hline
\end{tabular}

Evaluation code:

$\mathrm{E}=$ Evaluated

NE or $\mathrm{P}=$ Potential sites, require additional data for evaluation

$\mathrm{R}=$ Rejected 
Alaska Community List

from State of Alaska Department of Commerce, Community, and Economic Development Community Database

\begin{tabular}{|c|c|c|c|}
\hline COMMUNITY & $\begin{array}{c}\text { DCCED } \\
\text { POPULATION }\end{array}$ & $\begin{array}{l}\text { Evaluation } \\
\text { Code }\end{array}$ & Notes \\
\hline Fox & 390 & NE & Railbelt \\
\hline Fritz Creek & 1818 & NE & Water flows need further evaluation \\
\hline Funny River & 796 & NE & Water flows need further evaluation \\
\hline Gakona & 202 & $P$ & \\
\hline Galena & 564 & $\mathrm{E}$ & \\
\hline Gambell & 666 & NE & Water flows need further evaluation \\
\hline Game Creek & 16 & $\mathrm{R}$ & No Power Distrib System \\
\hline Gateway & 4068 & NE & Railbelt \\
\hline Georgetown & 3 & $\mathrm{R}$ & No Power Distrib System \\
\hline Girdwood & 2000 & NE & Railbelt \\
\hline Glacier View & 246 & NE & Railbelt \\
\hline Glennallen & 473 & NE & Water flows need further evaluation \\
\hline Golovin & 154 & NE & Water flows need further evaluation \\
\hline Goodnews Bay & 237 & NE & Water flows need further evaluation \\
\hline Grayling & 168 & $\mathrm{E}$ & \\
\hline Gulkana & 131 & $P$ & \\
\hline Gustavus & 451 & NE & Water flows need further evaluation \\
\hline Haines Borough & 2286 & $P$ & \\
\hline Halibut Cove & 27 & NE & Water flows need further evaluation \\
\hline Hamilton & 0 & $\mathrm{R}$ & No Power Distrib System \\
\hline Happy Valley & 561 & NE & Water flows need further evaluation \\
\hline Harding-Birch Lakes & 287 & NE & Railbelt \\
\hline Healy Lake & 10 & NE & Water flows need further evaluation \\
\hline Healy & 1002 & NE & Railbelt \\
\hline Hobart Bay & 1 & $\mathrm{R}$ & No Power Distrib System \\
\hline Hollis & 193 & NE & Water flows need further evaluation \\
\hline Holy Cross & 187 & $\mathrm{E}$ & \\
\hline Homer & 5551 & NE & Water flows need further evaluation \\
\hline Hoonah & 764 & NE & Water flows need further evaluation \\
\hline Hooper Bay & 1158 & NE & Water flows need further evaluation \\
\hline Hope & 151 & NE & Railbelt \\
\hline Houston & 1664 & NE & Railbelt \\
\hline Hughes & 83 & $E$ & \\
\hline Huslia & 265 & $E$ & \\
\hline Hydaburg & 340 & NE & Water flows need further evaluation \\
\hline Hyder & 87 & $\mathrm{R}$ & Terrain \\
\hline Igiugig & 64 & $\mathrm{E}$ & \\
\hline Iliamna & 91 & $P$ & \\
\hline Ivanof Bay & 0 & $\mathrm{R}$ & Insufficient Population \\
\hline
\end{tabular}

Evaluation code:

$\mathrm{E}=$ Evaluated

NE or $\mathrm{P}=$ Potential sites, require additional data for evaluation

$\mathrm{R}=$ Rejected 
Alaska Community List

from State of Alaska Department of Commerce, Community, and Economic Development Community Database

\begin{tabular}{|c|c|c|c|}
\hline COMMUNITY & $\begin{array}{c}\text { DCCED } \\
\text { POPULATION }\end{array}$ & $\begin{array}{l}\text { Evaluation } \\
\text { Code }\end{array}$ & Notes \\
\hline Jakolof Bay & 0 & $\mathrm{R}$ & Insufficient Population \\
\hline Juneau & 30661 & NE & Hydro in use \\
\hline Kachemak & 430 & $\mathrm{R}$ & Environmental sensitivity \\
\hline Kaguyak & 0 & $\mathrm{R}$ & Insufficient Population \\
\hline Kake & 497 & $\mathrm{NE}$ & Water flows need further evaluation \\
\hline Kaktovik & 286 & $\mathrm{R}$ & Short Season \\
\hline Kalifornsky & 7495 & $\mathrm{R}$ & Environmental sensitivity \\
\hline Kaltag & 172 & $\mathrm{E}$ & \\
\hline Kanatak & 0 & $\mathrm{R}$ & No Power Distrib System \\
\hline Karluk & 38 & NE & Water flows need further evaluation \\
\hline Kasaan & 56 & NE & Water flows need further evaluation \\
\hline Kasigluk & 567 & NE & Water flows need further evaluation \\
\hline Kasilof & 536 & $\mathrm{R}$ & Environmental sensitivity \\
\hline Kenai & 7115 & $\mathrm{R}$ & Environmental sensitivity \\
\hline Kenny Lake & 412 & $\mathrm{NE}$ & Water flows need further evaluation \\
\hline Ketchikan & 7503 & NE & Water flows need further evaluation \\
\hline Kiana & 374 & $\mathrm{E}$ & \\
\hline King Cove & 744 & $\mathrm{P}$ & \\
\hline King Island & 0 & $\mathrm{R}$ & No Power Distrib System \\
\hline King Salmon & 383 & NE & Water flows need further evaluation \\
\hline Kipnuk & 671 & $\mathrm{NE}$ & Water flows need further evaluation \\
\hline Kivalina & 410 & NE & Water flows need further evaluation \\
\hline Klawock & 782 & $\mathrm{NE}$ & Water flows need further evaluation \\
\hline Klukwan & 72 & $\mathrm{P}$ & \\
\hline Knik River & 631 & NE & Railbelt \\
\hline Knik-Fairview & 13824 & NE & Railbelt \\
\hline Kobuk & 122 & $\mathrm{P}$ & \\
\hline Kodiak Station & 1321 & $\mathrm{R}$ & Govt Facility \\
\hline Kodiak & 6626 & $\mathrm{NE}$ & Water flows need further evaluation \\
\hline Kokhanok & 184 & NE & Water flows need further evaluation \\
\hline Koliganek & 182 & $\mathrm{NE}$ & Water flows need further evaluation \\
\hline Kongiganak & 465 & NE & Water flows need further evaluation \\
\hline Kotlik & 618 & $\mathrm{NE}$ & Water flows need further evaluation \\
\hline Kotzebue & 3154 & NE & Water flows need further evaluation \\
\hline Koyuk & 358 & $\mathrm{E}$ & \\
\hline Koyukuk & 105 & $\mathrm{E}$ & \\
\hline Kupreanof & 24 & $\mathrm{R}$ & No Power Distrib System \\
\hline Kwethluk & 764 & NE & Water flows need further evaluation \\
\hline Kwigillingok & 365 & $\mathrm{NE}$ & Water flows need further evaluation \\
\hline
\end{tabular}

Evaluation code:

$\mathrm{E}=$ Evaluated

NE or $\mathrm{P}=$ Potential sites, require additional data for evaluation

$\mathrm{R}=$ Rejected 
Alaska Community List

from State of Alaska Department of Commerce, Community, and Economic Development Community Database

\begin{tabular}{|c|c|c|c|}
\hline COMMUNITY & $\begin{array}{c}\text { DCCED } \\
\text { POPULATION }\end{array}$ & $\begin{array}{l}\text { Evaluation } \\
\text { Code }\end{array}$ & Notes \\
\hline Lake Louise & 100 & NE & Railbelt \\
\hline Lake Minchumina & 17 & NE & Water flows need further evaluation \\
\hline Larsen Bay & 79 & NE & Water flows need further evaluation \\
\hline Lazy Mountain & 1446 & NE & Railbelt \\
\hline Levelock & 88 & $\mathrm{NE}$ & Water flows need further evaluation \\
\hline Lime Village & 19 & $\mathrm{P}$ & \\
\hline Livengood & 24 & $\mathrm{R}$ & No Power Distrib System \\
\hline Lowell Point & 76 & NE & Water flows need further evaluation \\
\hline Lower Kalskag & 251 & $\mathrm{E}$ & \\
\hline Lutak & 38 & $\mathrm{R}$ & No Power Distrib System \\
\hline Manley Hot Springs & 81 & $\mathrm{E}$ & \\
\hline Manokotak & 438 & NE & Water flows need further evaluation \\
\hline Marshall & 414 & $E$ & \\
\hline Mary's Igloo & 0 & $\mathrm{R}$ & No Power Distrib System \\
\hline McCarthy & 51 & $\mathrm{R}$ & No Power Distrib System \\
\hline McGrath & 322 & $\mathrm{E}$ & \\
\hline McKinley Park & 168 & NE & Railbelt \\
\hline Meadow Lakes & 7319 & NE & Railbelt \\
\hline Mekoryuk & 174 & NE & Water flows need further evaluation \\
\hline Mendeltna & 57 & NE & Water flows need further evaluation \\
\hline Mentasta Lake & 120 & $\mathrm{NE}$ & Water flows need further evaluation \\
\hline Metlakatla & 1499 & NE & Water flows need further evaluation \\
\hline Meyers Chuck & 16 & $\mathrm{R}$ & No Power Distrib System \\
\hline Miller Landing & 0 & $\mathrm{R}$ & Insufficient Population \\
\hline Minto & 191 & NE & Water flows need further evaluation \\
\hline Moose Creek & 729 & NE & Railbelt \\
\hline Moose Pass & 189 & NE & Railbelt \\
\hline Mosquito Lake & 235 & NE & Water flows need further evaluation \\
\hline Mountain Village & 782 & $E$ & \\
\hline Mud Bay & 178 & $\mathrm{R}$ & No Power Distrib System \\
\hline Naknek & 516 & $\mathrm{NE}$ & Water flows need further evaluation \\
\hline Nanwalek & 226 & NE & Water flows need further evaluation \\
\hline Napaimute & 0 & $\mathrm{R}$ & No Power Distrib System \\
\hline Napakiak & 337 & NE & Water flows need further evaluation \\
\hline Napaskiak & 428 & NE & Water flows need further evaluation \\
\hline Naukati Bay & 118 & NE & Water flows need further evaluation \\
\hline Nelchina & 51 & $\mathrm{NE}$ & Water flows need further evaluation \\
\hline Nelson Lagoon & 60 & NE & Water flows need further evaluation \\
\hline Nenana & 479 & NE & Railbelt \\
\hline
\end{tabular}

Evaluation code:

$\mathrm{E}=$ Evaluated

NE or $\mathrm{P}=$ Potential sites, require additional data for evaluation

$\mathrm{R}=$ Rejected 
Alaska Community List

from State of Alaska Department of Commerce, Community, and Economic Development Community Database

\begin{tabular}{|c|c|c|c|}
\hline COMMUNITY & $\begin{array}{c}\text { DCCED } \\
\text { POPULATION }\end{array}$ & $\begin{array}{l}\text { Evaluation } \\
\text { Code }\end{array}$ & Notes \\
\hline New Allakaket & 37 & $P$ & \\
\hline New Stuyahok & 519 & NE & Water flows need further evaluation \\
\hline Newhalen & 162 & $P$ & \\
\hline Newtok & 355 & NE & Water flows need further evaluation \\
\hline Nightmute & 264 & NE & Water flows need further evaluation \\
\hline Nikiski & 4465 & NE & Water flows need further evaluation \\
\hline Nikolaevsk & 315 & NE & Water flows need further evaluation \\
\hline Nikolai & 87 & $\mathrm{E}$ & \\
\hline Nikolski & 33 & NE & Water flows need further evaluation \\
\hline Ninilchik & 824 & $\mathrm{R}$ & Environmental sensitivity \\
\hline Noatak & 486 & $\mathrm{E}$ & \\
\hline Nome & 3468 & NE & Water flows need further evaluation \\
\hline Nondalton & 186 & NE & Water flows need further evaluation \\
\hline Noorvik & 628 & $\mathrm{R}$ & Tidal Influence \\
\hline North Pole & 2200 & NE & Railbelt \\
\hline Northway Junction & 60 & $P$ & \\
\hline Northway Village & 76 & $P$ & \\
\hline Northway & 88 & $\mathrm{E}$ & \\
\hline Nuiqsut & 424 & $\mathrm{R}$ & Short Season \\
\hline Nulato & 240 & $\mathrm{E}$ & \\
\hline Nunam Iqua & 193 & NE & Water flows need further evaluation \\
\hline Nunam Iqua & 193 & NE & Water flows need further evaluation \\
\hline Nunapitchuk & 539 & NE & Water flows need further evaluation \\
\hline Ohogamiut & 0 & $\mathrm{R}$ & No Power Distrib System \\
\hline Old Harbor & 193 & NE & Water flows need further evaluation \\
\hline Oscarville & 109 & NE & Water flows need further evaluation \\
\hline Ouzinkie & 170 & NE & Water flows need further evaluation \\
\hline Paimiut & 2 & $\mathrm{R}$ & No Power Distrib System \\
\hline Palmer & 5532 & NE & Railbelt \\
\hline Pauloff Harbor & 0 & $\mathrm{R}$ & No Power Distrib System \\
\hline Paxson & 16 & NE & Private utility \\
\hline Pedro Bay & 48 & NE & Water flows need further evaluation \\
\hline Pelican & 122 & $\mathrm{R}$ & Terrain \\
\hline Perryville & 122 & NE & Water flows need further evaluation \\
\hline Petersburg & 2973 & NE & Water flows need further evaluation \\
\hline Petersville & 6 & $\mathrm{R}$ & No Power Distrib System \\
\hline Pilot Point & 66 & NE & Water flows need further evaluation \\
\hline Pilot Station & 577 & $\mathrm{E}$ & \\
\hline Pitkas Point & 113 & $E$ & \\
\hline
\end{tabular}

Evaluation code:

$\mathrm{E}=$ Evaluated

NE or $\mathrm{P}=$ Potential sites, require additional data for evaluation

$\mathrm{R}=$ Rejected 
Alaska Community List

from State of Alaska Department of Commerce, Community, and Economic Development Community Database

\begin{tabular}{|c|c|c|c|}
\hline COMMUNITY & $\begin{array}{c}\text { DCCED } \\
\text { POPULATION }\end{array}$ & $\begin{array}{l}\text { Evaluation } \\
\text { Code }\end{array}$ & Notes \\
\hline Platinum & 57 & $\mathrm{NE}$ & Water flows need further evaluation \\
\hline Pleasant Valley & 765 & NE & Railbelt \\
\hline Point Baker & 11 & $\mathrm{R}$ & No Power Distrib System \\
\hline Point Hope & 713 & $\mathrm{R}$ & Short Season \\
\hline Point Lay & 234 & $\mathrm{R}$ & Short Season \\
\hline Point MacKenzie & 273 & NE & Railbelt \\
\hline Pope-Vannoy Landing & 5 & $\mathrm{R}$ & No Power Distrib System \\
\hline Port Alexander & 61 & $\mathrm{R}$ & No Power Distrib System \\
\hline Port Alsworth & 118 & NE & Water flows need further evaluation \\
\hline Port Clarence & 23 & $\mathrm{R}$ & Govt Facility \\
\hline Port Graham & 137 & NE & Water flows need further evaluation \\
\hline Port Heiden & 83 & NE & Water flows need further evaluation \\
\hline Port Lions & 200 & $\mathrm{NE}$ & Water flows need further evaluation \\
\hline Port Protection & 72 & $\mathrm{R}$ & No Power Distrib System \\
\hline Port William & 0 & $\mathrm{R}$ & No Power Distrib System \\
\hline Portage Creek & 7 & $\mathrm{R}$ & No Power Distrib System \\
\hline Primrose & 65 & NE & Water flows need further evaluation \\
\hline Prudhoe Bay & 3 & $\mathrm{R}$ & Short Season \\
\hline Prudhoe Bay & 3 & $\mathrm{R}$ & Short Season \\
\hline Quinhagak & 680 & NE & Water flows need further evaluation \\
\hline Rampart & 12 & $\mathrm{R}$ & Insufficient Population \\
\hline Red Devil & 44 & $\mathrm{E}$ & \\
\hline Red Dog Mine & 35 & $\mathrm{NE}$ & Corporate generators \\
\hline Ridgeway & 2050 & NE & Water flows need further evaluation \\
\hline Ruby & 149 & $\mathrm{E}$ & \\
\hline Russian Mission & 363 & $\mathrm{E}$ & \\
\hline Saint George & 111 & NE & Water flows need further evaluation \\
\hline Saint Mary's & 553 & $\mathrm{E}$ & \\
\hline Saint Michael & 446 & $\mathrm{NE}$ & Water flows need further evaluation \\
\hline Saint Paul & 459 & NE & Water flows need further evaluation \\
\hline Salamatof & 855 & $\mathrm{R}$ & Environmental sensitivity \\
\hline Salcha & 985 & NE & Railbelt \\
\hline Sand Point & 1001 & $\mathrm{NE}$ & Water flows need further evaluation \\
\hline Savoonga & 721 & NE & Water flows need further evaluation \\
\hline Saxman & 434 & $\mathrm{NE}$ & Water flows need further evaluation \\
\hline Scammon Bay & 528 & $\mathrm{NE}$ & Water flows need further evaluation \\
\hline Selawik & 849 & $\mathrm{NE}$ & Water flows need further evaluation \\
\hline Seldovia Village & 166 & NE & Water flows need further evaluation \\
\hline Seldovia & 265 & NE & Water flows need further evaluation \\
\hline
\end{tabular}

Evaluation code:

$\mathrm{E}=$ Evaluated

NE or $\mathrm{P}=$ Potential sites, require additional data for evaluation

$\mathrm{R}=$ Rejected 
Alaska Community List

from State of Alaska Department of Commerce, Community, and Economic Development Community Database

\begin{tabular}{|c|c|c|c|}
\hline COMMUNITY & $\begin{array}{c}\text { DCCED } \\
\text { POPULATION }\end{array}$ & $\begin{array}{l}\text { Evaluation } \\
\text { Code }\end{array}$ & Notes \\
\hline Seward & 2609 & NE & Water flows need further evaluation \\
\hline Shageluk & 97 & NE & Water flows need further evaluation \\
\hline Shaktoolik & 231 & NE & Water flows need further evaluation \\
\hline Shemya Station & 27 & $\mathrm{R}$ & Govt Facility \\
\hline Shishmaref & 606 & NE & Water flows need further evaluation \\
\hline Shungnak & 270 & $E$ & \\
\hline Silver Springs & 198 & $P$ & \\
\hline Sitka & 8627 & $\mathrm{R}$ & Terrain \\
\hline Skagway & 865 & NE & Water flows need further evaluation \\
\hline Skwentna & 73 & $\mathrm{R}$ & No Power Distrib System \\
\hline Slana & 102 & $\mathrm{E}$ & \\
\hline Sleetmute & 71 & $\mathrm{E}$ & \\
\hline Soldotna & 4021 & $\mathrm{R}$ & Environmental sensitivity \\
\hline Solomon & 0 & $\mathrm{R}$ & Insufficient Population \\
\hline South Naknek & 68 & NE & Water flows need further evaluation \\
\hline Stebbins & 605 & NE & Water flows need further evaluation \\
\hline Sterling & 5348 & $\mathrm{R}$ & Environmental sensitivity \\
\hline Stevens Village & 64 & $\mathrm{E}$ & \\
\hline Stony River & 48 & $\mathrm{E}$ & \\
\hline Sunrise & 19 & NE & Railbelt \\
\hline Susitna & 16 & $\mathrm{R}$ & No Power Distrib System \\
\hline Sutton-Alpine & 1407 & NE & Railbelt \\
\hline Takotna & 53 & NE & Water flows need further evaluation \\
\hline Talkeetna & 894 & NE & Railbelt \\
\hline Tanacross & 203 & $\mathrm{E}$ & (see Tok/Dot Lake/Tanacross) \\
\hline Tanaina & 7407 & NE & Railbelt \\
\hline Tanana & 251 & $\mathrm{E}$ & \\
\hline Tatitlek & 83 & NE & Water flows need further evaluation \\
\hline Tazlina & 207 & NE & Water flows need further evaluation \\
\hline Telida & 3 & $\mathrm{R}$ & Insufficient Population \\
\hline Teller & 261 & NE & Water flows need further evaluation \\
\hline Tenakee Springs & 104 & $\mathrm{R}$ & Terrain \\
\hline Tetlin & 169 & NE & Water flows need further evaluation \\
\hline Thom's Place & 6 & $\mathrm{R}$ & Insufficient Population \\
\hline Thorne Bay & 424 & NE & Water flows need further evaluation \\
\hline Togiak & 820 & NE & Water flows need further evaluation \\
\hline Tok & 1429 & $E$ & \\
\hline Toksook Bay & 596 & NE & Water flows need further evaluation \\
\hline Tolsona & 26 & NE & Water flows need further evaluation \\
\hline
\end{tabular}

Evaluation code:

$\mathrm{E}=$ Evaluated

NE or $\mathrm{P}=$ Potential sites, require additional data for evaluation

$\mathrm{R}=$ Rejected 
Alaska Community List

from State of Alaska Department of Commerce, Community, and Economic Development Community Database

\begin{tabular}{|c|c|c|c|}
\hline COMMUNITY & $\begin{array}{c}\text { DCCED } \\
\text { POPULATION }\end{array}$ & $\begin{array}{l}\text { Evaluation } \\
\text { Code }\end{array}$ & Notes \\
\hline Tonsina & 78 & $\mathrm{NE}$ & Water flows need further evaluation \\
\hline Trapper Creek & 444 & NE & Railbelt \\
\hline Tuluksak & 471 & NE & Water flows need further evaluation \\
\hline Tuntutuliak & 384 & NE & Water flows need further evaluation \\
\hline Tununak & 330 & $\mathrm{NE}$ & Water flows need further evaluation \\
\hline Twin Hills & 74 & NE & Water flows need further evaluation \\
\hline Two Rivers & 663 & NE & Railbelt \\
\hline Tyonek & 166 & NE & Railbelt \\
\hline Uganik & 0 & $\mathrm{R}$ & Insufficient Population \\
\hline Ugashik & 15 & $\mathrm{R}$ & No Power Distrib System \\
\hline Umkumiute & 0 & $\mathrm{R}$ & No Power Distrib System \\
\hline Unalakleet & 725 & NE & Water flows need further evaluation \\
\hline Unalaska & 3662 & NE & Water flows need further evaluation \\
\hline Unga & 0 & $\mathrm{R}$ & No Power Distrib System \\
\hline Upper Kalskag & 223 & $E$ & \\
\hline Valdez & 4498 & $\mathrm{R}$ & Terrain \\
\hline Venetie & 185 & NE & Water flows need further evaluation \\
\hline Wainwright & 551 & $\mathrm{R}$ & Short Season \\
\hline Wales & 148 & NE & Water flows need further evaluation \\
\hline Wasilla & 7245 & NE & Railbelt \\
\hline Whale Pass & 60 & NE & Water flows need further evaluation \\
\hline White Mountain & 202 & NE & Water flows need further evaluation \\
\hline Whitestone & 173 & $\mathrm{NE}$ & Railbelt \\
\hline Whittier & 159 & NE & Railbelt \\
\hline Willow Creek & 157 & NE & Water flows need further evaluation \\
\hline Willow & 2218 & NE & Railbelt \\
\hline Wiseman & 16 & $\mathrm{R}$ & No Power Distrib System \\
\hline Womens Bay & 740 & $\mathrm{NE}$ & Water flows need further evaluation \\
\hline Woody Island & 0 & $\mathrm{R}$ & No Power Distrib System \\
\hline Wrangell & 2058 & NE & Water flows need further evaluation \\
\hline Y & 1057 & $\mathrm{NE}$ & Railbelt \\
\hline Yakutat & 628 & NE & Water flows need further evaluation \\
\hline Total & 636500 & 382 & \\
\hline
\end{tabular}

Evaluation code:

$\mathrm{E}=$ Evaluated

NE or $\mathrm{P}=$ Potential sites, require additional data for evaluation

$\mathrm{R}=$ Rejected 


\begin{tabular}{|c|c|c|c|c|c|c|c|c|c|c|c|c|c|c|c|c|c|}
\hline Community & River & $\begin{array}{c}\text { Avg } \\
\text { Velocity } \\
\text { (Ft/Sec) }\end{array}$ & $\begin{array}{c}\text { Max } \\
\text { Velocity } \\
\text { (Ft/Sec) }\end{array}$ & $\begin{array}{l}\text { Est intertie } \\
\text { distance } \\
\text { (ft) }\end{array}$ & $\begin{array}{l}\text { Avg Fuel Cost } \\
\text { Per kWh }\end{array}$ & $\begin{array}{c}\text { Avg Non-Fuel } \\
\text { Cost } \\
(2009-2020) \\
\end{array}$ & \begin{tabular}{|c|} 
Average Annual \\
kWh (2009- \\
$2020)$ \\
\end{tabular} & $\begin{array}{l}\text { Avg Ratio Non- } \\
\text { Fuel to Fuel }\end{array}$ & $\begin{array}{c}\text { Average } \\
\text { Summer Load } \\
(\mathbf{2 0 0 9 - 2 0 2 0 )}\end{array}$ & $\begin{array}{c}\text { Summer Load } \\
\text { Range } \\
(2009-2020) \\
\end{array}$ & $\begin{array}{l}\text { Load } \\
\text { Range } \\
\text { Trend }\end{array}$ & $\begin{array}{c}\text { Water } \\
\text { turbine kW }\end{array}$ & $\begin{array}{c}\text { Summer } \\
\text { Production } \\
\text { Offset }\end{array}$ & $\begin{array}{c}\text { Yearly } \\
\text { Production/ } \\
\text { Cost Savings } \\
\text { (Pct) } \\
\end{array}$ & \begin{tabular}{|c|} 
Yearly \\
Production/ \\
Cost Savings \\
(\$)
\end{tabular} & $\begin{array}{c}\text { Avg } \\
\text { Population } \\
\text { (2009-2020) }\end{array}$ & $\begin{array}{c}\text { Per Capita Cost } \\
\text { Savings }\end{array}$ \\
\hline Allakaket/Alatna & Koyukuk & & & 500 & $\$ 0.46$ & $\$ 121,985$ & 703,077 & 0.38 & 72 & $68-76$ & Up & 100 & $100 \%$ & $30 \%$ & $\$ 96,646$ & 132 & $\$ 732$ \\
\hline Ambler* & Kobuk & & & 700 & $\$ 0.62$ & $\$ 350,750$ & $1,385,110$ & 0.41 & 142 & $127-148$ & Up & 150 & $100 \%$ & $30 \%$ & $\$ 255,872$ & 249 & $\$ 1,028$ \\
\hline Aniak & Kuskokwim & 3.70 & 9.00 & 500 & $\$ 0.50$ & $\$ 1,042,858$ & $2,541,020$ & 0.83 & 261 & $266-262$ & Even & 300 & $100 \%$ & $30 \%$ & $\$ 378,902$ & 465 & $\$ 815$ \\
\hline Anvik* & Yukon & 3.70 & 9.00 & 1,750 & $\$ 0.49$ & $\$ 123,050$ & 445,992 & 0.56 & 46 & $41-45$ & Up & 75 & $100 \%$ & $30 \%$ & $\$ 65,420$ & 86 & $\$ 761$ \\
\hline Bettles & Koyukuk & & & 500 & $\$ 0.45$ & $\$ 117,802$ & 464,822 & 0.56 & 48 & $67-33$ & Down & 100 & $100 \%$ & $30 \%$ & $\$ 63,373$ & 58 & $\$ 1,093$ \\
\hline Chitina & Copper & 5.57 & 7.25 & 4,000 & $\$ 0.32$ & $\$ 60,320$ & 392,778 & 0.48 & 40 & $44-37$ & Down & 50 & $100 \%$ & $30 \%$ & $\$ 38,042$ & 111 & $\$ 343$ \\
\hline \begin{tabular}{|l|} 
Chuathbaluk \\
\end{tabular} & Kuskokwim & 4.00 & 8.00 & 500 & $\$ 0.55$ & $\$ 118,867$ & 350,666 & 0.61 & 36 & $28-43$ & Up & 50 & $100 \%$ & $30 \%$ & $\$ 58,049$ & 78 & $\$ 744$ \\
\hline Circle & Yukon & & & 500 & $\$ 0.45$ & $\$ 85,445$ & 347,571 & 0.54 & 36 & $34-35$ & Even & 50 & $100 \%$ & $30 \%$ & $\$ 47,057$ & 115 & $\$ 409$ \\
\hline Crooked Creek & Kuskokwim & & & 500 & $\$ 0.51$ & $\$ 114,630$ & 306,349 & 0.74 & 31 & $29-34$ & Up & 50 & $100 \%$ & $30 \%$ & $\$ 46,693$ & 131 & $\$ 356$ \\
\hline \begin{tabular}{|l|} 
Fort Yukon \\
\end{tabular} & Yukon & & & 3,000 & $\$ 0.35$ & $\$ 125,768$ & $3,384,401$ & 0.11 & 348 & $318-380$ & Up & 400 & $100 \%$ & $30 \%$ & $\$ 352,032$ & 608 & $\$ 579$ \\
\hline Galena* & Yukon & 3.60 & 13.00 & 1,000 & $\$ 0.39$ & $\$ 1,368,500$ & $3,918,056$ & 0.90 & 403 & $669-100$ & Down & 500 & $100 \%$ & $30 \%$ & $\$ 458,442$ & 486 & $\$ 943$ \\
\hline Grayling* & Yukon & 3.60 & 9.00 & 500 & $\$ 0.50$ & $\$ 143,750$ & 637,308 & 0.45 & 65 & $60-70$ & Up & 100 & $100 \%$ & $30 \%$ & $\$ 95,376$ & 142 & $\$ 672$ \\
\hline \begin{tabular}{|l} 
Holy Cross* \\
\end{tabular} & Yukon & 3.10 & 10.00 & 3,500 & $\$ 0.52$ & $\$ 170,430$ & 516,535 & 0.64 & 53 & $66-60$ & Down & 100 & $100 \%$ & $30 \%$ & $\$ 80,372$ & 169 & $\$ 476$ \\
\hline Hughes ${ }^{* *}$ & Koyukuk & & & 500 & $\$ 0.28$ & $\$ 75,446$ & 432,056 & 0.63 & 44 & $40-54$ & Up & 75 & $100 \%$ & $30 \%$ & $\$ 35,654$ & 71 & $\$ 503$ \\
\hline Huslia* & Koyukuk & & & 500 & $\$ 0.39$ & $\$ 255,300$ & $1,007,445$ & 0.65 & 104 & $95-108$ & Up & 150 & $100 \%$ & $30 \%$ & $\$ 117,386$ & 224 & $\$ 524$ \\
\hline Igiugig & Kvichak & & & 1,000 & $\$ 0.70$ & $\$ 28,605$ & 252,108 & 0.16 & 26 & $24-27$ & Up & 50 & $100 \%$ & $30 \%$ & $\$ 53,242$ & 63 & $\$ 850$ \\
\hline \begin{tabular}{|l} 
Kalskag** \\
\end{tabular} & Kuskokwim & 3.70 & 8.00 & 750 & $\$ 0.15$ & $\$ 308,200$ & $1,223,304$ & 1.64 & 126 & $123-126$ & Even & 150 & $100 \%$ & $30 \%$ & $\$ 56,461$ & 255 & $\$ 221$ \\
\hline Kaltag $^{*}$ & Yukon & 3.50 & 11.00 & 500 & $\$ 0.31$ & $\$ 540,500$ & 799,384 & 2.16 & 82 & $76-87$ & Up & 100 & $100 \%$ & $30 \%$ & $\$ 75,009$ & 167 & $\$ 449$ \\
\hline Kiana* & Kobuk & 1.00 & 3.92 & 500 & $\$ 0.46$ & $\$ 437,000$ & $1,710,873$ & 0.56 & 176 & $171-183$ & Up & 200 & $100 \%$ & $30 \%$ & $\$ 234,637$ & 391 & $\$ 600$ \\
\hline Koyukuk* & Yukon & 3.00 & 9.00 & 750 & $\$ 0.30$ & $\$ 12,650$ & 255,000 & 0.17 & 27 & $25-27$ & Even & 50 & $100 \%$ & $31 \%$ & $\$ 23,345$ & 80 & $\$ 292$ \\
\hline \begin{tabular}{|l|} 
Manley Hot Springs \\
\end{tabular} & Tanana & & & $2 \mathrm{mi}$ & $\$ 0.48$ & $\$ 82,643$ & 272,515 & 0.64 & 28 & $29-27$ & Down & 50 & $100 \%$ & $30 \%$ & $\$ 38,948$ & 68 & $\$ 571$ \\
\hline Marshall* & Yukon & 3.80 & 8.00 & 500 & $\$ 0.37$ & $\$ 331,200$ & $1,436,418$ & 0.62 & 148 & $130-165$ & Up & 200 & $100 \%$ & $30 \%$ & $\$ 160,476$ & 409 & $\$ 392$ \\
\hline McGrath & Kuskokwim & 2.80 & 4.47 & 500 & $\$ 0.45$ & $\$ 206,391$ & $2,467,219$ & 0.19 & 253 & $285-225$ & Down & 300 & $100 \%$ & $30 \%$ & $\$ 333,912$ & 237 & $\$ 1,409$ \\
\hline \begin{tabular}{|l|} 
Mountain Village* \\
\end{tabular} & Yukon & 2.10 & 7.00 & 500 & $\$ 0.31$ & $\$ 709,550$ & $2,774,392$ & 0.83 & 285 & $281-291$ & Up & 300 & $100 \%$ & $30 \%$ & $\$ 256,870$ & 823 & $\$ 312$ \\
\hline Nikolai & Kuskokwim & & & 500 & $\$ 0.26$ & $\$ 54,787$ & 454,863 & 0.47 & 47 & $45-48$ & Up & 75 & $100 \%$ & $30 \%$ & $\$ 35,242$ & 82 & $\$ 430$ \\
\hline Noatak & Noatak & 0.90 & 4.49 & 4,000 & $\$ 0.67$ & $\$ 508,300$ & $2,109,448$ & 0.36 & 217 & $200-247$ & Up & 300 & $100 \%$ & $30 \%$ & $\$ 422,645$ & 519 & $\$ 814$ \\
\hline Northway & Nabesna & & & 1,000 & $\$ 0.18$ & $\$ 59,755$ & $1,195,788$ & 0.27 & 123 & 143-105 & Down & 150 & $100 \%$ & $30 \%$ & $\$ 66,265$ & 141 & $\$ 469$ \\
\hline \begin{tabular}{|l|} 
Nulato** \\
\end{tabular} & Yukon & 2.80 & 10.00 & 500 & $\$ 0.43$ & $\$ 273,700$ & $\begin{array}{l}997,004 \\
\end{array}$ & 0.64 & 102 & $107-95$ & Down & 150 & $100 \%$ & $30 \%$ & $\$ 128,925$ & 230 & $\$ 561$ \\
\hline \begin{tabular}{|l} 
Pilot Station* \\
\end{tabular} & Yukon & 2.50 & 7.00 & 1,000 & $\$ 0.41$ & $\$ 46,000$ & $1,773,393$ & 0.06 & 182 & 181-187 & Up & 200 & $100 \%$ & $30 \%$ & $\$ 216,596$ & 612 & $\$ 354$ \\
\hline Red Devil & Kuskokwim & & & 500 & $\$ 0.62$ & $\$ 129,170$ & 145,085 & 1.43 & 15 & $15-15$ & Even & 25 & $100 \%$ & $30 \%$ & $\$ 27,177$ & 23 & $\$ 1,182$ \\
\hline Ruby* & Yukon & & & 2,000 & $\$ 0.15$ & $\$ 73,600$ & 669,601 & 0.72 & 69 & $68-68$ & Even & 100 & $100 \%$ & $30 \%$ & $\$ 30,758$ & 161 & $\$ 191$ \\
\hline Russian Mission* & Yukon & & & 750 & $\$ 0.38$ & $\$ 224,250$ & 924,302 & 0.65 & 95 & 92-101 & Up & 150 & $100 \%$ & $30 \%$ & $\$ 104,294$ & 354 & $\$ 295$ \\
\hline Shungnak* & Kobuk & & & 500 & $\$ 0.60$ & $\$ 394,450$ & $1,501,060$ & 0.44 & 154 & $151-154$ & Up & 200 & $100 \%$ & $30 \%$ & $\$ 268,663$ & 272 & $\$ 988$ \\
\hline Slana** & Copper & & & 750 & $\$ 0.32$ & $\$ 97,430$ & 931,425 & 0.33 & 96 & $53-135$ & Up & 150 & $100 \%$ & $30 \%$ & $\$ 44,439$ & 94 & $\$ 473$ \\
\hline Sleetmute & Kuskokwim & 2.90 & 4.00 & 500 & $\$ 0.63$ & $\$ 118,116$ & 329,862 & 0.57 & 34 & $26-40$ & Up & 50 & $100 \%$ & $30 \%$ & $\$ 62,131$ & 67 & $\$ 927$ \\
\hline St. Mary's/Pitka's** & Yukon & 2.70 & 9.00 & 3,500 & $\$ 0.44$ & $\$ 717,600$ & $3,239,575$ & 0.51 & 333 & $319-347$ & Up & 400 & $100 \%$ & $30 \%$ & $\$ 423,426$ & 842 & $\$ 5$ \\
\hline Stevens Village ${ }^{* * *}$ & Yukon & 4.00 & 6.04 & 1,000 & $\$ 0.50$ & $\$ 28,825$ & 280,000 & 0.21 & 29 & $29-29$ & Even & 50 & $100 \%$ & $30 \%$ & $\$ 41,796$ & 71 & $\$ 589$ \\
\hline \begin{tabular}{|l} 
Stony River \\
\end{tabular} & Kuskokwim & 2.90 & 3.24 & 500 & $\$ 0.71$ & $\$ 134,565$ & 133,293 & 1.43 & 14 & $13-13$ & Down & 25 & $100 \%$ & $30 \%$ & $\$ 28,238$ & 36 & $\$ 784$ \\
\hline Tanana & Tanana & 1.60 & & 500 & $\$ 0.43$ & $\$ 592,766$ & $1,233,407$ & 1.13 & 127 & $140-121$ & Down & 150 & $100 \%$ & $30 \%$ & $\$ 157,404$ & 238 & $\$ 6$ \\
\hline Tok/Dot Lake/Tanacross & Tanana & & & 500 & $\$ 0.33$ & $\$ 1,187,229$ & $11,852,560$ & 0.30 & 1,218 & $1245-1204$ & Down & 400 & $33 \%$ & $10 \%$ & $\$ 385,638$ & 1742 & $\$ 221$ \\
\hline
\end{tabular}

\begin{tabular}{l|l|l}
\hline Tok/Dot Lake/Tanacross & Tanana & \\
\hline
\end{tabular}

Non-Fuel Costs based on highest value of 2008 and 2009 data, plus 15\%

Community PCE data too wide-ranging for realistic projection. These figures are estimates.

NOTES

1. Summer Load Range is the expected change (using PCE data trend to 2020) for monthly load between May 15 to September 15.

2. Percent Summer Percent Offset: Calculated using average of each year's (actual and projected) summer load minus turbine supplement.

3. Per Capita Savings: Calculated using an average of each year's estimated fuel offset, fuel cost, and population. 


\section{Nationwide River Resource Assessment}

\section{Poncelet Kinetics RHK100 Hydrokinetic Device}

Prepared by:

CE2 Engineers, Inc.

Report Date:

March 2011

Communities located throughout the Lower 48 states and Hawaii may potentially benefit by integrating an RHK100 hydrokinetic device into their existing power system. Potential benefit will depend on the community's proximity to water, the estimated stream velocity, the estimated amount of power derived from the stream, and the value of electricity offset. In each of these states there are several hundred streams and rivers that may prove adequate for hydrokinetic power generation using the RHK100. Stream velocity data collected by the United States Geological Survey demonstrate this potential by state providing an approximation of the value of power offset. Although there appears to be considerable river energy in each state, the potential benefit of adding an RHK100 to a community's existing system remains unclear and will require a community-by-community and a river-by-river analysis. 


\section{Contents}

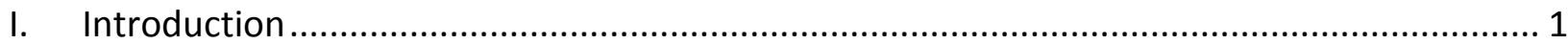

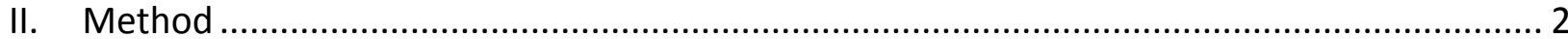

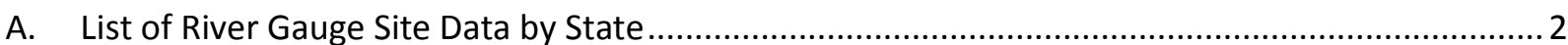

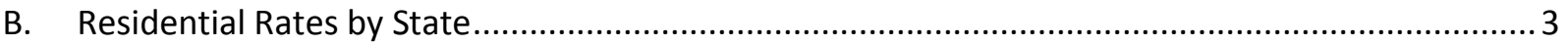

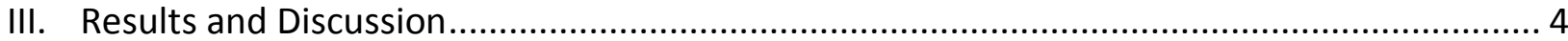

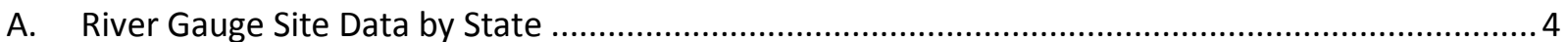

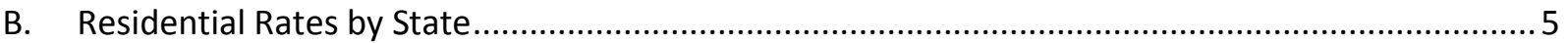

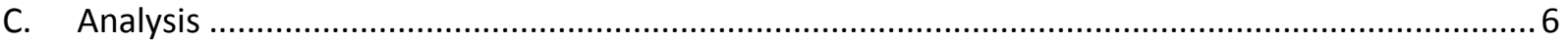

\section{List of Appendices}

Appendix A-Stream Gauging Sites

Appendix B-Potential Energy (kW) Production

Appendix C-Energy Production and Residential Cost Savings Projections

Appendix D-Residential Rate Projections 


\section{Introduction}

Whitestone Power and Communications (WPC) is in the process of developing and trademarking an electrical generation device called "the Poncelet Kinetics RHK100". This River In-Stream Energy Conversion (RISEC) device can be used in communities located in proximity to a sufficient water resource to generate electrical power from the hydrokinetic water flow. The RHK100 is a pontoonmounted undershot water wheel with a nominal electrical power output capacity of $100 \mathrm{~kW}$. The preliminary float footprint is estimated at 34 feet long by 19 feet wide, with a weight of approximately 15,000 pounds. The installation will be moored to the shore and protected with Coast Guard-approved safety equipment.

WPC contracted CE2 Engineers, Inc. (CE2) to perform a preliminary assessment of river energy in the Lower 48 states. The aim of the preliminary assessment was to identify the potential to extract energy from rivers using the RHK100. The assessment includes:

1. a summary count of USGS surface water gauging data sites, per state, where average stream velocity measurements fall between $3 \mathrm{feet} / \mathrm{second}$ and $16 \mathrm{feet} / \mathrm{second}$,

2. a summary estimate of potential kilowatts, by velocity range, by state,

3. a summary table of projected residential cost per kilowatt hour, by state,

4. a summary table of potential energy cost savings, by state. 


\section{Method}

The four components of the assessment were performed independently. The methods employed are described here.

\section{A. List of River Gauge Site Data by State}

Data describing surface water flow for rivers and streams in the Lower 48 states and Hawaii exist in several formats on the United States Geological Survey (USGS) National Water Information System at http://waterdata.usgs.gov/nwis/measurements. The "Field Measurements" database provided the most comprehensive data set used in this assessment.

USGS NWIS has stream gauge velocity data available for thousands of locations in all 50 states. Many recordings are taken at sites along minor and major rivers throughout the country. Multiple measurements are taken at each site, and any number of sites may be situated along a particular river or stream. Therefore, a "site" refers only to a gauging station along a river. The site data are downloadable from the NWIS website on a state-by-state basis. The data obtained for this assessment contained many tens of thousands of data entries per state.

The site velocity data were analyzed through a three-step process. First, all sites measurements of less than $3 \mathrm{feet} / \mathrm{second}$ were filtered out due to an insufficient quantity of economicallyrecoverable energy. Then, an average velocity was calculated for each site. The sites were then categorized and counted based on average velocity measurement.

Identifying the location of the sites was not attempted in this assessment. Each river gauge site is identified in the database by a "Site Code" that refers to a separate list of site location descriptions. These data exist in a text format (e.g. "\# USGS 03410045 PINE CREEK ABOVE MOUTH NEAR ONEIDA, TN") and do not lend themselves easily to either a database or a geographic analysis.

The site code description was included in the downloadable data records for each state. The NWIS database does contain county information for each gauging site, but these data are not available for download. County information, as well as latitude and longitude information for each site, are only available as "display" when viewing the data for an individual site. For the purposes of summarizing large amounts of site data for this assessment, the geographical data for each particular site were not included. 
At this preliminary stage no geographical examination of river velocity data was performed.

River names, latitude/longitude coordinates, and county information are available for further analysis as needed.

\section{B. Residential Rates by State}

The U.S. Department of Energy, Energy Information Administration (EIA) maintains a website with data on various measurements of energy production, consumption, and cost throughout the nation. A simple cross-tabulation of the data tables downloaded from the EIA website (http://www.eia.doe.gov/electricity/) provided an overview of the prices residential customers are paying for electricity. 


\section{Results and Discussion}

\section{A. River Gauge Site Data by State}

The table in Appendix A shows a count of the gauging station sites within rivers and streams in each of the Lower 48 states and Hawaii. Each site has multiple velocity measurements, and the average velocity was computed.

Each site enumerated in the assembly of this table should not be confused with a single river or stream. Any single river may have a number of river gauging sites along its length. While every site listed in this table will not prove to be acceptable for deployment of the RHK100 device, it is assumed for the purposes of assessing the magnitude of the potential resource, that each site represents a potential RHK100 device location.

The USGS NWIS database does not describe a particular method of sampling. The standard, if any, for the placement of river gauging sites is unknown. The site measurements are treated simply as individual spots on a river where velocity measures were taken.

The number of sites varies by state for obvious reasons of size, geography, and topography. Some states covering small geographic areas have fewer rivers and streams, and thus fewer data sites: Delaware has 23, Rhode Island has 40, and Vermont has 49. Louisiana only has 58 sites with data, possibly because a large percentage of the water in that state moves slowly. The states with the most sites are California (774), Idaho (629), and New York (564). Generally, the more sites per state, the more potential energy for the RHK100 to capture.

Site data revealed that the majority of the gauging sites in most states are on streams with an average velocity ranging between 3 to 4 feet/second. In California, for example, 378 of the 774 sites are in the 3-4 ft/sec range.

In each state, the number of stream sites where the velocity averaged greater than 6 feet/second represents a small portion of the total sites, including California (43 out of $774=$ $5.6 \%)$, Kansas (4.5\%), Massachusetts (4.3\%). In Florida, $14.4 \%$ of sites had an average velocity of 6 or greater, which points to a sampling pattern where slower rivers had fewer gauging sites compared to other states.

The table in Appendix B shows the potential amount of energy generated if a 100kW RHK100 device were installed at every data site in every state. Although this is certainly an unrealistic expectation, the estimate is useful in this energy assessment in showing how the riverine resources are distributed BY STATE, as well as the distribution of potential energy between rivers of different velocities. 
The amount of energy potentially derived from a river depends on the river's velocity. In this assessment, the lowest range stream velocity of 3.0 to 4.0 feet/second was considered the baseline, where one RHK100 installed at one of these sites would generate 100kW of power.

As the velocity increases by 1 feet/second, the amount of potential extracted energy increases by a power of 3 . With $3.5 \mathrm{feet} / \mathrm{second}$ as the baseline where $100 \mathrm{~kW}$ are generated, each incremental increase of $1 \mathrm{foot} / \mathrm{second}$ was calculated. So, for every site in the $4-5 \mathrm{ft} / \mathrm{sec}$ range, approximately $200 \%$ more energy is generated than at the $3-4 \mathrm{ft} / \mathrm{sec}$ range. In the $5-6 \mathrm{ft} / \mathrm{sec}$ range, $400 \%$ more energy would be generated. At the $9-10 \mathrm{ft} / \mathrm{sec}$ range, the increase would be $2000 \%$. And at the top of this table, the $15-16 \mathrm{ft} / \mathrm{sec}$ range, $8600 \%$ more energy would be generated than if the same device were installed at the 3-4 ft/sec velocity site.

Some states have enough high-velocity sites to potentially generate a large amount of electricity. North Carolina has two (2) sites in the 15-16 ft/sec range, as does Florida, Illinois, and Texas.

Using this formula to estimate potential energy generation at stream sites in each of the velocity ranges from 3 to 16 feet/second, an estimate for the total potential energy was created BY STATE. The states with the lowest kilowatt generation potential are Rhode Island $(5,200)$, Vermont $(8,400)$, and New Hampshire $(17,300)$. Other low-potential states are New Hampshire $(17,300)$, Maine $(19,700)$, and Delaware $(23,200)$.

The states with the highest kilowatt generation potential are California $(198,000)$, New York $(176,600)$, Colorado $(116,800)$, and Pennsylvania $(108,900)$.

\section{B. Residential Rates by State}

The Energy Information Administration publishes residential electricity rate data for each of the United States from 1999 to 2009. These figures were used to compute a "least squares" trend line, a statistical instrument useful for observing mathematical trends in the real world and using those to predict future trends. Residential electric costs, per state, were projected through the year 2030.

Appendix $C$ shows energy production and residential cost saving projections for each state. Currently, customers in New York, Connecticut, Massachusetts and Rhode Island pay the most among the contiguous 48 states. Hawaii is highest overall. The 2010 costs (in cents) and projected costs for 2020 and 2030 are shown in the matrix on the next page. 


\begin{tabular}{|l|c|c|c|}
\hline State & $\begin{array}{c}\text { 2010 Rate } \\
\text { (Projected) }\end{array}$ & $\begin{array}{c}\text { 2020 Rate } \\
\text { (Projected) }\end{array}$ & $\begin{array}{c}\text { 2030 Rate } \\
\text { (Projected) }\end{array}$ \\
\hline Hawaii & 25.8 & 34.4 & 43.0 \\
\hline New York & 17.3 & 20.1 & 22.9 \\
\hline Connecticut & 17.3 & 21.4 & 25.5 \\
\hline Massachusetts & 15.9 & 19.3 & 22.7 \\
\hline Rhode Island & 14.8 & 17.3 & 19.8 \\
\hline
\end{tabular}

The cost of electricity is not expected to rise above 10 cents per kilowatt hour (kWh) in a number of states, including: Arkansas, Arizona, Idaho, Kansas, Kentucky, Nebraska, New Mexico, and South Dakota. Costs will remain below 9 cents in Illinois, Missouri, North Dakota, Utah and West Virginia.

Appendix D shows the projected costs for residential electricity per kWh, per state. These figures are used to calculate the potential benefit of using an RHK100 to capture hydrokinetic power, as reflected in cost savings to residential customers.

\section{Analysis}

The data published by the USGS and the EIA provide a basis for estimating both the potential river and stream energy in each of the Lower 48 states and Hawaii, and the potential cost savings of capturing stream energy using an RHK100 hydrokinetic device. To recap, the analysis represents a situation where an RHK100 is deployed at each and every gauging site reported in the USGS database, after eliminating sites where velocity measurements were under 3 feet/second. Nothing was done to determine a site's viability, and it is certain that many sites included in this assessment may be either difficult or impossible to equip with an RHK100. Reasons include terrain (steepness, narrowness), volume, depth, seasonal ice, proximity to a community, environmental impact, shipping, or recreational use, among others. None of these variables are considered in this assessment.

The cost savings figures, likewise, do not take into consideration the cost of building, deploying, or operating/maintaining an RHK100. They reflect only the high-end potential deferred cost of deploying the maximum number of RHK100s in any given state.

The table in Appendix $C$ shows the estimated projected potential cost savings by state. California, with its middle-high residential energy rates and its large number of potential RHK100 locations (with a higher percentage of those in fast-moving waters), could potentially benefit the most from installation of the RHK100 hydrokinetic device. Any one site in California could save the equivalent of $\$ 31.6$ million in 2010 residential rate dollars. With 774 RHK100s deployed throughout the entire state, California could save $\$ 24.5$ billion (in 2010 residential rate 
dollars). With the projected increase in residential rates, these potential savings rise to $\$ 40.5$ million per site, and \$31.4 billion statewide, in 2030 (Appendix D).

The following matrix, data taken from Appendix D, shows the five states with the highest and lowest potential savings, by site and by state.

\begin{tabular}{|c|c|c|c|}
\hline State & 2010 & 2020 & 2030 \\
\hline \multicolumn{4}{|c|}{ Highest Savings Per Site (in millions } \\
\hline Delaware & $\$ 106.3$ & $\$ 125.8$ & $\$ 145.3$ \\
\hline Hawaii & $\$ 55.2$ & $\$ 73.7$ & $\$ 92.1$ \\
\hline Florida & $\$ 45.1$ & $\$ 53.8$ & $\$ 62.5$ \\
\hline New York & $\$ 47.4$ & $\$ 55.1$ & $\$ 62.8$ \\
\hline Texas & $\$ 38.5$ & $\$ 47.7$ & $\$ 57.0$ \\
\hline \multicolumn{4}{|c|}{ Lowest Savings Per Site (in millions) } \\
\hline Michigan & $\$ 12.2$ & $\$ 13.8$ & $\$ 15.3$ \\
\hline South Dakota & $\$ 12.5$ & $\$ 13.6$ & $\$ 14.7$ \\
\hline Missouri & $\$ 13.2$ & $\$ 13.7$ & $\$ 14.1$ \\
\hline North Dakota & $\$ 13.2$ & $\$ 14.4$ & $\$ 15.6$ \\
\hline Kansas & $\$ 14.8$ & $\$ 15.5$ & $\$ 16.3$ \\
\hline \multicolumn{4}{|c|}{ Highest Savings Per State (in billions) } \\
\hline California & $\$ 24.5$ & $\$ 27.9$ & $\$ 31.4$ \\
\hline New York & $\$ 26.8$ & $\$ 31.1$ & $\$ 35.4$ \\
\hline Texas & $\$ 17.2$ & $\$ 21.3$ & $\$ 25.4$ \\
\hline Idaho & $\$ 10.8$ & $\$ 12.7$ & $\$ 14.6$ \\
\hline Colorado & $\$ 9.7$ & $\$ 11.2$ & $\$ 12.7$ \\
\hline \multicolumn{4}{|c|}{ Lowest By State (In billions) } \\
\hline Rhode Island & $\$ 0.7$ & $\$ 0.8$ & $\$ 0.9$ \\
\hline Vermont & $\$ 1.1$ & $\$ 1.3$ & $\$ 1.5$ \\
\hline Louisiana & $\$ 1.6$ & $\$ 1.7$ & $\$ 1.9$ \\
\hline North Dakota & $\$ 2.0$ & $\$ 2.2$ & $\$ 2.4$ \\
\hline West Virginia & $\$ 2.3$ & $\$ 2.4$ & $\$ 2.6$ \\
\hline
\end{tabular}

While the analysis of the EIA data showed the cost of residential power rising in all states, some states will rise faster than others. That difference in rate of increase affects the annual fixed RHK100 cost savings, and causes some states' cost savings to increase more rapidly than others. 
In sum, rivers and streams in the Lower 48 states and Hawaii may potentially contain vast amounts of moving water where an RHK100 hydrokinetic device would successfully generate electricity. The estimates used in this report represent a possible maximum amount of energy generated by the RHK100 in these rivers and streams (with a velocity over 3 feet/second), and a broad comparison of potential cost savings between states.

The estimates should only serve as a general guideline to each state's potential. Data were not screened or corrected for issues relating to sampling bias, river dimensions, seasonal ice, proximity to a community power plant, boat traffic conditions, recreation, or environmental sensitivity, and any particular proposal to develop a hydrokinetic device would have to take all these into close consideration.

The cost savings estimates do not include any accounting for the cost of engineering, building, deploying, operating, or maintaining the RHK100 device. Those capital and operational costs would reduce the cost savings reported here. 
Appendix A-Stream Gauging Sites 


\begin{tabular}{|c|c|c|c|c|c|c|c|c|c|c|c|c|c|c|c|c|c|c|c|c|c|}
\hline \multicolumn{22}{|l|}{ Average } \\
\hline Feet/Second & AL & $A R$ & $\mathbf{A Z}$ & CA & CO & CT & DE & FL & GA & $\mathrm{HI}$ & IA & ID & IL & IN & KS & KY & LA & MA & MD & ME & MI \\
\hline $3-4$ & 128 & 106 & 97 & 378 & 278 & 43 & 5 & 115 & 324 & 37 & 223 & 318 & 146 & 129 & 128 & 175 & 37 & 89 & 75 & 33 & 127 \\
\hline $4-5$ & 50 & 64 & 72 & 256 & 187 & 49 & 7 & 44 & 117 & 18 & 125 & 218 & 49 & 51 & 53 & 92 & 17 & 38 & 53 & 40 & 51 \\
\hline $5-6$ & 12 & 20 & 34 & 97 & 63 & 7 & 3 & 14 & 36 & 10 & 31 & 55 & 6 & 7 & 9 & 22 & & 8 & 18 & 21 & 7 \\
\hline $6-7$ & 5 & 8 & 8 & 20 & 10 & 4 & 2 & 7 & 11 & 8 & 15 & 12 & 2 & 4 & 4 & 6 & & 2 & 6 & & \\
\hline $7-8$ & 3 & 4 & 3 & 6 & 6 & 4 & 2 & 5 & 9 & & 6 & 11 & 4 & 3 & 2 & 11 & 1 & 3 & 5 & & \\
\hline 8-9 & 2 & & & 6 & & 1 & 1 & 3 & 4 & & 4 & 4 & 1 & 1 & 1 & 3 & & 1 & 1 & & \\
\hline $9-10$ & & 2 & 1 & 3 & & 2 & & 4 & 1 & 1 & 2 & 2 & 1 & 3 & & 1 & & & 1 & & \\
\hline $10-11$ & & 1 & & 1 & & & 1 & 2 & 1 & & 1 & & 2 & & 1 & 1 & 1 & & 3 & & \\
\hline $11-12$ & & 2 & & 3 & & & & 3 & 1 & & 2 & 2 & & & & 1 & 1 & & 1 & & \\
\hline $12-13$ & & 1 & & 2 & & & & 3 & 1 & & 1 & 3 & 2 & & 1 & & & & & & \\
\hline $13-14$ & 2 & 2 & & & & 1 & 1 & & 2 & & & 1 & 1 & & & 1 & 1 & & 1 & & \\
\hline $14-15$ & 1 & & & 1 & 2 & 1 & 1 & & & & 1 & 2 & & 3 & & & & & & & \\
\hline $15-16$ & 1 & 1 & & 1 & & & & 2 & & & 1 & 1 & 2 & & & & & & & & \\
\hline State Total & 204 & 211 & 215 & 774 & 546 & 112 & 23 & 202 & 507 & 74 & 412 & 629 & 216 & 201 & 199 & 313 & 58 & 141 & 164 & 94 & 185 \\
\hline
\end{tabular}




\begin{tabular}{|c|c|c|c|c|c|c|c|c|c|c|c|c|c|c|c|c|c|c|c|c|c|}
\hline \multicolumn{22}{|l|}{ Average } \\
\hline & MN & MO & MS & MT & NC & ND & NE & NH & NJ & NM & NV & NY & $\mathrm{OH}$ & OK & OR & PA & RI & SC & SD & TN & $\mathrm{TX}$ \\
\hline $3-4$ & 177 & 203 & 111 & 203 & 139 & 94 & 125 & 29 & 147 & 106 & 159 & 240 & 112 & 109 & 137 & 303 & 30 & 87 & 135 & 133 & 239 \\
\hline $4-5$ & 89 & 112 & 54 & 112 & 76 & 40 & 47 & 32 & 71 & 72 & 62 & 199 & 60 & 71 & 141 & 132 & 9 & 18 & 65 & 81 & 126 \\
\hline $5-6$ & 20 & 46 & 12 & 46 & 29 & 8 & 5 & 14 & 18 & 10 & 16 & 73 & 13 & 15 & 48 & 27 & 1 & 7 & 3 & 24 & 38 \\
\hline $6-7$ & 11 & 4 & 4 & 4 & 12 & 4 & 1 & 4 & 11 & 5 & 7 & 22 & 3 & 7 & 10 & 9 & & 2 & 6 & 9 & 12 \\
\hline $7-8$ & 3 & 2 & 4 & 2 & 4 & 5 & 1 & & 4 & 2 & 3 & 9 & 2 & 3 & & 3 & & 2 & 5 & 6 & 13 \\
\hline $8-9$ & 3 & & & & 3 & & 1 & & 3 & & & 8 & 1 & & & & & & 1 & & 1 \\
\hline $9-10$ & & & 3 & & 2 & & & & 3 & 2 & 1 & 3 & 2 & & 1 & & & 1 & & 1 & 5 \\
\hline $10-11$ & 3 & 1 & & 1 & & & 1 & & & & 2 & 4 & 1 & & & 3 & & 1 & & 1 & 4 \\
\hline $11-12$ & 2 & & 1 & & 2 & 1 & & & & 2 & 1 & 1 & 1 & & & 1 & & & & 1 & \\
\hline $12-13$ & & & 2 & & 2 & & & & & 1 & & & & & & & & & & 1 & 1 \\
\hline $13-14$ & 1 & 1 & & 1 & & & & & 1 & & & 4 & & 1 & & 1 & & & & & 2 \\
\hline $14-15$ & & & 1 & & & & 1 & & & & 1 & 1 & & & & 1 & & 1 & & & 3 \\
\hline $15-16$ & & & & & 2 & & & & & 1 & & & 1 & & & 1 & & & & & 2 \\
\hline State Total & 309 & 369 & 192 & 369 & 271 & 152 & 182 & 79 & 258 & 201 & 252 & 564 & 196 & 206 & 337 & 481 & 40 & 119 & 215 & 257 & 446 \\
\hline
\end{tabular}




\begin{tabular}{|c|c|c|c|c|c|c|c|r}
\hline Average & \multicolumn{7}{|c|}{ VA } \\
Feet/Second & UT & VA & VT & \multicolumn{1}{c}{ WI } & WV & WY & State Total \\
\hline $3-4$ & 147 & 165 & 24 & 144 & 180 & 52 & 150 & 6871 \\
$4-5$ & 88 & 78 & 20 & 157 & 64 & 48 & 98 & 3873 \\
$5-6$ & 33 & 27 & 5 & 64 & 18 & 28 & 15 & 1143 \\
$6-7$ & 21 & 6 & & 15 & 6 & 4 & 5 & 338 \\
$7-8$ & 1 & 1 & & 4 & 4 & 2 & & 173 \\
$8-9$ & 3 & 1 & & 3 & 1 & & & 62 \\
$9-10$ & & & & 1 & 1 & & & 50 \\
$10-11$ & & & & & & 1 & 1 & 39 \\
$11-12$ & & & & & & & & 29 \\
$12-13$ & & & & & 1 & 1 & & 23 \\
$13-14$ & & & & & & & & 25 \\
$14-15$ & 1 & & & & 1 & & & 23 \\
$15-16$ & & & & & & & & 16 \\
\hline State Total & $\mathbf{2 9 4}$ & $\mathbf{2 7 8}$ & $\mathbf{4 9}$ & $\mathbf{3 8 8}$ & $\mathbf{2 7 6}$ & $\mathbf{1 3 6}$ & $\mathbf{2 6 9}$ & $\mathbf{1 2 6 6 5}$ \\
\hline
\end{tabular}


Appendix B-Potential Energy (kW) Production 
POTENTIAL ENERGY (kW) PRODUCTION

GROUPED BY VELOCITY

(BASED ON 100kW PER 3.5 FEET/SECOND)

\begin{tabular}{|c|c|c|c|c|c|c|c|}
\hline $\begin{array}{c}\text { Average } \\
\text { Feet/Second }\end{array}$ & $\mathrm{AL}$ & AR & $A Z$ & CA & $\mathrm{CO}$ & CT & DE \\
\hline $3-4$ & 12,800 & 10,600 & 9,700 & 37,800 & 27,800 & 4,300 & 500 \\
\hline $4-5$ & 10,000 & 12,800 & 14,400 & 51,200 & 37,400 & 9,800 & 1,400 \\
\hline $6-7$ & 3,000 & 4,800 & 4,800 & 12,000 & 6,000 & 2,400 & 1,200 \\
\hline $7-8$ & 3,000 & 4,000 & 3,000 & 6,000 & 6,000 & 4,000 & 2,000 \\
\hline $10-11$ & - & 2,700 & - & 2,700 & - & - & 2,700 \\
\hline $11-12$ & - & 7,000 & - & 10,500 & - & - & - \\
\hline $12-13$ & - & 4,500 & - & 9,000 & - & - & - \\
\hline $13-14$ & 11,400 & 11,400 & - & - & - & 5,700 & 5,700 \\
\hline $14-15$ & 7,100 & - & - & 7,100 & 14,200 & 7,100 & 7,100 \\
\hline $15-16$ & 8,600 & 8,600 & - & 8,600 & - & - & - \\
\hline Total kWh Year Site $(B 52 * 8760)$ & $2,726,765$ & $3,254,900$ & $1,935,349$ & $2,242,062$ & $1,870,725$ & $3,245,893$ & $8,836,174$ \\
\hline Total kWh Year State (B33*8760) & $556,260,000$ & $686,784,000$ & $416,100,000$ & $1,735,356,000$ & $1,021,416,000$ & $363,540,000$ & $203,232,000$ \\
\hline
\end{tabular}


POTENTIAL ENERGY (kW) PRODUCTION

GROUPED BY VELOCITY

(BASED ON 100kW PER 3.5 FEET/SECOND)

\begin{tabular}{|c|c|c|c|c|c|c|c|}
\hline $\begin{array}{c}\text { Average } \\
\text { Feet/Second }\end{array}$ & $\mathrm{FL}$ & GA & $\mathrm{HI}$ & $\mathrm{IA}$ & ID & IL & IN \\
\hline $3-4$ & 11,500 & 32,400 & 3,700 & 22,300 & 31,800 & 14,600 & 12,900 \\
\hline $4-5$ & 8,800 & 23,400 & 3,600 & 25,000 & 43,600 & 9,800 & 10,200 \\
\hline $5-6$ & 5,600 & 14,400 & 4,000 & 12,400 & 22,000 & 2,400 & 2,800 \\
\hline $6-7$ & 4,200 & 6,600 & 4,800 & 9,000 & 7,200 & 1,200 & 2,400 \\
\hline $7-8$ & 5,000 & 9,000 & - & 6,000 & 11,000 & 4,000 & 3,000 \\
\hline $8-9$ & 4,200 & 5,600 & - & 5,600 & 5,600 & 1,400 & 1,400 \\
\hline $9-10$ & 8,000 & 2,000 & 2,000 & 4,000 & 4,000 & 2,000 & 6,000 \\
\hline $10-11$ & 5,400 & 2,700 & - & 2,700 & - & 5,400 & - \\
\hline $11-12$ & 10,500 & 3,500 & - & 7,000 & 7,000 & - & - \\
\hline $12-13$ & 13,500 & 4,500 & - & 4,500 & 13,500 & 9,000 & - \\
\hline $13-14$ & - & 11,400 & - & - & 5,700 & 5,700 & - \\
\hline $14-15$ & - & - & - & 7,100 & 14,200 & - & 21,300 \\
\hline $15-16$ & 17,200 & - & - & 8,600 & 8,600 & 17,200 & - \\
\hline Total Potential kW & 93,900 & 115,500 & 18,100 & 114,200 & 174,200 & 72,700 & 60,000 \\
\hline Total Number of State Sites & 202 & 507 & 74 & 412 & 629 & 216 & 201 \\
\hline kW Per Site (B33/B34) & 465 & 228 & 245 & 277 & 277 & 337 & 299 \\
\hline Total kWh Year Site (B52*8760) & $4,072,099$ & $1,995,621$ & $2,142,649$ & $2,428,136$ & $2,426,060$ & $2,948,389$ & $2,614,925$ \\
\hline Total kWh Year State (B33*8760) & $822,564,000$ & $1,011,780,000$ & $158,556,000$ & $1,000,392,000$ & $1,525,992,000$ & $636,852,000$ & $525,600,000$ \\
\hline
\end{tabular}


POTENTIAL ENERGY (kW) PRODUCTION

GROUPED BY VELOCITY

(BASED ON 100kW PER 3.5 FEET/SECOND)

\begin{tabular}{|c|c|c|c|c|c|c|c|}
\hline $\begin{array}{c}\text { Average } \\
\text { Feet/Second }\end{array}$ & KS & KY & LA & $\mathrm{MA}$ & $\mathrm{MD}$ & $\mathrm{ME}$ & MI \\
\hline $3-4$ & 12,800 & 17,500 & 3,700 & 8,900 & 7,500 & 3,300 & 12,700 \\
\hline $4-5$ & 10,600 & 18,400 & 3,400 & 7,600 & 10,600 & 8,000 & 10,200 \\
\hline $5-6$ & 3,600 & 8,800 & - & 3,200 & 7,200 & 8,400 & 2,800 \\
\hline $6-7$ & 2,400 & 3,600 & - & 1,200 & 3,600 & - & - \\
\hline $7-8$ & 2,000 & 11,000 & 1,000 & 3,000 & 5,000 & - & - \\
\hline $8-9$ & 1,400 & 4,200 & - & 1,400 & 1,400 & - & - \\
\hline $9-10$ & - & 2,000 & - & - & 2,000 & - & - \\
\hline $10-11$ & 2,700 & 2,700 & 2,700 & - & 8,100 & - & - \\
\hline $11-12$ & - & 3,500 & 3,500 & - & 3,500 & - & - \\
\hline $12-13$ & 4,500 & - & - & - & - & - & - \\
\hline $13-14$ & - & 5,700 & 5,700 & - & 5,700 & - & - \\
\hline $14-15$ & - & - & - & - & - & - & - \\
\hline $15-16$ & - & - & - & - & - & - & - \\
\hline Total Potential kW & 40,000 & 77,400 & 20,000 & 25,300 & 54,600 & 19,700 & 25,700 \\
\hline Total Number of State Sites & 199 & 313 & 58 & 141 & 164 & 94 & 185 \\
\hline kW Per Site (B33/B34) & 201 & 247 & 345 & 179 & 333 & 210 & 139 \\
\hline Total kWh Year Site (B52*8760) & $1,760,804$ & $2,166,211$ & $3,020,690$ & $1,571,830$ & $2,916,439$ & $1,835,872$ & $1,216,930$ \\
\hline Total kWh Year State (B33*8760) & $350,400,000$ & $678,024,000$ & $175,200,000$ & $221,628,000$ & $478,296,000$ & $172,572,000$ & $225,132,000$ \\
\hline
\end{tabular}


POTENTIAL ENERGY (kW) PRODUCTION

GROUPED BY VELOCITY

(BASED ON 100kW PER 3.5 FEET/SECOND)

\begin{tabular}{|c|c|c|c|c|c|c|c|}
\hline $\begin{array}{c}\text { Average } \\
\text { Feet/Second }\end{array}$ & $\mathrm{MN}$ & MO & MS & MT & NC & ND & $\mathrm{NE}$ \\
\hline $3-4$ & 17,700 & 20,300 & 11,100 & 20,300 & 13,900 & 9,400 & 12,500 \\
\hline $4-5$ & 17,800 & 22,400 & 10,800 & 22,400 & 15,200 & 8,000 & 9,400 \\
\hline $5-6$ & 8,000 & 18,400 & 4,800 & 18,400 & 11,600 & 3,200 & 2,000 \\
\hline $6-7$ & 6,600 & 2,400 & 2,400 & 2,400 & 7,200 & 2,400 & 600 \\
\hline $7-8$ & 3,000 & 2,000 & 4,000 & 2,000 & 4,000 & 5,000 & 1,000 \\
\hline $8-9$ & 4,200 & - & - & - & 4,200 & - & 1,400 \\
\hline $9-10$ & - & - & 6,000 & - & 4,000 & - & - \\
\hline $10-11$ & 8,100 & 2,700 & - & 2,700 & - & - & 2,700 \\
\hline $11-12$ & 7,000 & - & 3,500 & - & 7,000 & 3,500 & - \\
\hline $12-13$ & - & - & 9,000 & - & 9,000 & - & - \\
\hline $13-14$ & 5,700 & 5,700 & - & 5,700 & - & - & - \\
\hline $14-15$ & - & - & 7,100 & - & - & - & 7,100 \\
\hline $15-16$ & - & - & - & - & 17,200 & - & - \\
\hline Total Potential kW & 78,100 & 73,900 & 58,700 & 73,900 & 93,300 & 31,500 & 36,700 \\
\hline Total Number of State Sites & 309 & 369 & 192 & 369 & 271 & 152 & 182 \\
\hline kW Per Site (B33/B34) & 253 & 200 & 306 & 200 & 344 & 207 & 202 \\
\hline Total kWh Year Site (B52*8760) & $2,214,097$ & $1,754,374$ & $2,678,188$ & $1,754,374$ & $3,015,897$ & $1,815,395$ & $1,766,440$ \\
\hline Total kWh Year State (B33*8760) & $684,156,000$ & $647,364,000$ & $514,212,000$ & $647,364,000$ & $817,308,000$ & $275,940,000$ & $321,492,000$ \\
\hline
\end{tabular}


POTENTIAL ENERGY (kW) PRODUCTION

\section{GROUPED BY VELOCITY}

(BASED ON 100kW PER 3.5 FEET/SECOND)

\begin{tabular}{|c|c|c|c|c|c|c|c|}
\hline $\begin{array}{c}\text { Average } \\
\text { Feet/Second }\end{array}$ & $\mathrm{NH}$ & NJ & NM & NV & NY & $\mathrm{OH}$ & OK \\
\hline $3-4$ & 2,900 & 14,700 & 10,600 & 15,900 & 24,000 & 11,200 & 10,900 \\
\hline $4-5$ & 6,400 & 14,200 & 14,400 & 12,400 & 39,800 & 12,000 & 14,200 \\
\hline $5-6$ & 5,600 & 7,200 & 4,000 & 6,400 & 29,200 & 5,200 & 6,000 \\
\hline $6-7$ & 2,400 & 6,600 & 3,000 & 4,200 & 13,200 & 1,800 & 4,200 \\
\hline $7-8$ & - & 4,000 & 2,000 & 3,000 & 9,000 & 2,000 & 3,000 \\
\hline $8-9$ & - & 4,200 & - & - & 11,200 & 1,400 & - \\
\hline $9-10$ & - & 6,000 & 4,000 & 2,000 & 6,000 & 4,000 & - \\
\hline $10-11$ & - & - & - & 5,400 & 10,800 & 2,700 & - \\
\hline $11-12$ & - & - & 7,000 & 3,500 & 3,500 & 3,500 & - \\
\hline $12-13$ & - & - & 4,500 & - & - & - & - \\
\hline $13-14$ & - & 5,700 & - & - & 22,800 & - & 5,700 \\
\hline $14-15$ & - & - & - & 7,100 & 7,100 & - & - \\
\hline $15-16$ & - & - & 8,600 & - & - & 8,600 & - \\
\hline Total Potential kW & 17,300 & 62,600 & 58,100 & 59,900 & 176,600 & 52,400 & 44,000 \\
\hline Total Number of State Sites & 79 & 258 & 201 & 252 & 564 & 196 & 206 \\
\hline kW Per Site (B33/B34) & 219 & 243 & 289 & 238 & 313 & 267 & 214 \\
\hline Total kWh Year Site $(B 52 * 8760)$ & $1,918,329$ & $2,125,488$ & $2,532,119$ & $2,082,238$ & $2,742,936$ & $2,341,959$ & $1,871,068$ \\
\hline Total kWh Year State $(B 33 * 8760)$ & $151,548,000$ & $548,376,000$ & $508,956,000$ & $524,724,000$ & $1,547,016,000$ & $459,024,000$ & $385,440,000$ \\
\hline
\end{tabular}


POTENTIAL ENERGY (kW) PRODUCTION

GROUPED BY VELOCITY

(BASED ON 100kW PER 3.5 FEET/SECOND)

\begin{tabular}{|c|c|c|c|c|c|c|c|}
\hline $\begin{array}{c}\text { Average } \\
\text { Feet/Second }\end{array}$ & OR & PA & $\mathrm{RI}$ & SC & SD & TN & TX \\
\hline $3-4$ & 13,700 & 30,300 & 3,000 & 8,700 & 13,500 & 13,300 & 23,900 \\
\hline $4-5$ & 28,200 & 26,400 & 1,800 & 3,600 & 13,000 & 16,200 & 25,200 \\
\hline $5-6$ & 19,200 & 10,800 & 400 & 2,800 & 1,200 & 9,600 & 15,200 \\
\hline $6-7$ & 6,000 & 5,400 & - & 1,200 & 3,600 & 5,400 & 7,200 \\
\hline $7-8$ & - & 3,000 & - & 2,000 & 5,000 & 6,000 & 13,000 \\
\hline $8-9$ & - & - & - & - & 1,400 & - & 1,400 \\
\hline $9-10$ & 2,000 & - & - & 2,000 & - & 2,000 & 10,000 \\
\hline $10-11$ & - & 8,100 & - & 2,700 & - & 2,700 & 10,800 \\
\hline $11-12$ & - & 3,500 & - & - & - & 3,500 & - \\
\hline $12-13$ & - & - & - & - & - & 4,500 & 4,500 \\
\hline $13-14$ & - & 5,700 & - & - & - & - & 11,400 \\
\hline $14-15$ & - & 7,100 & - & 7,100 & - & - & 21,300 \\
\hline $15-16$ & - & 8,600 & - & - & - & - & 17,200 \\
\hline Total Potential kW & 69,100 & 108,900 & 5,200 & 30,100 & 37,700 & 63,200 & 161,100 \\
\hline Total Number of State Sites & 337 & 481 & 40 & 119 & 215 & 257 & 446 \\
\hline kW Per Site (B33/B34) & 205 & 226 & 130 & 253 & 175 & 246 & 361 \\
\hline Total kWh Year Site (B52*8760) & $1,796,190$ & $1,983,293$ & $1,138,800$ & $2,215,765$ & $1,536,056$ & $2,154,210$ & $3,164,206$ \\
\hline Total kWh Year State (B33*8760) & $605,316,000$ & $953,964,000$ & $45,552,000$ & $263,676,000$ & $330,252,000$ & $553,632,000$ & $1,411,236,000$ \\
\hline
\end{tabular}


POTENTIAL ENERGY (kW) PRODUCTION

GROUPED BY VELOCITY

(BASED ON 100kW PER 3.5 FEET/SECOND)

\begin{tabular}{|c|c|c|c|c|c|c|c|}
\hline $\begin{array}{c}\text { Average } \\
\text { Feet/Second }\end{array}$ & UT & VA & VT & WA & WI & WV & WY \\
\hline $3-4$ & 14,700 & 16,500 & 2,400 & 14,400 & 18,000 & 5,200 & 15,000 \\
\hline $4-5$ & 17,600 & 15,600 & 4,000 & 31,400 & 12,800 & 9,600 & 19,600 \\
\hline $5-6$ & 13,200 & 10,800 & 2,000 & 25,600 & 7,200 & 11,200 & 6,000 \\
\hline $6-7$ & 12,600 & 3,600 & - & 9,000 & 3,600 & 2,400 & 3,000 \\
\hline $7-8$ & 1,000 & 1,000 & - & 4,000 & 4,000 & 2,000 & - \\
\hline $8-9$ & 4,200 & 1,400 & - & 4,200 & 1,400 & - & - \\
\hline $9-10$ & - & - & - & 2,000 & 2,000 & - & - \\
\hline $10-11$ & - & - & - & - & - & 2,700 & 2,700 \\
\hline $11-12$ & - & - & - & - & - & - & - \\
\hline $12-13$ & - & - & - & - & 4,500 & 4,500 & - \\
\hline $13-14$ & - & - & - & - & - & - & - \\
\hline $14-15$ & 7,100 & - & - & - & 7,100 & - & - \\
\hline $15-16$ & - & - & - & - & - & - & - \\
\hline Total Potential kW & 70,400 & 48,900 & 8,400 & 90,600 & 60,600 & 37,600 & 46,300 \\
\hline Total Number of State Sites & 294 & 278 & 49 & 388 & 276 & 136 & 269 \\
\hline kW Per Site (B33/B34) & 239 & 176 & 171 & 234 & 220 & 276 & 172 \\
\hline Total kWh Year Site $(B 52 * 8760)$ & $2,097,633$ & $1,540,878$ & $1,501,714$ & $2,045,505$ & $1,923,391$ & $2,421,882$ & $1,507,762$ \\
\hline Total kWh Year State (B33*8760) & $616,704,000$ & $428,364,000$ & $73,584,000$ & $793,656,000$ & $530,856,000$ & $329,376,000$ & $405,588,000$ \\
\hline
\end{tabular}




\begin{tabular}{|c|r|}
\hline $\begin{array}{c}\text { Average } \\
\text { Feet/Second }\end{array}$ & \multicolumn{1}{|c|}{ All States } \\
\hline $3-4$ & 687,100 \\
\hline $4-5$ & 774,600 \\
$5-6$ & 457,200 \\
$6-7$ & 202,800 \\
$7-8$ & 173,000 \\
\hline $8-9$ & 86,800 \\
\hline $9-10$ & 100,000 \\
$10-11$ & 105,300 \\
$11-12$ & 101,500 \\
$12-13$ & 103,500 \\
$13-14$ & 142,500 \\
\hline $14-15$ & 163,300 \\
$15-16$ & 137,600 \\
\hline Total Potential kW & $3,235,200$ \\
\hline Total Number of State Sites & 12,665 \\
\hline kW Per Site (B33/B34) & 255 \\
\hline Total kWh Year Site (B52*8760) & $2,237,691$ \\
Total kWh Year State (B33*8760) & $28,340,352,000$ \\
\hline
\end{tabular}




\section{Appendix C-Energy Production and Residential Cost Savings Projections}


(BASED ON PRODUCTION RATE OF 100kW PER 3.5 FEET/SECOND)

\begin{tabular}{|c|c|c|c|c|c|c|c|}
\hline Total Number of State Sites & 204 & 211 & 215 & 774 & 546 & 112 & 23 \\
\hline Total kWh Year Site (B52*8760) & $2,726,765$ & $3,254,900$ & $1,935,349$ & $2,242,062$ & $1,870,725$ & $3,245,893$ & $8,836,174$ \\
\hline Total kWh Year State (B33*8760) & $556,260,000$ & $686,784,000$ & $416,100,000$ & $1,735,356,000$ & $1,021,416,000$ & $363,540,000$ & $203,232,000$ \\
\hline Est. Price per kWh (cents) 2010 & 9.40 & 8.35 & 9.32 & 14.10 & 9.50 & 17.28 & 12.04 \\
\hline Potential Savings Per Site, 2010 & $\$ 25,625,274$ & $\$ 27,174,650$ & $\$ 18,032,460$ & $\$ 31,613,546$ & $\$ 17,765,687$ & $\$ 56,091,591$ & $\$ 106,364,281$ \\
\hline Potential Savings Per Site, 2020 & $\$ 30,443,036$ & $\$ 28,211,079$ & $\$ 18,477,445$ & $\$ 36,086,376$ & $\$ 20,501,728$ & $\$ 69,457,836$ & $\$ 125,861,664$ \\
\hline Potential Savings Per Site, 2030 & $\$ 35,260,799$ & $\$ 29,247,508$ & $\$ 18,922,429$ & $\$ 40,559,205$ & $\$ 23,237,770$ & $\$ 82,824,081$ & $\$ 145,359,047$ \\
\hline Potential Savings Per State, 2010 & $\$ 5.2$ billion & $\$ 5.7$ billion & \$3.9 billion & $\$ 24.5$ billion & $\$ 9.7$ billion & $\$ 6.3$ billion & \$2.4 billion \\
\hline Potential Savings Per State, 2020 & $\$ 6.2$ billion & $\$ 6.0$ billion & $\$ 4.0$ billion & $\$ 27.9$ billion & $\$ 11.2$ billion & $\$ 7.8$ billion & $\$ 2.9$ billion \\
\hline
\end{tabular}


(BASED ON PRODUCTION RATE OF 100kW PER 3.5 FEET/SECOND)

\begin{tabular}{|c|c|c|c|c|c|c|c|}
\hline Description & $\mathrm{FL}$ & GA & $\mathrm{HI}$ & $\mathrm{IA}$ & ID & $\mathrm{IL}$ & IN \\
\hline Total Potential kW & 93,900 & 115,500 & 18,100 & 114,200 & 174,200 & 72,700 & 60,000 \\
\hline Total Number of State Sites & 202 & 507 & 74 & 412 & 629 & 216 & 201 \\
\hline kW Per Site (B33/B34) & 465 & 228 & 245 & 277 & 277 & 337 & 299 \\
\hline Total kWh Year Site (B52*8760) & $4,072,099$ & $1,995,621$ & $2,142,649$ & $2,428,136$ & $2,426,060$ & $2,948,389$ & $2,614,925$ \\
\hline Total kWh Year State (B33*8760) & $822,564,000$ & $1,011,780,000$ & $158,556,000$ & $1,000,392,000$ & $1,525,992,000$ & $636,852,000$ & $525,600,000$ \\
\hline Est. Price per kWh (cents) 2010 & 11.09 & 9.18 & 25.79 & 9.65 & 7.06 & 9.26 & 8.41 \\
\hline Est. Price per kWh (cents) 2020 & 13.23 & 10.21 & 34.40 & 10.68 & 8.30 & 8.92 & 9.47 \\
\hline Est. Price per kWh (cents) 2030 & 15.36 & 11.24 & 43.01 & 11.70 & 9.54 & 8.59 & 10.54 \\
\hline Potential Savings Per Site, 2010 & $\$ 45,166,008$ & $\$ 18,317,388$ & $\$ 55,256,653$ & $\$ 23,438,668$ & $\$ 17,119,176$ & $\$ 27,287,805$ & $\$ 21,980,512$ \\
\hline Potential Savings Per Site, 2020 & $\$ 53,863,154$ & $\$ 20,377,229$ & $\$ 73,706,791$ & $\$ 25,927,964$ & $\$ 20,132,963$ & $\$ 26,311,068$ & $\$ 24,769,242$ \\
\hline Potential Savings Per Site, 2030 & $\$ 62,560,300$ & $\$ 22,437,070$ & $\$ 92,156,929$ & $\$ 28,417,260$ & $\$ 23,146,751$ & $\$ 25,334,331$ & $\$ 27,557,971$ \\
\hline Potential Savings Per State, 2010 & $\$ 9.1$ billion & $\$ 9.3$ billion & $\$ 4.1$ billion & $\$ 9.7$ billion & $\$ 10.8$ billion & $\$ 5.9$ billion & $\$ 4.4$ billion \\
\hline Potential Savings Per State, 2020 & \$10.9 billion & $\$ 10.3$ billion & $\$ 5.5$ billion & $\$ 10.7$ billion & $\$ 12.7$ billion & $\$ 5.7$ billion & $\$ 5.0$ billion \\
\hline Potential Savings Per State, 2030 & $\$ 12.6$ billion & \$11.4 billion & $\$ 6.8$ billion & $\$ 11.7$ billion & \$14.6 billion & $\$ 5.5$ billion & $\$ 5.5$ billion \\
\hline
\end{tabular}


(BASED ON PRODUCTION RATE OF 100kW PER 3.5 FEET/SECOND)

\begin{tabular}{|c|c|c|c|c|c|c|c|}
\hline Description & KS & KY & LA & MA & MD & $\mathrm{ME}$ & MI \\
\hline Total Potential kW & 40,000 & 77,400 & 20,000 & 25,300 & 54,600 & 19,700 & 25,700 \\
\hline Total Number of State Sites & 199 & 313 & 58 & 141 & 164 & 94 & 185 \\
\hline kW Per Site (B33/B34) & 201 & 247 & 345 & 179 & 333 & 210 & 139 \\
\hline Total kWh Year Site $(B 52 * 8760)$ & $1,760,804$ & $2,166,211$ & $3,020,690$ & $1,571,830$ & $2,916,439$ & $1,835,872$ & $1,216,930$ \\
\hline Total kWh Year State (B33*8760) & $350,400,000$ & $678,024,000$ & $175,200,000$ & $221,628,000$ & $478,296,000$ & $172,572,000$ & $225,132,000$ \\
\hline Est. Price per kWh (cents) 2010 & 8.41 & 7.27 & 8.97 & 15.86 & 11.43 & 15.47 & 10.11 \\
\hline Est. Price per kWh (cents) 2020 & 8.84 & 8.37 & 9.97 & 19.27 & 13.78 & 17.96 & 11.36 \\
\hline Est. Price per kWh (cents) 2030 & 9.27 & 9.47 & 10.96 & 22.68 & 16.13 & 20.46 & 12.62 \\
\hline Potential Savings Per Site, 2010 & $\$ 14,812,439$ & $\$ 15,752,343$ & $\$ 27,087,955$ & $\$ 24,930,130$ & $\$ 33,340,424$ & $\$ 28,404,617$ & $\$ 12,297,331$ \\
\hline Potential Savings Per Site, 2020 & $\$ 15,565,084$ & $\$ 18,134,850$ & $\$ 30,101,377$ & $\$ 30,285,697$ & $\$ 40,190,986$ & $\$ 32,981,184$ & $\$ 13,828,009$ \\
\hline Potential Savings Per Site, 2030 & $\$ 16,317,728$ & $\$ 20,517,356$ & $\$ 33,114,799$ & $\$ 35,641,264$ & $\$ 47,041,547$ & $\$ 37,557,752$ & $\$ 15,358,687$ \\
\hline Potential Savings Per State, 2010 & \$2.9 billion & $\$ 4.9$ billion & \$1.6 billion & \$3.5 billion & $\$ 5.5$ billion & $\$ 2.7$ billion & $\$ 2.3$ billion \\
\hline Potential Savings Per State, 2020 & $\$ 3.1$ billion & $\$ 5.7$ billion & $\$ 1.7$ billion & $\$ 4.3$ billion & $\$ 6.6$ billion & $\$ 3.1$ billion & $\$ 2.6$ billion \\
\hline Potential Savings Per State, 2030 & $\$ 3.2$ billion & $\$ 6.4$ billion & $\$ 1.9$ billion & $\$ 5.0$ billion & $\$ 7.7$ billion & $\$ 3.5$ billion & $\$ 2.8$ billion \\
\hline
\end{tabular}


(BASED ON PRODUCTION RATE OF 100kW PER 3.5 FEET/SECOND)

\begin{tabular}{|c|c|c|c|c|c|c|c|}
\hline Description & $\mathrm{MN}$ & MO & MS & MT & NC & ND & NE \\
\hline Total Potential kW & 78,100 & 73,900 & 58,700 & 73,900 & 93,300 & 31,500 & 36,700 \\
\hline Total Number of State Sites & 309 & 369 & 192 & 369 & 271 & 152 & 182 \\
\hline kW Per Site (B33/B34) & 253 & 200 & 306 & 200 & 344 & 207 & 202 \\
\hline Total kWh Year Site (B52*8760) & $2,214,097$ & $1,754,374$ & $2,678,188$ & $1,754,374$ & $3,015,897$ & $1,815,395$ & $1,766,440$ \\
\hline Total kWh Year State (B33*8760) & $684,156,000$ & $647,364,000$ & $514,212,000$ & $647,364,000$ & $817,308,000$ & $275,940,000$ & $321,492,000$ \\
\hline Est. Price per kWh (cents) 2010 & 9.25 & 7.57 & 9.57 & 9.00 & 9.28 & 7.30 & 7.78 \\
\hline Est. Price per kWh (cents) 2020 & 10.67 & 7.81 & 11.27 & 10.91 & 10.11 & 7.95 & 8.75 \\
\hline Est. Price per kWh (cents) 2030 & 12.08 & 8.06 & 12.98 & 12.82 & 10.94 & 8.61 & 9.72 \\
\hline Potential Savings Per Site, 2010 & $\$ 20,486,458$ & $\$ 13,272,670$ & $\$ 25,620,105$ & $\$ 15,796,383$ & $\$ 27,988,315$ & $\$ 13,251,522$ & $\$ 13,748,478$ \\
\hline Potential Savings Per Site, 2020 & $\$ 23,615,160$ & $\$ 13,704,536$ & $\$ 30,186,314$ & $\$ 19,144,731$ & $\$ 30,490,829$ & $\$ 14,438,490$ & $\$ 15,462,190$ \\
\hline Potential Savings Per Site, 2030 & $\$ 26,743,862$ & $\$ 14,136,403$ & $\$ 34,752,523$ & $\$ 22,493,079$ & $\$ 32,993,343$ & $\$ 15,625,457$ & $\$ 17,175,902$ \\
\hline Potential Savings Per State, 2010 & $\$ 6.3$ billion & $\$ 4.9$ billion & $\$ 4.9$ billion & $\$ 5.8$ billion & $\$ 7.6$ billion & $\$ 2.0$ billion & $\$ 2.5$ billion \\
\hline Potential Savings Per State, 2020 & $\$ 7.3$ billion & $\$ 5.1$ billion & $\$ 5.8$ billion & $\$ 7.1$ billion & $\$ 8.3$ billion & $\$ 2.2$ billion & $\$ 2.8$ billion \\
\hline Potential Savings Per State, 2030 & $\$ 8.3$ billion & $\$ 5.2$ billion & $\$ 6.7$ billion & $\$ 8.3$ billion & $\$ 8.9$ billion & $\$ 2.4$ billion & $\$ 3.1$ billion \\
\hline
\end{tabular}


(BASED ON PRODUCTION RATE OF 100kW PER 3.5 FEET/SECOND)

\begin{tabular}{|c|c|c|c|c|c|c|c|}
\hline Total Number of State Sites & 79 & 258 & 201 & 252 & 564 & 196 & 206 \\
\hline Total kWh Year Site $(B 52 * 8760)$ & $1,918,329$ & $2,125,488$ & $2,532,119$ & $2,082,238$ & $2,742,936$ & $2,341,959$ & $1,871,068$ \\
\hline Total kWh Year State (B33*8760) & $151,548,000$ & $548,376,000$ & $508,956,000$ & $524,724,000$ & $1,547,016,000$ & $459,024,000$ & $385,440,000$ \\
\hline Est. Price per kWh (cents) 2010 & 15.18 & 13.73 & 9.23 & 12.18 & 17.31 & 9.58 & 8.44 \\
\hline Potential Savings Per Site, 2010 & $\$ 29,110,745$ & $\$ 29,179,935$ & $\$ 23,359,468$ & $\$ 25,357,057$ & $\$ 47,469,398$ & $\$ 22,439,544$ & $\$ 15,796,344$ \\
\hline Potential Savings Per Site, 2020 & $\$ 32,857,978$ & $\$ 32,954,355$ & $\$ 23,908,728$ & $\$ 32,774,365$ & $\$ 55,135,389$ & $\$ 24,332,128$ & $\$ 17,728,749$ \\
\hline Potential Savings Per Site, 2030 & $\$ 36,605,210$ & $\$ 36,728,775$ & $\$ 24,457,989$ & $\$ 40,191,673$ & $\$ 62,801,380$ & $\$ 26,224,713$ & $\$ 19,661,154$ \\
\hline Potential Savings Per State, 2010 & $\$ 2.3$ billion & $\$ 7.5$ billion & $\$ 4.7$ billion & \$6.4 billion & \$26.8 billion & $\$ 4.4$ billion & \$3.3 billion \\
\hline Potential Savings Per State, 2020 & $\$ 2.6$ billion & $\$ 8.5$ billion & $\$ 4.8$ billion & $\$ 8.3$ billion & $\$ 31.1$ billion & $\$ 4.8$ billion & $\$ 3.7$ billion \\
\hline
\end{tabular}


(BASED ON PRODUCTION RATE OF 100kW PER 3.5 FEET/SECOND)

\begin{tabular}{|c|c|c|c|c|c|c|c|}
\hline Description & OR & PA & $\mathrm{RI}$ & SC & SD & TN & TX \\
\hline Total Potential kW & 69,100 & 108,900 & 5,200 & 30,100 & 37,700 & 63,200 & 161,100 \\
\hline Total Number of State Sites & 337 & 481 & 40 & 119 & 215 & 257 & 446 \\
\hline kW Per Site (B33/B34) & 205 & 226 & 130 & 253 & 175 & 246 & 361 \\
\hline Total kWh Year Site $(B 52 * 8760)$ & $1,796,190$ & $1,983,293$ & $1,138,800$ & $2,215,765$ & $1,536,056$ & $2,154,210$ & $3,164,206$ \\
\hline Total kWh Year State (B33*8760) & $605,316,000$ & $953,964,000$ & $45,552,000$ & $263,676,000$ & $330,252,000$ & $553,632,000$ & $1,411,236,000$ \\
\hline Est. Price per kWh (cents) 2010 & 8.50 & 10.74 & 14.80 & 9.46 & 8.19 & 8.28 & 12.18 \\
\hline Est. Price per kWh (cents) 2020 & 10.56 & 11.54 & 17.29 & 10.84 & 8.91 & 9.86 & 15.10 \\
\hline Est. Price per kWh (cents) 2030 & 12.62 & 12.33 & 19.78 & 12.22 & 9.62 & 11.44 & 18.02 \\
\hline Potential Savings Per Site, 2010 & $\$ 15,265,251$ & $\$ 21,295,662$ & $\$ 16,854,060$ & $\$ 20,970,580$ & $\$ 12,578,438$ & $\$ 17,839,014$ & $\$ 38,551,024$ \\
\hline Potential Savings Per Site, 2020 & $\$ 18,962,296$ & $\$ 22,878,569$ & $\$ 19,687,874$ & $\$ 24,027,836$ & $\$ 13,681,164$ & $\$ 21,239,589$ & $\$ 47,782,893$ \\
\hline Potential Savings Per Site, 2030 & $\$ 22,659,341$ & $\$ 24,461,475$ & $\$ 22,521,688$ & $\$ 27,085,091$ & $\$ 14,783,890$ & $\$ 24,640,163$ & $\$ 57,014,762$ \\
\hline Potential Savings Per State, 2010 & $\$ 5.1$ billion & $\$ 10.2$ billion & \$0.7 billion & $\$ 2.5$ billion & $\$ 2.7$ billion & $\$ 4.6$ billion & $\$ 17.2$ billion \\
\hline Potential Savings Per State, 2020 & $\$ 6.4$ billion & $\$ 11.0$ billion & \$0.8 billion & $\$ 2.9$ billion & $\$ 2.9$ billion & $\$ 5.5$ billion & $\$ 21.3$ billion \\
\hline Potential Savings Per State, 2030 & $\$ 7.6$ billion & \$11.8 billion & \$0.9 billion & $\$ 3.2$ billion & $\$ 3.2$ billion & $\$ 6.3$ billion & $\$ 25.4$ billion \\
\hline
\end{tabular}


(BASED ON PRODUCTION RATE OF 100kW PER 3.5 FEET/SECOND)

\begin{tabular}{|c|c|c|c|c|c|c|c|}
\hline Description & UT & VA & VT & WA & WI & WV & WY \\
\hline Total Potential kW & 70,400 & 48,900 & 8,400 & 90,600 & 60,600 & 37,600 & 46,300 \\
\hline Total Number of State Sites & 294 & 278 & 49 & 388 & 276 & 136 & 269 \\
\hline kW Per Site (B33/B34) & 239 & 176 & 171 & 234 & 220 & 276 & 172 \\
\hline Total kWh Year Site $(B 52 * 8760)$ & $2,097,633$ & $1,540,878$ & $1,501,714$ & $2,045,505$ & $1,923,391$ & $2,421,882$ & $1,507,762$ \\
\hline Total kWh Year State (B33*8760) & $616,704,000$ & $428,364,000$ & $73,584,000$ & $793,656,000$ & $530,856,000$ & $329,376,000$ & $405,588,000$ \\
\hline Est. Price per kWh (cents) 2010 & 7.77 & 9.11 & 14.94 & 7.53 & 11.08 & 6.87 & 8.14 \\
\hline Est. Price per kWh (cents) 2020 & 8.38 & 10.16 & 17.83 & 9.30 & 13.75 & 7.34 & 9.44 \\
\hline Est. Price per kWh (cents) 2030 & 8.98 & 11.20 & 20.71 & 11.06 & 16.42 & 7.80 & 10.74 \\
\hline Potential Savings Per Site, 2010 & $\$ 16,304,678$ & $\$ 14,035,855$ & $\$ 22,440,828$ & $\$ 15,403,192$ & $\$ 21,307,633$ & $\$ 16,650,314$ & $\$ 12,266,359$ \\
\hline Potential Savings Per Site, 2020 & $\$ 17,570,039$ & $\$ 15,649,374$ & $\$ 26,772,878$ & $\$ 19,017,431$ & $\$ 26,448,872$ & $\$ 17,766,565$ & $\$ 14,229,284$ \\
\hline Potential Savings Per Site, 2030 & $\$ 18,835,401$ & $\$ 17,262,893$ & $\$ 31,104,929$ & $\$ 22,631,669$ & $\$ 31,590,111$ & $\$ 18,882,816$ & $\$ 16,192,208$ \\
\hline Potential Savings Per State, 2010 & $\$ 4.8$ billion & \$3.9 billion & $\$ 1.1$ billion & $\$ 6.0$ billion & $\$ 5.9$ billion & $\$ 2.3$ billion & $\$ 3.3$ billion \\
\hline Potential Savings Per State, 2020 & $\$ 5.2$ billion & $\$ 4.4$ billion & $\$ 1.3$ billion & \$7.4 billion & $\$ 7.3$ billion & \$2.4 billion & \$3.8 billion \\
\hline Potential Savings Per State, 2030 & \$5.5 billion & $\$ 4.8$ billion & $\$ 1.5$ billion & $\$ 8.8$ billion & $\$ 8.7$ billion & $\$ 2.6$ billion & \$4.4 billion \\
\hline
\end{tabular}




\begin{tabular}{|l|c|}
\hline Description & All States \\
\hline Total Potential kW & $3,235,200$ \\
Total Number of State Sites & 12,665 \\
kW Per Site (B33/B34) & 255 \\
Total kWh Year Site (B52*8760) & $2,237,691$ \\
Total kWh Year State (B33*8760) & $28,340,352,000$ \\
\hline Est. Price per kWh (cents) 2010 & \\
\hline Est. Price per kWh (cents) 2020 & \\
\hline Est. Price per kWh (cents) 2030 & \\
\hline Potential Savings Per Site, 2010 & $\$ 1,232,498,247$ \\
Potential Savings Per Site, 2020 & $\$ 1,427,663,367$ \\
Potential Savings Per Site, 2030 & $\$ 1,622,828,486$ \\
\hline Potential Savings Per State, 2010 & $\$ 294.0$ billion \\
\hline Potential Savings Per State, 2020 & $\$ 338.3$ billion \\
Potential Savings Per State, 2030 & $\$ 382.6$ billion \\
\hline
\end{tabular}




\section{Appendix D-Residential Rate Projections}


Rates are expressed in cents per kWh

\begin{tabular}{|l|r|r|r|r|r|}
\hline Residential Rates & Year & & & & \\
State & 1990 & 2000 & 2010 & 2020 & 2030 \\
\hline AL & 6.59 & 7.05 & 9.40 & 11.16 & 12.93 \\
AR & 8.07 & 7.45 & 8.35 & 8.67 & 8.99 \\
AZ & 9.04 & 8.44 & 9.32 & 9.55 & 9.78 \\
CA & 9.98 & 10.89 & 14.10 & 16.10 & 18.09 \\
CO & 7.02 & 7.31 & 9.50 & 10.96 & 12.42 \\
CT & 10.01 & 10.86 & 17.28 & 21.40 & 25.52 \\
DE & 8.39 & 8.54 & 12.04 & 14.24 & 16.45 \\
FL & 7.77 & 7.77 & 11.09 & 13.23 & 15.36 \\
GA & 7.46 & 7.60 & 9.18 & 10.21 & 11.24 \\
HI & 10.26 & 16.41 & 25.79 & 34.40 & 43.01 \\
IA & 7.81 & 8.37 & 9.65 & 10.68 & 11.70 \\
ID & 4.87 & 5.39 & 7.06 & 8.30 & 9.54 \\
IL & 9.92 & 8.83 & 9.26 & 8.92 & 8.59 \\
IN & 6.87 & 6.87 & 8.41 & 9.47 & 10.54 \\
KS & 7.83 & 7.65 & 8.41 & 8.84 & 9.27 \\
KY & 5.69 & 5.47 & 7.27 & 8.37 & 9.47 \\
LA & 7.41 & 7.67 & 8.97 & 9.97 & 10.96 \\
MA & 9.66 & 10.53 & 15.86 & 19.27 & 22.68 \\
MD & 7.22 & 7.95 & 11.43 & 13.78 & 16.13 \\
ME & 9.30 & 12.49 & 15.47 & 17.96 & 20.46 \\
MI & 7.83 & 8.52 & 10.11 & 11.36 & 12.62 \\
MN & 6.80 & 7.52 & 9.25 & 10.67 & 12.08 \\
MO & 7.36 & 7.04 & 7.57 & 7.81 & 8.06 \\
MS & 6.89 & 6.93 & 9.57 & 11.27 & 12.98 \\
MT & 5.45 & 6.49 & 9.00 & 10.91 & 12.82 \\
NC & 7.84 & 7.97 & 9.28 & 10.11 & 10.94 \\
ND & 6.26 & 6.44 & 7.30 & 7.95 & 8.61 \\
NE & 6.23 & 6.53 & 7.78 & 8.75 & 9.72 \\
NH & 10.34 & 13.15 & 15.18 & 17.13 & 19.08 \\
NJ & 10.36 & 10.27 & 13.73 & 15.50 & 17.28 \\
NM & 8.94 & 8.36 & 9.23 & 9.44 & 9.66 \\
NV & 5.70 & 7.28 & 12.18 & 15.74 & 19.30 \\
NY & 11.44 & 13.97 & 17.31 & 20.10 & 22.90 \\
OH & 8.05 & 8.61 & 9.58 & 10.39 & 11.20 \\
OK & 6.58 & 7.03 & 8.44 & 9.48 & 10.51 \\
OR & 4.73 & 5.88 & 8.50 & 10.56 & 12.62 \\
PA & 9.22 & 9.53 & 10.74 & 11.54 & 12.33 \\
RI & 9.84 & 11.28 & 14.80 & 17.29 & 19.78 \\
SC & 7.15 & 7.58 & 9.46 & 10.84 & 12.22
\end{tabular}


Rates are expressed in cents per kWh

\begin{tabular}{|l|r|r|r|r|r|}
\hline Residential Rates & Year & & & & \\
State & 1990 & 2000 & 2010 & 2020 & 2030 \\
\hline SD & 6.95 & 7.42 & 8.19 & 8.91 & 9.62 \\
TN & 5.69 & 6.33 & 8.28 & 9.86 & 11.44 \\
TX & 7.20 & 7.96 & 12.18 & 15.10 & 18.02 \\
UT & 7.13 & 6.29 & 7.77 & 8.38 & 8.98 \\
VA & 7.25 & 7.52 & 9.11 & 10.16 & 11.20 \\
VT & 9.27 & 12.30 & 14.94 & 17.83 & 20.71 \\
WA & 4.39 & 5.13 & 7.53 & 9.30 & 11.06 \\
WI & 6.63 & 7.53 & 11.08 & 13.75 & 16.42 \\
WV & 5.90 & 6.27 & 6.87 & 7.34 & 7.80 \\
WY & 5.97 & 6.50 & 8.14 & 9.44 & 10.74 \\
\hline Maximum Rate & 11.44 & 16.41 & 25.79 & 34.40 & 43.01 \\
\hline
\end{tabular}

Note: 1990 and 2000 data are unprojected costs reported by EIA. The 2010, 2020, and 2030 rates are projected. 